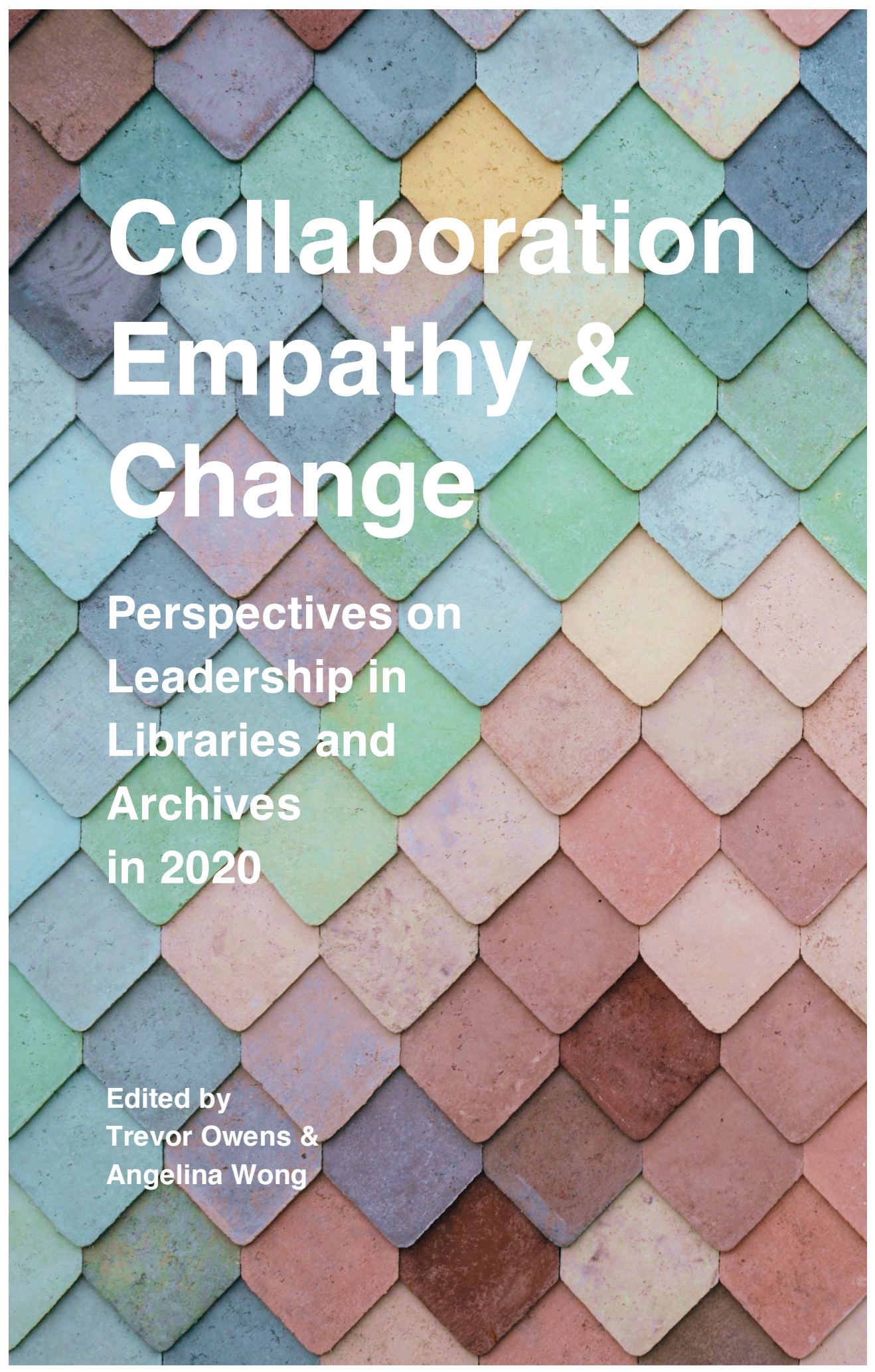


The contents of this book are licensed CC BY-NC-ND 2.0 (https://creativecommons.org/licenses/by-nc-nd/4.o/)

Each essay's copyright is held by its author.

Cover Image by Andrew Ridley available on Unsplash at https://unsplash.com/photos/jR4Zf-riEjI

The book can be downloaded from

https://osf.io/preprints/socarxiv/3gnds 


\section{Collaboration, \\ Empathy, \& \\ Change}

PeRsPectives ON

LEADERSHIP IN LIBRARIES \&

ARCHIVES IN 2020

Edited by Trevor Owens \&

Angelina Wong 



\section{Contents}

\section{Introduction}

1. Collaboration, Empathy, and Change: Library 1

Leadership in $\mathbf{2 0 2 0}$

Trevor Owens

\section{Leadership in Archives \& Special Collections}

2. Collaboration, Support, and Innovation:

Perspectives from Meghan Bryant on Leadership in Archives

Jacob Hopkins

3. William Noel: An Intuitive Leader Angelina Wong

4. Librarian of Note: Anna Kijas, Head Librarian of the Lilly Music Library Jessica H. Grimmer

5. Leadership Profile of Daniel Boomhower: An Analysis Across Organizational Processes Within the Context of Leadership Frames Danielle S. Fitch

\section{Executive Perspectives in Academic Libraries}

6. Information Organization Perspectives: A Look Into Academic Library Leadership Through the 70 Life of a Library Dean Aaron Wilson

7. "Living Well": The Transitive Leadership of 84 Courtney Young Maureen Jones 
8. Effecting Change: A Profile on Successfully Promoting Change in the Workplace Jason Riggin

\section{Leadership in Federal Service}

9. Lessons in Practical Macromanaging: Dr. Jeffrey 113 Reznick's Perspectives on Leadership and Public Service Miranda Downey

10. Change Management in Government Information 126 Organizations: The Influence of Behavior-Focused Leadership Bailey DeSimone

11. Joe Puccio: The Power of Empathy at the Library of 142 Congress Laura O’Hanlon

12. Building the Future Through People: A Leadership 155 Profile of Pamela Wright, Chief Innovation Officer at the National Archives and Records Administration Selena St. Andre

\section{Beyond Libraries and Archives}

13. Marvin Pinkert: A Life in Museums Ellen Goodman

14. Management Through Alignment: A Profile on the 194 Career of Toby Pearlstein Rebecca Fink 


\section{Toward a More Equitable Future}

15. A Library Freedom Dream: In Conversation With Fobazi Ettarh Zahra Osman

16. Can Anyone Be a Storyteller? Equity, Diversity, and 241 Inclusion in Cultural Heritage Tannaz Motevalli 



\section{Collaboration,}

Empathy, \& Change

LIBRARY LEADERSHIP IN 2020

Trevor Owens

2020 was hard. It was hard in a lot of different ways at the same time. The COVID-19 pandemic has stressed nearly every aspect of our technical, social, and political systems and infrastructure. In this global context, people working in libraries, archives, and museums continue to struggle with how to take care of each other and persist in their work. Students aspiring for careers or for advancement in their careers transitioned to online courses. Through it all, we have faced major challenges in maintaining our health and well-being.

In that fraught context, the students in the organizational theory and leadership course I taught at the University of Maryland's iSchool worked together to produce this book. Every student in the University of Maryland's iSchool MLIS program is required to take Achieving Organizational Excellence, a course focused on "the principles, practices, and techniques required for effective leadership and management." I'm really proud of the work that we did together over the semester. This book distills, documents, and communicates much of what we have learned together.

\section{Context for this book}

Each chapter of this book was written for the course in the Fall of 2020. With some support from me, each student 
connected with an individual working in a leadership role in an information organization relevant to their career interests. Each student interviewed their subject to learn about that person's approach to leadership and organizations. Students then drew from those interviews to develop essays connecting their subject's perspectives to literature on organizational theory and leadership. Inclusion of essays in this book was optional. Some students preferred not to publish their work here. Some interview subjects preferred that their perspectives not be widely shared. As a result, the scope of this book is intentionally noncomprehensive. This is not a survey of various areas and roles in the field. Instead, the book brings together voices and perspectives anchored in these particular students.

The book is itself part of the pedagogical approach of the course. It's one thing to read about leadership and organizational theory. It's another to see how ideas from books and journal articles connect to the real-world experiences of leaders in the field. It's still a whole other level of learning to synthesize perspectives from leaders in the field with the literature and publish it. Library and archives practitioners working in the field wrote most of our course readings. A key part of joining that professional community of practice is developing the ability to contribute to the professional dialog in our scholarship and writing.

\section{Overview of the book's structure and contributions}

The structure and content of the book emerges out of the career interests of the students and the ideas and perspectives of their interview subjects. To that end, I have 
organized the book primarily around the types of roles and organizations that individual interview subjects come from. The first section of the book includes a selection of essays on leadership in archives and special collections. The second section includes essays focused on senior leaders in academic libraries. The third section focuses on leaders in library organizations in the U.S. federal government. The fourth section focuses on work outside of libraries and archives, specifically in museums, humanities research centers, and corporations. The final section of the book offers two essays that more broadly explore issues on the need for libraries and archives to develop field-wide toward a more equitable future.

There are a range of crosscutting issues and themes that emerge in the book. First and foremost, the realities of the COVID-19 pandemic assert themselves throughout the text. Many of the interview subjects were in the midst of figuring out how to maintain and continue the operations of their organizations in the midst of a global crisis. To that end, the collection of essays in this book offers a unique opportunity to explore the more or less real-time processing and response to the challenges the pandemic presents.

The essays are also connected by consistent application of ideas and frameworks from Bolman and Deal's book Reframing Organizations: Artistry, Choice, and Leadership. Bolman and Deal's perspectives are focused on developing and exploring four competing frames for thinking about leadership and organizations: a structural frame tied up in separation of duties and functions, a human resource frame focused on how to support people in organizations to flourish and grow, a political frame focused on how scarcity 
of resources produces the need to build coalitions, and a symbolic frame focused on the ways that symbols, values, rituals, and ceremonies create and sustain organizational cultures. Throughout the book, students apply and explore issues in how these frames work to approach the perspectives of their interview subjects. As a result, the book presents a sustained exploration of how these frames of leadership fit with the perspectives of leaders in the library and archives community at the end of the second decade of the $21^{\text {st }}$ Century.

I'm deeply grateful for the time and care that the individuals profiled in this book took to share their ideas and perspectives with our class and now more broadly in this book. As you might imagine, the Fall of 2020 was a stressful time to be working in library and information organizations. In that context, it would have been entirely reasonable for leaders in the field not to be able to make time for talking with students about their careers or library and archives organizations. All of the individuals featured in the profiles in this book were willing to make time to talk with students and give feedback and input on their drafts. The wisdom and insights they shared with students are invaluable.

It's been a pleasure to have the chance to develop this book and facilitate this dialog between leaders in the field and students working to start or advance their careers. I learned so much from the generous and thoughtful perspectives offered by interview subjects and drawn into focus by students in the course. I hope you will, too. 


\section{Leadership in}

Archives and Special

\section{Collections \\ SECTION I}




\section{Collaboration,}

Support, and Innovation

\section{PERSPECTIVES FROM MEGHAN BRYANT ON LEADERSHIP IN ARCHIVES}

Jacob Hopkins

In 2016, Dr. Meghan Bryant stepped into a new role established by William \& Mary Libraries (Williamsburg, Virginia) as the Frances Lightfoot Robb Public Services and Instruction Archivist. The creation of this position signals William \& Mary Libraries' commitment to supporting and sustaining an instruction and outreach program within the Special Collections Research Center (SCRC) at Earl Gregg Swem Library.

While predecessors of Bryant regularly folded courseintegrated instruction and campus and community outreach into their work, their official titles and position descriptions treated instruction and outreach more as additional duties than central responsibilities. William \& Mary Libraries' concerted effort to dedicate a position solely to special collections public services and instruction reflects a current movement of university special collections and archives to democratize and promote special collections across disciplines and users. 
Jason Tomberlin and Matthew Turi (2012) characterize this trend as an opportunity for a special collections library "to assert its role as a unique and irreplaceable contributor," much like the rare items for which it cares, "to the University's core mission” (p. 2). Indeed, Bryant's everyday work as the Public Services and Instruction Archivist regularly connects the SCRC to myriad university academic departments, student organizations, and external community groups, forming a dynamic network that upholds and strengthens the university's expressed values, including Belonging, Curiosity, Excellence, and Service (William \& Mary, 2020). While Bryant is the only professional faculty member in the library system solely dedicated to special collections instruction and outreach, she regularly seeks the input, engagement, and feedback of partners both inside and outside the library.

In a position centered around, and dependent upon, the public's interactions with special collections, Bryant strives to expand and engage the SCRC's audience, making collections "more easily accessible to them and used more often and innovatively by them." She approaches her role as a facilitator and collaborator, not a gatekeeper.

The following profile offers a glimpse of Bryant's leadership in action, in particular highlighting her collaborations that sustain and grow the SCRC's instruction and outreach program, her support for staff under her supervision, and her creativity and innovation, particularly in times of overload or crisis. Tying Bryant's own words, perspectives, and experiences to Lee G. Bolman and Terrence E. Deal's Reframing Organizations, as well as other literature on management and organizational theory, situates Bryant's 
attitudes toward leadership within a larger context that considers the opportunities, limitations, and negotiations of information organizations.

\section{Collaboration}

The SCRC's instruction and outreach program engages and responds to several diverse groups of stakeholders, including students, faculty and staff, volunteers, donors, community partners, university administration, and members of the William \& Mary Libraries Board of Directors.

In coordinating and negotiating these varied needs, interests, and skills, Bryant's daily work involves relationship management, or "initiating, building, and maintaining relationships inside and outside of the organization" (Martin, 2019, p. 8). To be effective, these relationships require responsive engagement and a foundation of mutual understanding - requisites that demand a leader's time, cooperative trust-building, and open communication. Bryant credits these partnerships with shaping and enriching both the SCRC's collections and its programming.

Bryant views the university's students as the "primary stakeholders" in the SCRC's public services initiatives. The SCRC regularly engages undergraduate and graduate students through course-integrated instruction, one-on-one research appointments, social media, and programming like open houses and lectures. Bryant coordinates all of these services, and they unite around an overarching goal of 
meeting the needs of students of all backgrounds and experiences. In describing her vision for students' experiences with SCRC, Bryant explains that she wants students to visit special collections "not as an obligation but as an opportunity to involve themselves in a space that will support their interests, their scholarship, and their ideas." Here she stresses the importance of a physical place "where people congregate, think, discuss, learn, and collaborate" (Evans \& Greenwell, 200o, p. 299) and retires outmoded notions of archives as static, hidden, or guarded spaces.

Teaching faculty also heavily informs the SCRC's public services, especially the instruction program. Throughout an academic semester, Bryant frequently meets with faculty to discuss how the SCRC can best support a professor's class, including scheduling time for students to visit special collections, acquiring rare and unique materials relevant to the course, and promoting students' research on the SCRC's blog and other social media. Faculty that schedule a special collections instruction session with Bryant for one semester often make it a habit to include special collections instruction in their syllabi for future semesters. And they also regularly share their experiences with instruction sessions with departmental colleagues and other faculty, generating interest and involvement in special collections by word of mouth. Reading Bryant's influence through Bolman and Deal's (2017) political frame of organizations, her power here originates from reputation and everexpanding alliances and networks (p. 192). Aside from word of mouth publicity, Bryant also promotes the SCRC's instruction program at faculty open houses and workshops, making herself available to new and lasting connections. 
But perhaps Bryant's most impactful collaborations come from within the SCRC department itself. She calls her departmental colleagues a "small but mighty team" and recognizes advantages to working in a smaller library unit. Aside from Bryant, six full-time professional faculty and four hourly employees also work in the SCRC, and each devotes time to the public services Bryant oversees, including reference and instruction. While most of these staff members are not under Bryant's direct line of supervision, she coordinates an instruction program that "brings together independent staff with complementary areas of expertise, experience, knowledge, and interests." This description recalls Katzenbach and Smith's (1993) definition of high-performing teams: "a small number of people with complementary skills, who are committed to a common purpose, set of performance goals and approach for which they hold themselves mutually accountable" (as cited in Bolman \& Deal, 2017, p. 105).

Bryant praises her colleagues' willingness to collaborate with instruction, or even lead instruction sessions on their own, as the demand for SCRC instruction outweighs her personal availability. She says, "No matter what class we have that comes in, we always have someone who knows about the topic, or, even if they don't know anything about the topic, is interested and excited and willing to dive in and participate." This shared responsibility grants Bryant more time and space to connect with stakeholders and direct the instruction program forward in innovative ways without always having to worry over day-to-day operations.

Yet she also recognizes the challenges of leading a large instruction program within a relatively small department. 
Without an internal sub-department dedicated to instruction and outreach, "every single person [in the SCRC] is so stacked with projects, deadlines, and pressing matters, and anything else like instruction is an added responsibility...time and energy that takes them away from their 'assigned duties." Bryant does not encounter resistance in rallying support for the SCRC's instruction program from her intradepartmental colleagues; in fact, she calls it "easy" because "everyone understands that it's a group effort" that is meaningful and worthwhile. By respecting and recognizing her colleagues' unique skills as assets to the SCRC's public services mission, Bryant leads by encouraging individual "discretion and judgment so [her departmental teammates] can feel personally accountable for their results" (Hackman et al., 1987, as cited in Bolman \& Deal, 2017, p. 149).

While this agency and autonomy offers a sense of empowerment, the accompanying work overload can prove challenging. "Everyone has to be the master of organizing their own time," Bryant confesses. And this push to do more (often with less) can lead to feelings of burnout or depersonalization, symptoms of the "vocational awe" often assigned to librarianship (Geary \& Hickey, 2019; Ettarh, 2018). Bryant copes with burnout and difficult situations in the workplace by maintaining open lines of communication-both with her SCRC colleagues and her personal family and friends.

"My colleagues and I are over-achievers and want to deliver the best service we can, and sometimes that means taking a step back, looking at the bigger picture, and seeking input," she says. "You're never the only genius in the room," she 
quips. Vocalizing her exhaustion to others can allow space for new perspectives and clarity to emerge. The shared responsibility of the SCRC's instruction program, structured around the lateral coordination of all SCRC staff, encourages and requires open communication, group buyin, and collaborative solutions.

\section{Supervision and Support}

Starting her role as Public Services and Instruction Archivist, Bryant inherited three supervisees who worked at the SCRC before she arrived and continue to work there today. "I adopted them-or maybe they adopted me," she reflects. This sense of "adoption" recalls the central metaphor of Bolman and Deal's (2017) human resources frame, one lens for understanding organizations: the organization as a family (p. 17). Regular meetings and informal conversations with these employees allowed Bryant to better understand and appreciate their unique interests, needs, and skills. Likewise, Bryant turned to these individuals to acquaint herself with the inner workings of the SCRC's collections and services, as well as the larger library organizational structure and culture. These communications laid the foundation for an "integration of advocacy and inquiry” espoused by Argyris and Schön's Model II of interpersonal behaviors, in which Bryant and her supervisees can "express openly what they think and feel and actively seek understanding of others' thoughts and feelings" (Bolman \& Deal, p. 163).

Recognizing and valuing the experiences of her supervisees, Bryant strives to transparently direct overarching goals for 
the SCRC's public services initiatives, while simultaneously granting these individuals their own control and independence in helping realize these goals. This autonomy, one of Daniel H. Pink's (2009) essential elements for fostering intrinsically motivated work, positions the employees under Bryant's line of supervision more as collaborators than subordinates.

Aside from faculty and staff, student assistants also play a significant role in the SCRC's public services. Each academic semester, Bryant manages around fifteen student employees who assist with reference, collection retrieval, programming, and exhibition curation.

The process for hiring student employees does not involve a formal interview; rather, students are most often hired based on their skill sets and availability. For this reason, Bryant often does not personally know each new hire before they begin working with her, which can be a good thing:

We're not hiring people based on our subjective opinions of them based on an interview, but we're hiring people that physically want to be here helping us and are able to do that, so in that way it gives a level of equitability to the hiring.

Hiring chiefly according to availability and expressed interest results in a student workforce motivated by intrinsic interest, or the "inherent satisfaction of the activity itself" (Pink, 2009, p. 47).

Aside from the advantages the SCRC gains from this diverse and motivated workforce, Bryant witnesses firsthand the benefits the students also reap: 
We end up, inevitably, with this very unique group of people who have often never met or crossed paths, and they become part of this larger team that we have, and we get to see friendships form and teamwork develop.

This camaraderie grows from a workplace culture that values individual interests, skills, and feelings as important components for nurturing group accomplishments. Additionally, Bryant finds excitement in student assistants "discovering new interests and developing new skills that they didn't have before they started working here," recognizing creativity and curiosity as valuable assets for both the SCRC's public services and the individual student employees.

Bryant admits that it is challenging finding the time to regularly check-in with every employee she supervises. Inspired by her own supervisor, the Director of the SCRC, she adopts an "open door policy" and encourages her supervisees to feel comfortable walking into her office at any time to share comments, concerns, and interests. She admires her own supervisor for always "being available to his staff and always having my back-it can feel like there's not a hierarchy, which of course there is-but with him you sort of forget that, because he really values his staff." She strives to emulate this spirit of equality and approachability with her own supervisees. In her first job working in archives, at The Valentine, a museum in Richmond, Virginia, her former supervisor encouraged her to ask questions and check-in frequently. She recalls: 
She never lost patience with answering my questions...never showed any hint of being frustrated with me, and I respected that a lot. I don't want anyone to ever feel like I'm bothered by them or inconvenienced by them. I think it's a good thing to ask questions.

As someone who supervises several employees, all with different responsibilities and skills, Bryant has one priority that always guides her: "encouraging and validating the work that people are doing, no matter what it is." Her end goal echoes Bolman and Deal's (2017) sentiment that "apart from their homes, people spend more time on the job than anywhere else. With that kind of personal stake, they want to be part of something that matters and contribute to a greater good" (p. 128). She posits that money or other rewards mean little without recognition and gratitude and that her role as a supervisor is ultimately to encourage people to do work that feels "productive, enjoyable, worthwhile."

Archival work has more recently been described under the umbrella of "maintenance work," highlighting the routine and continual care, emotional labor, and other work that often goes unrecognized and undocumented in archives (Arnold, 2016; Olson et al., 2019). Bryant strives to validate the work of all the people she supervises, "no matter what the task or project," because their commitment to "giving their time and efforts to us, and working as part of our team, is worth recognizing." This conscious effort to recognize and uplift all work done by all employees both supports Bryant's mission of fostering a team effort for SCRC's public services and the future of the profession, 
which relies on archivists better representing themselves and the value and labor of their work.

\section{Innovation}

Bryant is no stranger to leading during change. As William \& Mary Libraries' inaugural Instruction and Public Services Archivist, she has grown the SCRC's instruction program into a prominent library service that regularly unites partners across campus in conversation and collaboration. But the COVID-19 pandemic of 2020 has necessitated more innovation and collaboration than ever before.

When practiced as a regular and continual routine, relationship management forms dependable partnerships that "lead to better teamwork and an easier time managing change" (Martin, 2019, p. 9). Thanks in part to her preexisting strong relationships with invested stakeholders, including students, faculty and staff, and her library colleagues, Bryant has continued the SCRC's instruction program even as instruction has moved to online-only or blended modes of delivery. Likewise, the pandemic has introduced new collaborators into Bryant's network as the university-wide push to support virtual teaching, learning, and outreach breaks down organizational silos, innovating community and possibility even in a time of physical distance.

Bryant reflects on her work before the pandemic:

There's always an ebb and flow to the work volume, but during the height of the semester, especially, when you're working at max capacity, you know 
there exist these opportunities for collaboration and creative problem-solving, but may not grasp them.

She points to work overload and the organization's preexisting structure as factors keeping library silos in place. While the SCRC's instruction and outreach program regularly involves students, staff, and community members in its planning and intentions, the actual day-to-day work usually falls on Bryant and the help of her departmental colleagues, their time permitting.

"But then COVID happened, and guess what, you have to get creative," she continues, as she explains the new partnerships she has formed in adapting SCRC's instruction and outreach program to fit virtual environments. In particular, Bryant has benefitted recently from the support of the staff at the Reeder Media Center, another department within Swem Library that is responsible for supplying and teaching with technology.

In the shift to online learning, the Reeder Media Center, whose staff is even smaller than SCRC's, has stepped forward to provide guidance and expertise for librarians and archivists leading instruction sessions and virtual reference appointments. This support has proven invaluable to Bryant and her collaborators who were anxious about the SCRC's instruction program's success in an online environment without actual material collections. Thanks to the staff at the Media Center, the SCRC now has access to both the physical hardware (computers, microphones, tripods, document cameras) needed to facilitate an online learning experience and another partnership to serve as a sounding board for brainstorming and troubleshooting. The 
pandemic, despite all the hardship and limitations it imposes, has also broken silo walls, a change that can "lead to more flexible workflows, foster creativity and collaboration and...more productive staff relationships" (Kowalski, 2017, p. 13).

Similarly, the realities of the COVID-19 pandemic have also required Bryant to approach her relationship with student employees differently. Financial restrictions and efforts to de-densify workspaces severely limited the number of student assistants the SCRC could rehire in Fall 2020. Rather than try to replicate the same work that was done before, but with fewer employees, Bryant retooled the students' work responsibilities to better fit both their individual talents and the most pressing needs of the department.

In Fall 2020, she involved an available and interested student assistant in the SCRC's instruction program. While student assistants have always assisted instructional efforts in more indirect ways, such as by retrieving collections and helping set up the classroom, a reduced student workforce and new instructional demands provided an opportunity to involve a student assistant more consistently and thoroughly and with greater responsibility and autonomy. This more individualized supervision benefits both the student employee, who receives insight and experience in the actual work of archives, and Bryant, who sees students, already regularly engaged in online learning, as good judges of what does and does not work in the virtual classroom. "We're the 'authorities," she states, reflecting on her relationship with student employees, "but we certainly don't know everything." Here Bryant again emphasizes the 
collaborative work of archives and strives to treat her supervisees as equal partners.

\section{Conclusion}

The Public Services and Instruction Archivist position at William \& Mary Libraries is named in honor of the late Frances Lightfoot Robb, an alumna and longtime volunteer at the Special Collections Research Center who left Swem Library with a \$2 million donation in 2015. This gift, the largest in the Libraries' history, funds the Public Services and Instruction Archivist position and also established endowments to support the acquisition, processing, and preservation of manuscript collections.

As a volunteer at the SCRC, Robb processed large archival collections, including the papers of the Tucker-Colemans, a prominent Virginia family. Today these papers are one of the SCRC's most used collections, thanks in part to Robb's detailed description and arrangement. In the local community, Robb was the first president of the Williamsburg Historic Records Association, whose records are also housed at the SCRC. In addition to the generous donation she left Swem Library, over her lifetime, she also gifted several collections to the SCRC, including a letter written by Thomas Jefferson, an oil painting by Thomas Sully, and her own family's papers. With generosity and care, she connected people and organizations across campus and community and planned for the future of libraries and archives. 
Having her title connected to Frances Lightfoot Robb's name reminds Bryant of how integral volunteerism, collaboration, and teamwork are to the success of any institution, but especially libraries. "We depend a lot on the time and generosity of volunteers and donors, and [Robb] was both of those things," she says. As a leader who regularly collaborates with students, faculty and staff, volunteers, community members, and donors-overlapping audiences that all have a shared space in special collections-Bryant nurtures and grows the seeds of community and engagement sown by Robb and others before her. "Having the role that I have in outreach and engagement," she says, "I hope Frances Robb would be proud of that and the legacy she left behind."

\section{Author bio}

Jacob Hopkins is an aspiring archivist with a passion for community outreach, social justice, and participatory archives. He is currently in the Master of Library and Information Science program at the University of Maryland, College Park.

\section{References}

Arnold, H. (2016, August 2). Critical work: Archivists as maintainers. Hillel Arnold. https://hillelarnold.com/blog/2016/o8/criticalwork/

Bolman, L. G., \& Deal, T. E. (2017). Reframing organizations: Artistry, choice, and leadership. ( $6^{\text {th }}$ edition). Jossey-Bass. 
Ettarh, F. (2018, January 10). Vocational awe and librarianship: The lies we tell ourselves. In the Library with the Lead Pipe.

http://www.inthelibrarywiththeleadpipe.org/2018/vocationalawe/

Evans, G. E., \& Greenwell, S. (200o). Management basics for information professionals. (4 ${ }^{\text {th }}$ edition). American Library Association.

Geary, J., \& Hickey, B. (2019, October 16). When does burnout begin?: The relationship between graduate school employment and burnout amongst librarians. In the Library with the Lead Pipe.

http://www.inthelibrarywiththeleadpipe.org/2019/when-doesburnout-begin/

Kowalski, M. (2017). Breaking down silo walls: Successful collaboration across library departments. Library Leadership E Management, 31(2). https://doi.org/10.5860/llm.v31i2.7202

Martin, J. (2019). Emotional intelligence, emotional culture, and library leadership. Library Leadership E Management, 33(2). https://doi.org/10.5860/llm.v33i2.7329

Olson, D., Meyerson, J., Parsons, M. A., Castro, J., Lassere, M., Wright, D. J., Arnold, H., Galvan, A. S., Hswe, P., Nowviskie, B., Russell, A., Vinsel, L., Acker, A., et al. (2019). Information maintenance as a practice of care: An invitation to reflect and share. Zenodo. http://doi.org/10.5281/zenodo.3251131

Pink, D. H. (2011). Drive: The surprising truth about what motivates us. Riverhead Books.

Tomberlin, J., \& Turi, M. (2012). Supporting student work: Some thoughts about special collections instruction. Journal of Library Administration, 52(3), pp. 304-312. https://doi.org/10.1080/01930826.2012.684512

William \& Mary. (2019, November 22). Vision, mission, values. https://www.wm.edu/about/administration/vision-missionvalues/ 


\section{William Noel}

AN INTUITIVE LEADER

Angelina Wong

"I never intended to be a leader." William Noel is not the only information leader to say such words. To be fair, he only ever wanted to be a curator. Evans and Greenwell (2000) claim that many librarians who end up in managerial positions never studied to be managers. Yet successful librarians are those who do adapt to their positions as leaders. Some eventually seek management training, but Noel is one of a few exceptions who never might. Not because of unwillingness, but because of schedule constraints and his nature as "an intuitive leader."

One could argue that William Noel leads by intuition and common sense. This essay discusses his methodology and experiences in the field of information science from the perspective of the four organizational frames coined by Bolman and Deal (2017). These frames are: Structural, Human Resources, Political, and Symbolic. Unless otherwise cited, all quotations come from Noel during an interview I conducted on October 22, 2020.

Despite never having taken a management course or participated in a Library and Information Science program, Noel's approach to organizations matches many aspects of organizational theory discussed in the literature. For example, in our interview, he emphasized the need for setting an agenda and listening to everyone in the 
organization, recommendations made by a number of organization leaders (Bolman \& Deal, 2017; Kalil, 2017; Mierke \& Williamson, 2016). Noel's success in synthesizing these frames unknowingly and following role models throughout his career, basically learning on the job, makes him an intuitive leader.

\section{Background}

William Noel is a middle child of three. This environment put him in a beneficial middleman position. He had to learn early on how to listen and communicate to different family members from different relative age groups and perspectives. This skill carried him throughout his career as an effective communicator between constituents in every organization for which he worked.

Long before working in any information organization, Noel completed his PhD in 1993 from Cambridge University, where he studied at Downing College as an undergraduate, postgraduate, and British Academy Post-Doctoral Research Fellow in the Department of History of Art. Four years later, he worked for some time as a curator at the Walters Art Museum in Baltimore, where he learned "what not to do" as a manager and discovered flaws in the curating profession. During this time, he also developed what would be arguably his most famous project, The Archimedes Palimpsest.

Due to personal circumstances, he moved to the University of Pennsylvania to direct the Schoenberg Institute for Manuscript Studies and the Kislak Center for Special Collections, Rare Books and Manuscripts. Very recently, he 
left his two director positions for an offer to be the John T. Maltsberger III '55 Associate University Librarian for Special Collections at Princeton University.

Since March 2020, Noel has been adapting to his new organization and the virtual restrictions implemented because of the COVID-19 pandemic, which shut down the nation around the same time as his employment. Though he has yet to meet his team in person, by the time of this writing, he has been using all tools at his disposal to create camaraderie, remain productive, and uphold morale.

\section{Structure}

An organizational structure lays out "[t]he right combination of goals, roles, relationships, and coordination...essential to organizational performance" (Bolman \& Deal, 2017, p. 47). The most obvious form of a structure is the organizational chart. Most organizational charts in information groups are pyramid-shape diagrams that show relationships between directors (employers) and staff (employees). This hierarchical structure dominates information organizations, which Noel argued is necessary for accountability and making work efficient. Hierarchies are not interesting in themselves; rather, the lateral interactions, the matrices, within them make them necessary for innovation.

The Special Collections organizational chart at Princeton University is almost identical to those from other university libraries. It is a simple hierarchy with one boss at the top, a middle manager who communicates between the boss and 
25

the workers, and the workers. At the Princeton University Special Collections, William Noel is the boss at the top. The one University Archivist and Deputy Head of Special Collections reports to him. In turn, that middle manager accounts for four other departments: three assistant university librarians and the senior curator. Also branching from the top is the wonderful assistant, who is pivotal in bridging messages to and from Will.

The use of hierarchies can promote the development of silos within any organization, especially those where communication is vertical. Noel described in detail the external structural issues of silos in the Princeton University Special Collections:

A lot of special collections are put together in chunks. At Princeton, for example, we have the Scheide library, which was the personal library of William Scheide, and he had a librarian. And we have the Cotsen Collection, which is a children's library, and the Cotsen Collection had a librarian. ...[The librarian] is responsible for everything to do with that library. [...] You then take this private library and you put it in the context of a university library, where actually we have...systems for all of those [responsibilities].

The university's special collections website reveals even more separate libraries than Noel mentioned, but the issue remains: every private library had their own system of management before merging with the university, and the merger pressures them to change their ways. 
Many of these libraries were already, and continue to be, separate entities with their own librarians and specialists. Noel understands why the librarians keep to their own collection, though: tradition really matters for special collections. It matters so much that librarians, and archivists, are willing to create silos to protect the culture within their unit, even though this self-preservation undermines the Princeton Library Special Collections as a whole. Breaking down silos (Kowalski, 2017, p. 4) and illuminating how libraries can interact for the greater good by mapping their interactions (Stroh, 2015) would create a more productive organization.

Noel described curation as a job where everyone is interested in promoting their own collection. This comes from the nature of the profession, an expectation to "do something brilliantly" rather than supporting the organization as a whole. In other words, to specialize. As a result, many special collections view themselves as separate from the larger library and each other.

Noel admitted that he was such a curator early in his career at the Walters Art Museum. He realized in future employments that "getting the Special Collections staff to realize that they have to interact with the wider library can be very hard." Realizing that there is not much he can do to change the structure, after all the siloed collections do require their own librarians and are therefore separate departments in their own right, Noel intends to harmonize the greatest assets of the library world: people. 


\section{Human Resources}

"The successful human resource leader believes that people are the center of any organization (Bolman \& Deal, 2017, p. 317). At the time of this writing, William Noel only meets his special collections team virtually, but he expressed great concern for their well-being during our interview. His immediate goal is to keep up morale. Human resources is at the forefront of his thoughts when he meets them in social and professional meetings. As described in the introduction, Noel learned early on how to listen. He also loves to talk and motivate.

Noel enjoys "getting people on the same page about things." When asked to describe his organization metaphorically as a well-known activity, he compared it to a boat where he is the sailor. The goal is to "get everyone on board." The open sea is the outside environment where external events can assist or destroy the ship. His job is to put up the correct sails and use his best judgment to ride out the weather and keep everyone safe.

Much recent research has been done on human needs in organizations. Daniel Pink (2011) wrote an entire book on the development of human resource principles since the dawn of humanity. Pink particularly emphasizes the existence of intrinsic and extrinsic types of people, Types I and $\mathrm{X}$ respectively (Chapter 3 ). The intrinsic types tend to be self-motivated and find personal reward in the work itself, provided that their basic needs are met, such as adequate compensation. Type $\mathrm{X}$ people are motivated solely on the amount of compensation they receive for working, 
which tends to diminish performance quality when monetary value depreciates or disappears.

The rest of this section will demonstrate just how much of an intrinsic leader William Noel is. Through his philosophy of openness, both in conversation and information, people follow him.

Noel's first curation position at the Walters Art Museum gave him the most experience in human resources. The museum director at the time, Gary Vikan, taught Noel not to take things personally and to avoid confrontations. Noel's immediate director, Griffith Mann, was inspirational in his ability to make everyone feel heard. Having this experience already with his family, Noel realized that his skills can transfer to an organization. Getting along with others is necessary to make an organization effective.

He also learned how to use a common goal to motivate people to work together. His time at the Walters Art Museum was also when he received the Archimedes Palimpsest project, discussed at the end of this chapter as a case study. The goal of any digitization project is two-fold: 1) Make high-quality scans of the resource and 2) Do not damage the resource. Noel's overarching objective on top of these is to make the resources accessible on the Internet.

When asked how he motivated his team to continue their high-quality work, Noel answered, "The cost of the content is borne by the organization rather than the user....[A] lot of people love that philosophy and so they are motivated to work for it." He added, though, that the people who do the work were compensated. His projects were not entirely voluntary, rather users do not pay the institution. 
29

After basic needs were met, it seems the project workers performed mainly for intrinsic benefits. Those who wanted to participate in the projects were welcome, but no one was coerced. All of his projects were completed partially through goodwill, no doubt a result of his prowess in motivational speaking but also by his philosophy of benefiting the public with open-source manuscripts. Those who worked on the Archimedes Palimpsest, for example, were experts on the subject, except Noel himself.

As explained in the Structure section, the nature of those working in a special collections is to specialize. They live for that work, so Noel did not need to motivate them intentionally. Getting the different units to mesh was his main job, in addition to being an ambassador to ensure everyone had manuscripts to read for the next year.

\section{Politics}

As everyone knows, organizations do not accomplish work on wishful thinking. Projects need funding. Before diving into familiar politics, let us briefly harken back to the structural frame and the issue of silos.

The Princeton University Special Collections is made up of a merger of formally private libraries. This structure has made it difficult for Noel to make the units in the special collections department connect, but he surprised me during our interview by arguing that silos can be good.

Noel: "[Silos] are often bad, but they're not always bad...." 
Wong: "Do you have an example where it worked out?"

[Laughter on both sides]

Noel: “That's a really good question!”

He gave a personal experience from his time as director of the Schoenberg Institute for Manuscript Studies at the University of Pennsylvania. Due to the nature of the IT department being answerable to all libraries on all things technology, Noel realized that timely support for his "little boutique-y manuscript projects” would be impossible.

Therefore, to go around this issue, he hired his own IT assistant. This person worked only for Noel's department, not the larger IT department. Through this setup, the members of the project had a direct bridge to the larger IT department, a bridge that also translated their messages from common vernacular to coded script. This perk saved members much time and effort in trying to communicate concerns themselves. Noel's manuscript projects flourished and everyone was happy, except jealous onlookers.

This seems like a structural issue. Why did I retell this story under politics?

William Noel's success came from recognizing a scarce resource and finding a path to that resource by bypassing his competition. His IT assistant was not supposed to be on any organizational chart. He was an addendum to the team to reach a commodity. This also shows that not all politics is about money and policies, but since that is the expectation, I will discuss those aspects of politics now. 
According to Bolman and Deal (2017, quoting Kotter, 1988) and Kalil (2017), the first step in political leadership to "getting things done" is creating an agenda (p. 205; p. 13). The agenda states the interests and vision of an organization and affected parties. It also includes recognizing where competition and conflicts currently or may exist. When drafting a project, these are the concerns Noel considers, but it is difficult to picture what his team can and cannot do without first knowing the budget. Without a grant, he would not know how to proceed with any project. As mentioned earlier, Noel excels at making an agenda. Our interview was speckled with him mentioning that he has a plan for this and that. A grant organizes his thoughts, but the amount must be specified prior to the planning phase.

Even when a budget is known, the rules underlying activities can make it difficult to implement any wellthought plan. For example, an issue Noel has with special collections in general is the policy surrounding internships, especially unpaid ones. Collection managers often hire temporary student workers to do permanent work. Considering the culture of corporate America, Noel finds this practice humanely unacceptable.

To remedy this issue in his current position, he uses his political power to pay temporary employees from endowed funds in order to keep interns on board for multiple projects. This in effect extends a temporary job to a more permanent one and allows the employed to build an actual career rather than meager experience in the field. (He was quick to add that not everyone has the money to do this, so 
he considers himself fortunate to be able to implement this plan due to his position at Princeton.)

Clearly, Noel is in a position of many forms of power (authoritative, controlling of rewards and agendas, expertise, reputation, etc.). His most effective source, I would argue, is his personality. Bolman and Deal (2017) calls this "personal power" via "influence tactics," and properly defines it as "power independent of other sources" (p. 193). Noel used this power to hire his own IT assistant at the University of Pennsylvania. He also uses this power to maintain followers for open access manuscripts despite constant criticism from fellow archivists on sustainability.

\section{Symbolism}

William Noel described Gary Vikan, former director of the Walters Art Museum in Baltimore, as "iconoclastic." His most notable actions were eliminating the general admission fee and providing open access to the museum's digital assets. It was from this role model that Noel developed his unwavering vision of open access manuscripts. In addition to his many TED talks and lectures advocating this practice, Noel's "About" description on LinkedIn simply reads "Free Medieval Manuscripts. Now."

He is clearly a man with a vision, and this is key in his ability to inspire others to "get on board." His belief, expressed by others in literature (Oppenheim, 2008; Owens, 2003), is that visible resources are more useful to the general public and are a way to promote one's institution. While I have yet to find evidence on the advertising effects 
of open access manuscripts, the general argument is that creators want their work to be seen. It should apply to curators as well to want their work to be seen.

The problem with special collections, as Noel and others have noted, is that they are self-centered and have no interest in change (Duff \& Johnson, 2003, p. 94). By Noel, "[special collections] are organized by professionals for professionals." We see this behavior quantified in the Association of Research Libraries (ARL) Statistics for 20172018, which reveal that the extremely elite libraries remain elite in nearly every aspect of an information organization. While remaining in a perpetual state may give a discipline, such as bibliography, a sense of immortality, such thinking is unsustainable and, as Noel colorfully phrased it, "is going to blow up."

Archives are due for a change. Mierke and Williamson's (2016) discussion on how organization leaders should change culture reflected exactly the concerns Noel has with the Princeton University Special Collections. During the interview, Noel emphasized that he only recently was appointed, just months before buildings closed because of the COVID-19 pandemic. In that short time, he noticed disharmony within his organization and a need for a culture change. His main goal with the organization is actually to make Princeton "less toxic," which one can argue is more in line with the human resources frame, except that the benefits of working at an Ivy League school easily covers the needs of a person's well-being (see "Salary Expenditures" for Princeton University in "ARL Statistics 2017-2018”). 
His objective is neither structural nor political, either. He is attempting an internal change, a change on a group culture. Culture is intangible and cannot be demanded. Every individual must be willing to adapt to the new culture in order for changes to be effective and permanent.

Unfortunately, building closures make it difficult for Noel to connect with his staff and implement change. Since reframing is still in process, his success is inconclusive at the time of this writing. Yet I would argue that Princeton made an excellent choice in hiring him to care for their Special Collections. Despite being virtual, he connects with his colleagues in weekly meetings, rituals of normalcy at this point. He has demonstrated on multiple occasions being passionate about manuscripts. He is an innovator who can set and implement agendas that inspire people from varied backgrounds to work toward a common goal. Surely the Princeton University Special Collections is in good hands.

\section{The Archimedes Palimpsest: A case study}

An Internet search for William Noel's name first yields many articles about his work in preserving and/or advocating for open-source ancient and medieval manuscripts. Every article about him also mentions The Archimedes Palimpsest project. What was this project?

According to the website "The Archimedes Palimpsest," the purpose was to use different types of digital scanning on the codex to reveal erased work by Archimedes, an Ancient Greek mathematician. Noel's job in the project was to direct 
operations on scanning the codex and make the entire object accessible on the Internet.

According to Noel, the project was essentially an experiment. Throughout the project, the technology they used to image the palimpsest kept changing, which offered opportunities to improve image quality for subsequent pages. Funding occurred yearly, despite expecting the project to span a decade.

The Archimedes Palimpsest project was privately funded by the owner of the resource who, by rights, made the final decisions on what may be done with the codex. Even though Noel was the project director, and thus made suggestions for project activities, he emphasized that the boss (the owner of the resource) always had the final say. This is politically and structurally fair.

Therefore, Noel had to argue his cases. He had to negotiate a quote (a grant) annually to continue reading the book and converting it into digital formats for the next year, but only for the next year. To his benefit, planning only one year in advance is much more manageable than the next three or five as most organizations do. After agreeing on the grant amount, Noel could set an agenda.

He realized quickly that he would need a project manager who can implement his plans. He chose a person named Michael Toth, the President and CTO of R. B. Toth Associates. Noel chose him to be the project manager because of his extensive experience in running preservation projects. Toth also signed on voluntarily. 
Noel was transparent with his team about funding: how much they had and allocation. Since they were working from grants, he also reminded his team that funding is temporary and there was no chance of future employment in this project. His vision of making the erased work of Archimedes legible and openly accessible through digital imaging inspired his team to see the project to completion anyway. (Note that participants were paid, but the motivation was not from the money.)

Structure in place, personal needs met, and politics aside, the team could focus on the vision of the project more often as work progressed. The ultimate goal was to expose Archimedes' lost work and share those findings.

William Noel's greatest strength as a leader was reminding people of the project's vision. Even when personal opinions differed and departmental work seemed unrelated, Noel revealed how everyone's part led to a single goal. He ensured there was constant work and funds through annual negotiations. After navigating the politics, he kept everyone motivated by providing the work they enjoyed doing and positioning people in their appropriate department.

\section{Conclusion}

William Noel emphasizes that "Your job is not about what your title is. It's about what it is that you want to do. What difference do you actually want to make?" Despite being head of the Princeton University Special Collections and leading many open access manuscript projects, Noel 
believes his actions and intentions are more important than his status.

His position at Princeton does not guarantee a dissolution of silos. He was the director of the Archimedes Palimpsest project but saw himself more as a middleman "brokering relationships between people who didn't understand each other very well." He funds what should be short-term internships because he can and believes it is humane. He delivers through personal power and by advocating a belief in free manuscripts.

William Noel is an intuitive leader. He never attended management training and probably never will, but that does not diminish his ability to lead people. According to him, "Leadership can come from anywhere."

\section{Author bio}

Angelina Wong is an academic educator and a private music teacher. She received her BA (2013) from the University of Maryland in Classical Languages and Literatures. Her major specialties are in historical linguistics and music. She currently studies to be a music librarian with an ambition to create an open access database of ancient music resources.

\section{References}

Bolman, L. G., \& Deal, T. E. (2017). Reframing organizations: Artistry, choice, and leadership. ( $6^{\text {th }}$ edition). Jossey-Bass. 
Duff, W. M., \& Johnson, C. A. (2003). Where is the list with all the names?: Information-seeking behavior of genealogists. The American Archivist, 66(1), pp. 79-95.

https://doi.org/10.17723/aarc.66.1.1375uj047224737n

Evans, G. E., \& Greenwell, S. (200o). Management basics for information professionals. (4 ${ }^{\text {th }}$ edition). American Library Association.

Kalil, T. (2017). Policy entrepreneurship at the White House: Getting things done in large organizations. Innovations: Technology, Governance, Globalization, 11(3/4), pp. 4-21. https://doi.org/10.1162/inov_a_00253.

Kowalski, M. (2017). Breaking down silo walls: Successful collaboration across library departments. Library Leadership \& Management, 31(2). https://doi.org/10.5860/llm.v31i2.7202

Mierke, J., \& Williamson, V. (2016). A framework for achieving organizational culture change. Library Leadership \& Management, 31(2). https://doi.org/10.1080/01930826.2018.1516949

Morris, S., \& Roebuck, G. (2019). ARL statistics 2017-2018. Association of Research Libraries. https://publications-arl-org.proxyum.researchport.umd.edu/ARL-Statistics-2017-2018/

Oppenheim, C. (2008). Electronic scholarly publishing and open access. Journal of Information Science, 34(4), pp. 577-590. https://doi.org/10.1177\%2Fo165551508092268

Owens, S. R. (2003). Revolution or evolution?: A shift to an open access model of publishing would clearly benefit science, but who should pay?. EMBO Reports, 4(8), pp. 741-743. https://doi.org/10.1038/sj.embor.embor913

Pink, D. H. (2011). Drive: The surprising truth about what motivates us. Riverhead Books.

Stroh, D. P. (2015). Systems thinking for social change: A practical guide to solving complex problems, avoiding unintended consequences, and achieving lasting results. Chelsea Green Publishing.

The Archimedes Palimpsest Project. (n.d.). The Archimedes Palimpsest. http://archimedespalimpsest.org/

Vikan, G. (n.d.). Gary Vikan. http://www.garyvikan.com/ 


\section{Librarian of Note}

ANNA KIJAS, HEAD LIBRARIAN

OF THE LILLY MUSIC LIBRARY

Jessica H. Grimmer, PhD

While the study of music may appear to an outsider as monolithic, as an academic subject it resides at the nexus of several fields and is highly cross-disciplinary. It relies first upon an understanding of musical styles, composition, theory, and often performing abilities of one or more instruments, but also necessarily includes understanding of political, cultural, and artistic history, as well as technological advances and their implications. Historically, it has required at least a cursory knowledge of the major European languages, though contemporary discourse about these requirements questions the colonialist origins of such a requirement. Specialist knowledge of a particular period of music often requires specific research skills, including an understanding of archives, specific cultures, other methods of music notation, and often fluency in a language of study.

To conduct research in this field also requires familiarity with many types of information sources. Information may be drawn from notated music, original compositional sketches and manuscripts, epistolary evidence, secondary monographs, collections, articles, and critical editions, as well as both audio and visual recordings of performances, historical and contemporary. To facilitate such simultaneously specific and broad research and study, music libraries must be equipped with leaders that possess 
thorough subject knowledge, training as librarians, and a clear leadership vision that guides their management of staff and of the organization.

Anna Kijas, head of the Lilly Music Library at Tufts University, has emerged as a leader in the field, having developed these areas of expertise to both guide her organization and continuing research and pedagogical aims. Kijas began her studies as an undergraduate majoring in music literature and performance at Northeastern University. There, she discovered a strong affinity for music research, and specifically for researching women in music. This interest led her to pursue a masters' degree in music history at Tufts University. Kijas credits musicologist Judith Tick at Northeastern, for whom she served as a research assistant for many years, as her primary musicology mentor and a guiding figure in her career. She also notes musicologist Jane Bernstein and music librarian Michael Rogan as sparking an interest in music librarianship. She was particularly interested in how musicians conduct research and connect with resources.

With the encouragement of these key mentors, Kijas began work on a Master of Library and Information Science degree program at Simmons University. During this program, she took librarian information science classes that offered hands-on practice with programming and database infrastructure. Kijas also developed a special interest in this digital work and has since undertaken self-guided learning through online programming courses, workshops, and by developing digital projects. 
Prior to her appointment as the Head of the Lilly Music Library at Tufts University, Kijas served as the Senior Digital Scholarship Librarian and Digital Studio Manager at Boston College University Libraries. She has also previously held the positions of Scholars' Collaborative Coordinator and Music and Dramatic Arts Librarian at the University of Connecticut Libraries.

Kijas appears exemplary in her role as a music librarian, possessing both the specialized subject knowledge and library training that the position requires. Moreover, her work as the head of the Lilly Music Library illustrates the collaborative efforts necessary to work within a larger academic library system, the understanding of what her staff within the music library need to successfully carry out their duties, and the eagerness to pursue leadership within the broader field of music research and continuing professional development.

\section{Working in the Tisch Library System}

The Lilly Music Library is organizationally located within Tufts University's Tisch Library System. It is one of two branches outside the main library, the other being the W. Van Alan Clark, Jr. Library at the School of the Museum of Fine Arts, abbreviated to the SMFA Library. Subject-specific libraries are common within academic library systems, and often reflect strong programs within a specific university. They also represent an academic institution's understanding of specific collections needed and used by their faculty and student constituencies. Subject specific librarians, by extension, serve these communities through their own deep 
understanding of the subject and the types of information useful to scholars (Pinfield, 2001).

The Lilly Music Library is physically located within the Department of Music, in the Perry and Marty Granoff Music Center. This building houses classrooms, a computer lab, ensemble rooms, teaching studios, and practice rooms as well as a performance hall, making it the hub for musical activities on campus. By virtue of its location within this ecosystem, the music library improves accessibility for the music faculty and students. While the service of this population remains the majority of the focus of the Lilly Library, it also serves the rest of Tufts University faculty, staff and student bodies as well as the surrounding geographic community.

Situated as such, this branch library is considered a portion of the overarching Tisch Library system. The Director of Tisch reports to dean of arts and sciences at Tufts University. Kijas, the head of one of the branch libraries, reports in turn to the newly appointed Associate Director of Tisch. As Kijas confirmed, there are areas in which the music library must go through the library system and also areas where they enjoy some degree of autonomy.

As a branch of the Tisch Library System, the music library supports all the strategic visions and all of the goals of the overarching library system. Therefore, the individual goals of the music library, as with all group and departments, must include and align with these goals. There are also services that require collaboration, including interlibrary loan, course reserves, campus holds and intercampus 
requests. Likewise, all budgets and services are tied into the central system.

However, there are areas of autonomy for Kijas in the music library, largely surrounding decisions around collection development, which is developed around the needs of the music faculty, curriculum, and graduate student research. Freedom also surrounds the identification of projects and initiatives, though those often take the form of fairly collaborative projects. One such project, currently in the pilot program stage, is making performances connected with the Department of Music available by pulling metadata from programs, creating a schema and ingesting them into the institutional repository.

Kijas' position, as head of the Lily Library but also subordinate to the overarching vision and goals of the Tisch Library System speaks to concerns raised by Bolman and Deal in both their description of their concepts of the structural frame and political frame. The structure, or organization of the library system into divisions by subject is necessary to best serve the constituents of a large academic institution but may contribute to difficulties working across the divides. Likewise, the position of the head of a subject library working within the larger system necessitates employment of the political frame, which informs when to work in lockstep with the organization, and when to campaign on behalf of one's own team and interests (Bolman \& Deal, 2013).

These necessary types of divisions of labor between branches or departments can cause "silos" to occur in some organizations, which may result in gaps or duplicates in work (Kowalski, 2017). However, the Tisch Library system 
facilitates working groups set up to intentionally facilitate conversations across divisions. Kijas participates in the Arts \& Humanities "cluster." This group is made up of subject librarians from across the arts and humanities and the fine arts college. Their bi-monthly discussions include resource sharing, budgeting, and collaborative efforts. Kijas praised these efforts, stating that the work done with her colleagues in this group has fostered "productive collaboration that allows for resource sharing and cross-divisional projects.”

This example of working horizontally across units within the organization illustrates a kind of engagement with shared governance, which champions collegiality and inclusiveness through inclusion (Meth and Westbrooks, 2018). Certainly, these ongoing groups aid in the maintenance of relationships and cooperative programs, as well as continued attention paid to the music library. Kijas' collaborative work within this working group fights against silos and also brings attention to the needs-budgetary and otherwise-of her own library.

The care that Tufts puts into this inclusionary working group also extends to their treatment of the librarians. Within Tufts University, librarians are aligned with staff, though they also enjoy a promotions process from entry level "affiliate librarians" to full librarian rank. Librarians here also receive professional development support through release time and library-supported travel and funding for continuing education. Scholarship is recognized as important and is a condition for advancement and is supported on an individual level, though not all librarians choose to go through the promotional process and may not participate in research. 
Kijas also described a sense of collegiality and respect across faculty, staff, and librarians at Tufts. She specifically cited support she received from the music faculty, stating that

I have heard from the music faculty that they value my background in music, musicology, and digital humanities.... I feel that the background and skills in music has helped me build strong relationships with the faculty and grad students, which might have been otherwise difficult. It has also opened opportunities for me, for example, to guest lecture or teach semester-long classes.

This sense of collegiality based on shared expertise speaks to the requirements for a subject-specialist librarian, as well as Bolamn and Deal's definition of the symbolic frame; in this case, Kijas' expertise imbues her position with authority, rather than merely inheriting the authority on the basis of the position itself and the structural frame (Bolman \& Deal, 2013).

The one downside that Kijas cited was the difficulty in finding time to do research or create scholarship. Unlike faculty, there is no formal process for sabbaticals or summers off to focus on this type of work. While they are often supported in other ways, these formal avenues are not available.

\section{Managing the Lilly Music Library}

As the head of the music library, Kijas also functions as a subject librarian. She described her work in this area as including "many requests for one-on-one consultations 
from both students and faculty who need support with research projects, class assignments, literature reviews, and the like." Before COVID-19 restrictions, these included inperson meetings, but are now relegated to virtual calls, telephone, and email. Kijas, embedded in the music school, also attends the department's faculty meetings, student orientations, and other relevant meetings in order to provide library updates that may impact them, offer feedback or information, and participate in discussions. Throughout the year she sends updates through the department's email list to ask for their suggestions or requests of music scores, titles, or recordings for acquisitions. Kijas describes this process as fairly collaborative, indicating that she "reach[es] out to individual faculty and graduate students when I am considering acquiring materials, especially special collection items, rare facsimiles, or other items relevant to their work or courses."

In addition to listening to the needs of faculty and graduate students, Kijas considers the format of items, the long-term preservation and sustainability of the items, and possible collaborative or shared resources. This extends to consideration of subscribing to databases; she necessarily questions their long-term sustainability plans, access and discovery. As her own research has concerned women and those people outside the canon, she has a special interest in collecting non-canonical works. This also reflects the restructuring of the music department to focus on music across culture, music as sound, and different representations of music. 
The Lilly Music Library is considerably smaller, as a subject specific branch, than the main Tisch Library. The staff space, study area, and stacks take up around 5,00o square feet. Like many branch libraries of this size, the library is run by Kijas, the head of the branch. One full-time staff member, the music library coordinator, reports directly to Kijas. Outside this one staff member, the library is staffed by student workers. Currently, eighteen students make up this workforce, though their numbers have climbed to 23 in the past.

Working with only one full time staff member, the music library coordinator, reporting to her has a number of advantages, according to Kijas. She reports that they enjoy a very positive work environment and a relationship built on mutual trust. Kijas does not believe in micromanaging, instead giving her coordinator autonomy in completing her work tasks and duties. Kijas believes that staff, and all people she interacts with, need to be shown empathy and compassion in what and how they want to work and grow, as it aligns with the organization's goals.

Kijas currently meets with her coordinator a few times a week; before the COVID-19 move to more remote work, they saw one another every day. Kijas's predecessor operated in much the same way, giving credit and support; as it produced positive results and aligned with her own ideas of management, Kijas saw no reason to change course.

Kijas likewise speaks very highly of her student workers, who are supervised by the music library coordinator. While the coordinator conducts the majority of the hands-on training, Kijas arranges and also provides guidance with their training projects. These trainings mostly apply to the 
day-to-day running of the library and include shelf reading, identifying call numbers, and re-shelving practices. The students are also trained on the types of musical objects they might be unfamiliar with, such as mini scores, critical editions, or facsimiles. They are likewise trained on customer service and helping patrons with the catalog system, basic front-end searching, ILL practices, scan-ondemand practices, pickups, and requests across campus. Kijas describes these trainings as fairly straightforward, though it may be brand new for an undergraduate unfamiliar with library practices or those unfamiliar with the types of information in music libraries. Outside these basic library skills, Kijas also trains them on encoding music incipits for some scores, an especial interest for her.

Management of these students necessarily takes a more hands-on approach. By virtue of being newer to the field, they require more frequent check-ins. By being more attuned to their needs, Kijas performs these check-ins particularly in reference to their developing knowledge and skill sets. To keep abreast of their progress, Kijas meets with the music library coordinator to review questions or address issues, like designing workflows around tasks that pose challenges for the students.

During the onset of the COVID-19 restrictions in the United States, the entire Tisch Library shut down. However, they began to introduce some services over the summer. In July, they began with no-contact pick-up. The Lilly Music Library opened a few weeks after the larger Tisch Library, during which they trained the students in new procedures. They're currently open with slightly reduced hours, plexiglass around the front desk, a self-checkout machine and reservation system for their reduced seating. 
Kijas hopes that the renewed focus on health and well-being continues through the post-pandemic period, affirming that she hopes that "there is more of a culture of care so that employees and students alike can take care of themselves year-round, stay home when sick, and prevent spreading germs." While Zoom fatigue is very understandable, Kijas believes that they will continue to provide virtual consultations after the return to more usual practice. She also believes that other practices will continue, like contactless pickup, a seat reservation system, or selfcheckout, because these create efficiencies in how students and patrons use the library, how much time they spend in the space, and may keep people healthy from other illnesses, like the flu.

Kijas, by working with both her music library coordinator and her student staff, appears to lean heavily into what Bolman and Deal define as the human resources frame, giving her staff the resources and information that they require to successfully carry out their roles, and then getting out of their way (Bolman \& Deal, 2013). In choosing this way of behaving, she also engages in the type of management that results in what Daniel Pink has advocated for in his seminal work on motivation in the intellectual workplacetrading in micromanaging for support and a hands-off approach (Pink, 2009). Her remarks surrounding new pandemic practices, and how she believes they may continue in a way that is beneficial to both employees and students, further evince her investment in supporting those she works with and manages.

She noted that while during her library degree she did take a course in management, it did not necessarily prepare her to manage a staff. This is one area that Kijas has taken steps 
to remediate, through connecting with mentors and through attending training for librarians in management positions. Kijas particularly recognized the work of DeEtta Jones, who specializes in diversity, equity, and inclusion in information institutions, and who has programmed the "inclusive managers toolkit” (see Diaz, J. R., Tellman, J., Jones, D. E., \& Association of Research Libraries, 1998). Kijas' willingness to lean into continuous professional development illustrates her commitment to developing expertise in all aspects of her position.

\section{Leadership in the Field}

Kijas' commitment to professional development is observed outside her position at Tufts, as she has taken on leadership positions in the broader music librarian and music research communities. She believes that professional development is key to understanding current scholarship and the new technology that applies to one's work. It is also a way to find new technology and training for herself and her staff, and to stay abreast of new opportunities.

Her service to the field and position as a leader in the music encoding and digital humanities further solidifies the local understanding of Kijas as a thought leader. This again highlights Bolman and Deal's negotiation of the symbolic frame, particularly as they identify the values of an organization (Bolman \& Deal, 2013). Tufts University, classified as an Rı Doctoral University with "very high research activity," according to the Carnegie Classification of Institutions of Higher Education, would, like its peer institutions, prize academic advancement, research, and 
pedagogy. By embodying these traits in her service to the field at large, Kijas' position is thereby imbued and reinforced by her stepping into the values espoused by the institution. This fact simultaneously and recursively elevates the institution through their retention of a leader in the field.

Outside of her role at the Lilly library, Kijas continues to develop her career and establish herself as a leader in the field, particularly through her involvement in the Music Encoding Initiative (MEI), where the author first encountered her work. Kijas, who regularly works on the development of pedagogical practices and exercises for MEI also hosted the May 2020 MEI conference virtually from Tufts University, to great effect. This virtual conference was by far the best among those the author attended over the course of the 2020 pandemic, being very smoothly run with an easily navigable interface and well-designed breakout rooms. Kijas subsequently ran an MEI pedagogy workshop with University of Maryland MITH faculty, Dr. Raff Viglianti at the November 2020 meeting of the American Musicological Society (AMS), which was met with high levels of engagement and enthusiasm.

Kijas feels that the outreach and promotion she engages in around music encoding and other digital musicology or digital humanities is a valuable way to promote understanding of these methods and usefulness among faculty, students and colleagues. She typically introduces MEI to student employees and music students through project-based work, for example having students create incipits for scores by women and people of color as a way to make these collections more discoverable. This project also 
dovetailed with the pandemic, as it provided remote work opportunities to students.

It also provides opportunities for pedagogical outreach. Kijas circulated the incipit project to MLA members to find other libraries to potentially collaborate and contribute to the project. She also views understanding MEI as one of the future skills of music librarians. The Library of Congress recognizes MusicXML and MEI as recommended formats for preservation, for example, and we have catalogs, such as RISM, where music incipits are rendered and can be searched, MEI guidelines have a FRBR module, which music catalogers already understand. All of these are examples where music librarians have contributed their knowledge in order to help create community standards and guidelines, and have informed the process because of their subject and format-based expertise.

\section{Conclusion}

As a music librarian, Kijas' career trajectory follows a welldefined path. From her undergraduate and masters' degree and demonstrated to great effect through her independent research and publication, she established a thorough understanding of the field. Her library training and foresight in developing coding abilities allowed her to develop expertise in key twenty-first century competencies.

In her work as the head of the Lilly Music Library, Kijas has grown into a leader that collaborates with colleagues across the organization and supports and empowers her staff to grow in their own skills. This leadership outlook is 
enhanced by the additional work she has taken on to develop her skills as a manager and become an inclusive librarian. Furthermore, by continuing to work with the Music Encoding Initiative, specifically in the area of pedagogy, she has positioned herself as a technological leader in the field.

Her work illustrates the tenets of several leadership theories and likewise speaks to the role of the librarian in the academy. First, Kijas' position as head of the Lily Music Library that functions within the larger Tisch Library system illustrates the political negotiation of spheres of influence, informing when to act as a leader, when to work in service of larger goals, and when to campaign on behalf of one's own team. Her management style leans heavily into a human resources-leaning method, as she prefers to give her employee and student workers the tools they need and, extra guidance when necessary, but to avoid micromanagement. Kijas" role as a thought leader in the broader community, particularly in encoding and the digital humanities, symbolically imbues her with authority within her institution and symbiotically raises the profile of her institution.

Finally, Kijas' work illustrates the role of many librarians who work in subject specific roles, like music or performing arts libraries. Individuals in these roles must demonstrate deep understanding and expertise not only in library science and management, but also in their subject area, nearly always gained through additional graduate degrees, and maintained through continued research and publication. Kijas demonstrates these qualities in a manner that defines her as a leader in the field. 


\section{Author bio}

Jessica Grimmer, $\mathrm{PhD}$ is a musicologist specializing in on late $19^{\text {th }}$ and $20^{\text {th }}$ century cultural history, centering on the relationships between music, institutions, and political discourse. Her current research focuses on the musical resonances of the Holocaust, both in Europe and in North America. She also researches and writes on sustainability of digital collections, with a special interest in encoded music.

\section{References}

Bolman, L. G., \& Deal, T. E. (2013). Reframing organizations: Artistry, choice, and leadership. ( $5^{\text {th }}$ edition). Jossey-Bass.

Brundy, C. (2018). Critical views of leadership and the academic library. Library Leadership E Management, 32(3), Article 3.

Dearie, T. N., Meth, M., \& Westbrooks, E. L. (Eds.). (2018). Academic library management: Case studies. ALA Neal-Schuman.

Diaz, J. R., Tellman, J. (1998). Affirmative action in ARL libraries: A SPEC kit 230. Association of Research Libraries, Office of Leadership and Management Services.

https://hdl.handle.net/2027/mdp.39015042818859

Kowalski, M. (2017). Breaking down silo walls: Successful collaboration across library departments. Library Leadership \& Management, 31 (2). https://journals.tdl.org/llm/index/php/llm/article/view/7202

Logan, F. (2012). Student workers: Essential partners in the twenty-first century academic library. Public Services Quarterly, 8(4), pp. 316-325. https://doi.org/10.1080/15228959.2012.731838

Pinfield, S. (2001). The changing role of subject librarians in academic libraries. Journal of Librarianship and Information Science, 33(1), pp. 32-38. https://doi.org/10.1177\%2Fo96100060103300104

Pink, D. H. (2009). Drive: The surprising truth about what motivates us. Riverhead Books.

Riley, C., \& Wales, B. (1997). Introducing the academic library to student employees. Technical Services Quarterly, 14(4), pp. 47-59. https://doi.org/10.1300/J124V14no4_05 


\section{Leadership Profile of Daniel Boomhower} AN ANALYSIS ACROSS ORGANIZATIONAL PROCESSES WITHIN THE CONTEXT OF LEADERSHIP FRAMES

Danielle S. Fitch

Since 2015, Daniel Boomhower has been the Director of the Research Library at Dumbarton Oaks, a Harvard University research institute, library, museum, and garden with a focus on Byzantine, Pre-Columbian, and Garden and Landscape studies. Boomhower leads the library in its efforts to support scholarly research in these three fields of study, namely through the research institute's residential fellowship program.

Formerly the Head of Reader Services in the Library of Congress' Music Division, Boomhower earned his MS in Library and Information Science from the University of Illinois at Urbana-Champaign and his PhD in Musicology from Case Western Reserve University. Boomhower has also held positions in the Hugh A. Glauser Music Library at Kent State University and in the Mendel Music Library at Princeton University. A scholar himself, Boomhower has published on the history of libraries and on the music of Johann Sebastian Bach and Johannes Brahms.

Over the course of his career, Boomhower developed a personal leadership style that was shaped by his 
observations of leaders in the organizations within which he worked. This paper will attempt to connect Boomhower's leadership experiences and perspectives with popular theories on leadership. Foremost is the theory of organizational frames, as presented by Lee Bolman and Terrence Deal in their book, Reframing Organizations. Bolman and Deal (2017) consolidate multitudes of organizational and social science research into four frames, or perspectives, for understanding organizations. By approaching leadership through these multiple perspectives, managers can avoid what Bolman and Deal define as the primary cause of managerial failure: "faulty thinking rooted in inadequate ideas" (p. 23). Simply put, the frames are tools that allow managers to expand their narrow views of organizations to see options and opportunities that they may have missed otherwise.

For context, the focus of each of the four frames is briefly described below:

Structural-Organizational and social architecture, division, and coordination of labor.

Human resources-Understanding people and relationships between organizations and people.

Political-Decision-making amidst scarcity of resources and divergent interests; power.

Symbolic-Meaning, organizational culture, values, and vision. (Bolman \& Deal, 2017) 


\section{Leadership}

When asked to define leadership, Boomhower summed up his perspectives as follows:

For me, the key to good leadership is empowering staff and doing that through a very clear mission; having a very logical and differentiated organizational structure so that people know where they fit...and how their effort contributes to the broader objectives, that then also have to be clearly outlined; having cooperatively developed goals and priorities, [which] is really critical to bringing into action the work that you want to achieve.

Within this statement, Boomhower touches upon themes from each of the four frames, utilizing a multi-frame approach even in how he defines leadership. First, we can see evidence of human resources considerations in Boomhower's emphasis on empowering his staff and making clear their purpose within the organization. By addressing the importance of a clearly defined organizational structure as a means of aligning staff roles and responsibilities, he conveys his use of the structural frame. Next, we can identify attention to the political concerns of allowing his staff to express their interests and ideas in Boomhower's stress on cooperative goal-setting (Bolman \& Deal, 2017). Finally, Boomhower's focus on a clear mission and well-defined objectives as tools for negotiating responsibilities and meaning fall into the symbolic frame (Bolman \& Deal, 2017). 
The characteristics that define leadership for Boomhower can be further analyzed across the organizational processes in which they exist. A sampling of these processes include strategic planning, goal-setting, communication, organizational change, and motivation. The remainder of this paper will be organized across these organizational processes to present in depth analysis on Boomhower's interpretations of leadership in the context of Bolman and Deal's organizational frames and other theories of leadership.

\section{Strategic Planning}

As defined by Evans and Greenwell (200o) in their book, Management Basics for Information Professionals, strategic planning is the process of creating actionable steps toward achieving a long-range organizational strategy as guided by the organization's mission, vision, and values. Boomhower believes in the importance of, and often underappreciation for, strategic planning and carry through. He noted that without a strategic plan "people don't know where they fit in, how important their work is, or how it relates to either the departmental or institutional objectives."

In Boomhower's experience, strategic planning is a critical tool to enable staff to know what the priorities and goals of the organization are and how exactly their work contributes to the achievement of those goals and the mission at large. For him, an organization's mission is the guiding force that helps his staff connect their day-to-day work with the broader objectives of the organization, and a way for them to feel empowered. 
Boomhower's perspective on strategic planning was recently informed by his experience with a substantial strategic planning process undertaken by the newly hired Harvard University Librarian, Martha Whitehead. Boomhower noted that he observed a "picture perfect implementation of a strategic planning process" and credited much of its success to Whitehead's emotional intelligence, her "sense of what people need to hear and how to develop conversations," and the importance she placed on listening to her employees. In fact, the first phase of the planning process involved listening sessions for Whitehead to learn about the Harvard Library culture and values. These conversations about what the staff valued in their work and in the organization struck Boomhower as very beneficial to understanding not only the organizational culture, but also what was motivating the staff to do their jobs, what they wanted their work to mean, and what they ultimately wanted to accomplish in their work.

The importance and execution of strategic planning as interpreted by Boomhower appears to be multi-framed. He acknowledges that strategic planning can serve the obvious structural purposes of setting objectives and coordinating people. He also addresses the human resources purposes that are served by using the strategic plan as a tool for clarifying his staff's importance and purpose (Bolman \& Deal, 2017).

Boomhower echoed the sentiments of Evans and Greenwell (2000) regarding the importance of staff participation as essential for library planning when he said, "[T]he creation of a strategic plan has to be bottom up and its execution has to be top down." With this Boomhower takes a political 
and/or symbolic approach to planning, which in contrast to a human resources approach, finds more success when initiated from below (Bolman \& Deal, 2017). A core assumption of the symbolic frame is that "culture forms the superglue that bonds an organization, unites people, and helps an enterprise to accomplish desired ends" (Bolman \& Deal, p. 242). Acknowledging that strategic planning can serve the purpose of reinforcing an organization's culture by having its values identified by the staff and reflected back in the plan is a very symbolic approach to planning.

\section{Goal-Setting}

When addressing the process of goal-setting, Boomhower disagrees with conventional wisdom that managers should set the goals and staff should execute them. He notes the importance of cooperatively developed goals, which have the benefit of garnering the buy-in, optimism, and energy of his staff. He notes that "you want [your staff] to be able to see that their voice is reflected back in the institutional priorities." Furthermore, he feels that a good staff is going to have good ideas and that, as a leader, you want to tap into that.

This sentiment is found in one of the core assumptions upon which the human resources frame is built: "People and organizations need each other. Organizations need ideas, energy and talent; people need careers, salaries and opportunities" (Bolman \& Deal, 2017, p. 118). Using this approach to the process of goal-setting, Boomhower is able to simultaneously encourage and harness the ideas, energy, and talent of his staff, which benefits both the organization 
61

and the staff. This mutual benefit between individuals and organizations is another assumption upon which the human resources frame is built (Bolman \& Deal, 2017).

The structural approach to the process of goal-setting emphasizes the benefit to the organization in keeping it moving in the right direction (Bolman \& Deal, 2017). Bolman and Deal note that goals are often embedded in strategy, and both goals and strategy can shape the structure of an organization, though the process is often "complex and subtle" (pp. 66-67). Boomhower acknowledges this subtle structural relationship noting that, as a leader, "You have the opportunity to take [the ideas from your staff] and shape them to point to specific outcomes, and then it is your marching orders on behalf of your organization to achieve those goals that you have identified."

Boomhower also approaches the process of goal-setting from a more political viewpoint as an opportunity for his staff to express their ideas and interests (Bolman \& Deal, 2017). Bolman and Deal explain that a combination of scarce resources and differing interests often results in conflict, but that as viewed through a political lens, this conflict is not necessarily a bad thing. Naturally, each staff member will have their own opinions on the nature and priorities of organizational goals. By encouraging a collaborative goalsetting process, Boomhower empowers his staff to share their opinions and participate in the negotiative process of making goal-setting decisions. 


\section{Communication}

For Boomhower, a key aspect of good leadership is communicating how the organizational pieces fit together and how jobs are differentiated, so that everyone has a clear understanding of where they fit in and what their responsibilities are. Furthermore, Boomhower places particular emphasis on transparency as one of his core leadership beliefs. His perspective on transparency was shaped by an experience he had as a library assistant in graduate school. The University Librarian at the time of his assistantship made a practice of sending a weekly email to every library staff member, including all the graduate assistants, that included her weekly schedule. Boomhower noted that he was struck by that level of transparency and noted that it really "telegraphed what her priorities were and where her attention was focused." He contrasted that with other leaders with whom he had experience whose whereabouts and activities were often unknown. As a result, Boomhower tries to communicate often and openly, noting that this level of communication is not easy, but that "a lack of transparency and a lack of clarity in institutional goals really erodes the effectiveness of a leader."

Unpacking Boomhower's interpretation of communication shows his multi-frame approach to the process.

Communication as a tool for sharing information and transmitting facts is a common structural view of this process, and one that Boomhower appreciates for ensuring a clear understanding of roles and responsibilities within the library (Bolman \& Deal, 2017). Using transparency of actions to communicate larger institutional goals and to foster meaningful working relationships with employees are more 
63

symbolic and human resources-centric approaches to the process. Evans and Greenwell (2000) echo this idea on an organizational level stating that "the greater the level of information sharing, the greater the organizational transparency, and generally the higher the trust stakeholders have in the organization's operations" (p. 78). Furthermore, using frequent informal communications as a method for implicitly showing progress towards achieving larger organizational goals utilizes a political approach to influencing employees and implicitly guiding their actions (Bolman \& Deal, 2017).

\section{Motivation}

Throughout his career, Boomhower has observed that "people work in libraries because they want to work in libraries. It is not just a job. They are bringing a lot more investment in the work and what they want their work to mean." He believes that as a leader, he can tap into this intrinsic motivation and let it inform his appreciation of the culture and the processes of defining objectives and building strategic plans. The intrinsic motivation that Boomhower describes is tantamount to vocational awe as described by Fobazi Ettarh (2018); it is the idea that librarianship is more than a career but instead a calling that is sacred and inherently good (p. 3).

Boomhower also believes in empowering his staff by not letting his own perspectives drive their work. His experience in the Music Division of the Library of Congress informed his actions in this area. As a music specialist, Boomhower could have let his knowledge of the subject matter 
complicate his responsibilities as a manager. Rather, by clearly delineating responsibilities and being mindful of letting his staff do their jobs without inserting his viewpoint on the work they were doing, he avoided "frustrating and demoralizing them." Furthermore, Boomhower tries to capitalize on the unique skill set of his staff, giving them a "wide latitude to play with their strengths" and "encouraging them to build the scope of their expertise."

These interpretations of motivation pull from both the symbolic and human resources frames. From the symbolic frame, we see how the idea that librarianship is a calling is woven into an organization's culture, and how a leader can use that culture to motivate their staff. Capitalizing on vocational awe and other internal motivators such as purpose and self-actualization is a decidedly human resources approach to the process of motivation. Daniel Pink (2009) describes this type of intrinsic motivation as Motivation 3.0 in his book Drive, explaining that there are three elements of motivation: autonomy, mastery, and purpose. Boomhower taps into all three elements by being mindful not to exert too much control on his staff's activities, by encouraging them to develop their strengths and close the gaps on their weaknesses, and by recognizing his staff's dedication to their work in service of something bigger than themselves (Pink, 2009).

Furthermore, Bennis and Nanus (1985) and Block (1987) argue that "human resources theorists place less emphasis on power and more on empowerment" (as cited in Bolman \& Deal, 2017, p. 190). Boomhower noted that "the idea of a leader is often packaged with this idea of power, and I would say it is completely the opposite." Rather, one of 
65

Boomhower's core leadership beliefs is the importance of empowering his staff. Transparency and communication of clearly delineated responsibilities are two ways in which Boomhower empowers his staff. However, information alone is not enough to fully empower employees. "It also involves encouraging autonomy and participation...and infusing work with meaning" (Bolman \& Deal, p. 144). As described above, Boomhower encourages these characteristics in his staff, dually motivating and empowering them. Boomhower clearly subscribes to the human resources interpretation that growth and selfactualization are key motivators (Bolman \& Deal, 2017).

\section{Organizational Change}

While direct observation and experience has largely shaped Boomhower's perspectives on leadership, he noted that the reports published by the Council on Library and Information Resources (CLIR) have also proven to be useful and influential. When analyzing Boomhower's interpretations of the process of organizational change, this influence appeared to be relevant.

When asked about his thoughts on organizational change, Boomhower noted, "If we are accomplishing our goals, if we are doing what we are supposed to be doing, there isn't a need for change." That said, he underscored that if an organization or staff continues to do what they have always done, that opportunities for improvement can be missed. Boomhower places himself within the "embrace change camp" explaining his perspective that "change for the sake of change is probably a good thing. But it's best achieved if 
you have a clearly defined mission and set of values and a long-range strategic plan.”

Parallels can be drawn between these perspectives and those shared by Chris Ferguson in a CLIR report titled Reflecting on Leadership. According to Ferguson (2003), in an era of persistent change, he finds success following the leadership model of servant leadership, attributed to Robert Greenleaf. Greenleaf (1970) describes a servant leader as one focused on service to others, who empowers people and who fosters their autonomy and self-actualization. Ferguson notes that "when agile response to sudden change is at a premium, servant leadership cultivates within organizations an increased capacity for efficient teamwork that uses mission as impelling force, values as cohering force, and vision as directing force" (p. 18).

Themes of servant leadership are found in Boomhower's beliefs on empowering and engaging his staff, listening to their ideas and collaborating with them on planning and goal-setting, and encouraging their professional development. This focus on and belief in people is a decidedly human resources view on leadership (Bolman \& Deal, 2017). Furthermore, Boomhower's approach to organizational change encompasses Ferguson's use of servant leadership as they both identify mission, values, and plans as tools for guiding successful change. The focus on communicating a vision during a time of uncertainty represents a symbolic view of organizational change (Bolman \& Deal, 2017).

Boomhower noted that in the absence of these guiding tools, an organization can also weather change by other 
means. Boomhower suggests that the resiliency of Dumbarton Oaks in the face of change is due to the deep dedication of the staff to the work that they do and to how much they embrace the founders' notions of the institution. Here again, Boomhower draws upon the idea of vocational awe and frames change through the human resources perspective. Additionally, Boomhower takes a symbolic approach to weathering change by leaning on the ideals of the organization's founders. He recognizes the power of these historic characters to influence the actions and behaviors of his staff and to lead them through the uncertainty of change (Bolman \& Deal, 2017).

\section{Conclusion}

Daniel Boomhower maintains a holistic view of his organization through his consideration of multiple perspectives while executing and continuously refining his leadership beliefs of transparency, collaboration, and empowerment. In analyzing the characteristics that define leadership for Boomhower across the organizational processes in which they exist, connections can be made between his multi-perspective approach and Bolman and Deal's leadership theory of organizational frames. Analysis revealed an interplay between Bolman and Deal's structural, political, symbolic, and human resources frames in Boomhower's interpretation of the organizational processes of strategic planning, goal-setting, communication, motivation, and organizational change. Despite its organizational and social science influences, leadership is more of an art form than a hard science, though, and Boomhower's personal leadership style is a culmination of a 
"lifetime of skill, knowledge, intuition, and wisdom" rather than a direct reflection of any one theory (Bolman \& Deal, 2017, p. 418).

\section{Author bio}

After twenty years as a Business Systems Analyst in government IT consulting, Danielle Fitch is pursuing her MLIS at the University of Maryland with the goal of widening her view of how information and information solutions can be used to make the world a better place. She has a professional interest in academic libraries with a focus on botany and horticulture.

\section{References}

Bolman, L. G., \& Deal, T. E. (2017). Reframing organizations: Artistry, choice, and leadership. ( $6^{\text {th }}$ edition). Jossey-Bass.

Dumbarton Oaks. (n.d.). Home of the humanities. https://www.doaks.org/about

Ettarh, F. (2018, January 10). Vocational awe and librarianship: The lies we tell ourselves. In the Library with the Lead Pipe. http://www.inthelibrarywiththeleadpipe.org/2018/vocationalawe/

Evans, G. E., \& Greenwell, S. (200o). Management basics for information professionals. ( $4^{\text {th }}$ edition). American Library Association.

Ferguson, C. (2003). Reflecting on leadership. Council on Library \& Information Resources.

https://www.clir.org/pubs/reports/pubi23/

Greenleaf, R. K. (2002). Servant leadership: A journey into the nature of legitimate power and greatness. ( $25^{\text {th }}$ edition). L. C. Spears, Ed. Paulist Press.

Pink, D. H. (2009). Drive: The surprising truth about what motivates us. Riverhead Books. 


\section{Executive}

\section{Perspectives in}

Academic Libraries

SECTION II 


\section{Information}

Organization

Perspectives

\section{A LOOK INTO ACADEMIC LIBRARY \\ LEADERSHIP THROUGH THE LIFE OF A \\ LIBRARY DEAN}

Aaron Wilson

The Academic Library serves as the focal point of research and knowledge in higher education. It serves as a meeting place for collaborative learning in groups, a support center for research, and a space for engagement with the campus community and the surrounding communities. When it comes to the overall vision of the library, the Dean of Libraries facilitates discussion and executes actions necessary to fulfill the organization's mission. From this leadership position, the individual must navigate various scenarios that can often have long-lasting effects on the information organization.

To better understand a dean's prospective in an information organization, I interviewed Jon E. Cawthorne, PhD, MLS. Our discussion centered around his previous leadership roles, viewpoints and leadership experiences. 


\section{Leader Profile - Jon E. Cawthorne}

Dr. Cawthorne serves as the Dean of Libraries and the Dean of the School of Information Science at Wayne State University in Detroit, Michigan, a dual role he has serviced in since 2017. This dual-role is unique and rare within higher education. Only a handful of institutions in the United States have an individual serving in both roles simultaneously. According to Cawthorne, dual-role has been in place at Wayne State for over 50 years, remarking, "We had a visionary Dean that kind of said that these two things should be together. We should have practitioners learn from student and students learn from practitioners." Wayne State is also a part of the Association of Research Libraries, which is an association of over 124 archives and libraries across the United States and Canada that are "a forum for the exchange of ideas and a catalyst for collection action to create, share, and sustain our global knowledge" (Association of Research Libraries, 2020).

Prior to joining Wayne State, Dr. Cawthorne served as Dean of West Virginia University Libraries in Morgantown, West Virginia and Associate Dean of Public Service and Assessment at Florida State University in Tallahassee, Florida. In June of 2019, Dr. Cawthorne was elected as VicePresident/President-elect of the Association of College and Research Libraries (ACRL), the largest division of the American Library Association (ALA). He currently serves as the President of the ACRL.

Cawthorne's leadership career started in Detroit, where he served as Director of the flagship branch of Detroit Public Library System and as Interim Deputy Director of the 
Library System. He has also served in leadership positions at Boston College and San Diego State University. He holds a $\mathrm{PhD}$. in Managerial Leadership in the Information

Professions from Simmons College and a Master of Library Science degree from the University of Maryland, School of Information Science (Wayne State University Libraries, 2020).

\section{PROMOTING ORGANIZATION DIVERSITY}

One of the prevailing issues within many university libraries centers around diversity. According to the Association of Research Libraries Annual Survey, Caucasians make up 83.8\% of professional staff in ARL Libraries, followed by Asian or Pacific Islander at $6.9 \%$, Black at 5.4\%, Hispanic at 3.6\%, and American Indian and Native Alaskan at $0.4 \%$ (Association of Research Libraries, 2019). Due to this lack of minority representation with the professional staff of these information organizations, there has been a concerted effort to improve opportunities for minorities.

This theme on diversity is discussed in Lee Bolman and Terrence Deal's book Reframing Organizations: Artistry, Choice, and Leadership, a resource highly recommended by Dr. Cawthorne. In the book they highlight promoting diversity as one of the Human Resource principles for managers, stating, "develop[ing] a variety of internal diversity initiatives, such a mentoring program to help people learn the ropes and get ahead" (Bolman \& Deal, 2017). Following his graduation from the UMD School of Information Science, Cawthorne took part in a two-year residency program at Ohio State University, which was geared toward minorities gaining experience within a large 
research library. He credited the program for introducing him to research libraries.

While in the program, Cawthorne, a newly graduated African-American librarian, noticed that their where not many people of color in libraries and only five Library Deans. He reached out to individuals like Emily Mobley, former Dean of Libraries at Perdue University, and Robert Wedgeworth, who previously served as Dean of the School of Library Services at Columbia University and Executive Director of the American Library Association. The discussion and advice gained from these leaders peaked his interest as to how someone becomes a Library Dean.

This experience at Ohio State would be a catalyst to a program he initiated while Dean of Libraries at West Virginia University. After being approached by university leadership with the goal of diversifying their libraries and the willingness to financially support this goal, Dr. Cawthorne decided to revive the program concept that he experienced at Ohio State. In addition to this concept, he wanted to expand this program to multiple institutions. He noted that the program was intended to "creating a pipeline for people to come into the profession."

In 2015, Cawthorne helped West Virginia University establish this diversity initiative, along with American University, the University of Iowa, and Virginia Polytechnic Institute and State University. The first program began with eight positions with over 350 applicants. From this initiative, in 2016, the Association of College and Research Libraries assumed responsibility of the initiative, now called the Diversity Alliance (Association of College \& Research 
Libraries, 2020), with over 55 institutions participating in the initiative. Dr. Cawthorne sees the initiative as "a longterm strategy to diversify every college research library in twenty-five years."

\section{LEADERSHIP INSPIRATIONS}

While conducting my initial research on Dr. Cawthorne, I came across a book which he collaborated with several library leaders entitled, Crucible Moments: Inspiring Library Leadership. In the book, editor Stephen J. Bell (2016) highlights two leaders that Jon admires, along with quotes from each: Maya Angelou who states, "People will forget what you said, people will forget what you did, but people will never forget how you fell” and Mahatma Gandhi, who noted, "Leaders don't create followers. They create more leaders." After reading this, I was curious to find out how Gandhi and Angelou's philosophies inspire his leadership approach.

"Leadership is creating something bigger than yourself and thinking about others," according to Cawthorne. Pertaining to Gandhi, he views working as a leader not just top down, paternalistic decision making, but one who thinks about the whole of the organization and placing it the context of the institution. Additionally, Cawthorne noted that "it requires you to think about the people that come through the library and influence them to become the leaders they're going to be." He went on to stress that it requires "one to do a significant amount of personal reflection, thought, and growth to articulate what it meant when you think you are creating a leader." In contrast, this would differ from striving for higher titles and positions, using for example 
the leadership of President Donald Trump, "someone who's in a leadership position, but has no idea what leadership is."

The Angelou viewpoint reminded Cawthorne of "every interaction he has had with people and how do those words make people feel to do something that inspires to be a part of something that he is doing." He recalled his arrival to Wayne State and the question asked by his staff, "What is your vision for the library?" Cawthorne said he wanted to be "The Best Research Librarian in the World," achieving this through four goals: Student Success and Retention, Scholarship, Community Engagements, and Organizational Development. In thinking about how his ideas he communicated to his staff, Cawthorne asked, "How does it resonate with people?" in hopes that others would see the vision that he was proposing. Both leadership viewpoints mirror aspects of the human resource frame from Bolman and Deal. This frame focuses on "what organizations and people do to and for one another" (Bolman \& Deal, 2017, p. 113). Examples of this include mangers finding ways to motivate, empower and invest in employees, building trust, encouraging employee participation, and facilitating open communication.

\section{Bolman and Deal: What is Your Frame?}

The Bolman and Deal book, Reframing Organizations: Artistry, Choice, and Leadership has been widely used as a coursebook in the study and discussion of organizational leadership. In the book, Bolman and Deal discuss the concepts that leaders operate between four frames: Structural, Human Resource, Political, and Symbolic. Dr, 
Cawthorne praised this book, saying, "If there's anybody who is really interested in leadership, that book is really great."

The structural frame focuses on the process of change. It may consist of strategy, planning, assigning tasks, and set goals. The human resource frame focuses on the individual with the organization. This frame places emphasis on giving members of the team power and support to do their job and their job. The political frame focuses on addressing conflict, whether between a group or person. In this frame, the organizations are seen as deal-makers, advocates, power players, networkers, and negotiators. Finally, the symbolic frame focuses on aligning the goals of the individual with that of the organization, in order to instill purpose in their work. A leader in this frame would be a visionary motivator that could convey their message through storytelling.

Cawthorne discussed his use of the book in when he gives a presentation at the Harvard Leadership Institute for Academic Librarians. The Institute, part of the Harvard Graduate School of Education, "helps college-level librarians and administrators deepen their management skills and prepare to become more effective leaders in a time of institutional change" (Harvard Graduate School of Education, 2020).

According to Dr. Cawthorne, the Institute is set up in case studies being given to 105 participants. They are given a series of case studies for their review and they spend between three to four days looking at how this leader works within the four frames. Then the Institute will have Dr. 
Cawthorne come in and talk about the book to the participants:

The first thing I tell them is not only have I read that book and not only do I know the case studies that they're studying, but I am the type of leader that works in all four frames, all the time. When I look at any issue, I can tell you what the issue is related to human resources, I can tell you what it is politically, symbolically, and structurally, and then figure out how we can navigate those things to get where we need to go.

He goes on to tell participants stories about himself, times he has failed, things they need to think about as they become leaders and know the benchmarks to whether you are a leader or not. Cawthorne noted, "we get into some difficult topics, but I think they appreciate the presentation." Traditionally, Dr. Cawthorne stays the entire day at the Institute and attends their Lobster Boil, allowing him time to follow up with the participants:

What I do is go around to each person, a hundred people, and talk to each one of them and I make a point to do this to demonstrate the kind of leadership that is really important that they should think about.

\section{Silos: Comfortable, but Limiting}

In mid-2019, Dr. Cawthorne was interviewed by Dr. Keith Whitfield, formerly the Provost and Senior Vice-President of Academic Affairs at Wayne State University, now 
President of the University of Nevada, Las Vegas, as his YouTube series, Cruising with the Provost. In the interview, Dr. Whitfield expresses appreciation for the collaborative work Dr. Cawthorne has done with other colleges, stating, "I think sometimes we've become siloed and we feel like that are colleges are kind of a tab on their own on their bottom and we're not; we're a university" (Wayne State University, 2019). Silos can often seem like an insurmountable obstacle for organizations, particularly with feelings on uncertainty and resistance from within, often becoming "barriers to organizational performance” (Evans \& Greenwell, 2020, p. 213). The question becomes, how do you address these uncertainties and resistance to breaking down silos within the information organization?

Dr. Cawthorne noted this was a two-part question. The first is a leadership question at the top of the organization and how this is done with colleagues with the university and how it is discussed with two people within the libraries. "We have these narrow areas of focus, Colleges of Education or Colleges of Engineering, and the Libraries on the campus, everywhere are truly interdisciplinary" according to Cawthorne. He went on the recommend that libraries should have a role in connecting disciplines, saying, "When you think about have all of human knowledge in our libraries and we don't ever stop to say, 'What are the connections between engineering or education?' and 'Why couldn't the library be the place that really begins to make that happen?" This could be aided by what is in the library's collections, panel discussions, and new scholarship research on the subject. 
He also highlighted how he acquaints colleagues to changes in the traditional libraries and resources available, noting:

I talk about it with my colleagues who have a traditional way of thinking about the libraries. So, in that respect, I can say some things there. But in the library, I really need to know my stuff. I need to be able to say, 'I know exactly what you're doing in cataloging, IT, reference, and as a faculty member.' And then be able to speak to them about what are the opportunities to do work in the future.

Cawthorne concluded with his hope for libraries taking on a more entrepreneurial role. For Academic Libraries, they have traditionally received money from the institution, only to use a majority of funding to pay for staff and scholarship. He used the example of the library offering a class on changing careers, open to everyone in the world for a small charge.

That would bring a kind of funding that would lead the best research libraries in the world. That the kind of work that would inspire at Yale, Harvard, or UCLA to wonder, "What is going on at Wayne State? How is it bringing in money?"

\section{Word of Wisdom for the Librarian to BE}

This talk with Dr. Cawthorne has truly been inspiring for me as a Master of Library and Information Science student at the University of Maryland iSchool. It has become very clear to me that the experiences through the numerous leadership positions he previously held influenced him 
personally and his style of management. I wondered what advice he would give to an up-and-coming library school student, like myself, regarding leadership.

His first recommendation to me was to really get to know who I am. Dr. Cawthorne cautioned:

These jobs are very, very difficult and they test you in many different ways. If you don't know who you are, then you can kind of go with the wind, wherever you want. However, you do not actually help your organization go in a direction that is positive and end a place where it needs to go.

He also reminded me not to be caught up in where I am going professionally, stating, "Don't get too anxious about what the career will be or how things will all happen. All that is going to work out."

Another concept that Dr. Cawthorne gave was in regards to thinking like a leader, noting:

The more time you spend with yourself and the more time you spend thinking about 'what would I do in that situation,' you begin to train yourself to think like that. That is helpful to train yourself for being in the position you're going to be in.

For example, Dr. Cawthorne wanted me to observe the work of my Dean of Libraries at the University of Maryland, Adrienne Lim, PhD, MLS. Look at the decisions, communications, and issues that have arisen. Then he told me to ask myself a question, "Would I do that same thing?" 
81

or "How would I do it just like that, but what would I do in addition to that?"

Dr. Cawthorne also advocated for being willing to participate in professional development. He recommended that I:

[T] ake leadership training. Go find any leadership training you can find, any books. They will help you contemplate how you might be as a leader. You are also able to network and get to know people. Those people will become super important as you move up because the irony is as you move up, you can't actually talk to people. You have to be accessible, be able to talk and be human.

Finally, he praised the work of this profession and why he loves the work he does, saying:

You're in a profession that is just.... I can't imagine doing anything else. I can't imagine working on top a foundation of reading, knowledge, information and facts. Those things are true and they'll be true for all the time on this earth. That is what our industry is built on.

He noted that we are in a time where facts and truths are being questioned and considered not as important.

Cawthorne says that, "We are in a season, and when we come out of this season-facts, truth, and knowledgethey're going to be just as important as they were when the season started." 


\section{Conclusion}

I have always felt anxious about my future within this profession, sometimes pessimistic about what the future may hold for my opportunities. Dr. Cawthorne's experiences and understanding of what leadership is within an information organization had shown me that true leadership starts with me. A successful leader of an information organization knows themselves, is connected with their staff and their work, and is an advocate for the organization.

Library Deans continue to navigate what can be turbulent waters. But with a mindset focused on keeping the work of information organization relevant and inspiring innovation and outreach amongst staff, the Academic Library will continue to be that focal point for knowledge and truth in higher education for the years to come.

\section{Author bio}

Aaron Wilson is the Database Editor/Copy Cataloger with the University of Maryland Libraries and is also in the first year of his MLIS program in the University of Maryland School of Information Science (UMD iSchool). He enjoys music, cooking, canning, and politics. 


\section{References}

Association of College \& Research Libraries. (2020, December 2). ACRL Diversity Alliance. Association of College \& Research Libraries (ACRL). http://www.ala.org/acrl/issues/diversityalliance

Association of Research Libraries. (2020, October 15). Who we are. https://www.arl.org/who-we-are/

Bell, S. J. (2016). Crucible moments: Inspiring library leadership. Mission Bell Media.

Bolman, L. G., \& Deal, T. E. (2017). Reframing organizations: Artistry, choice, and leadership. ( $6^{\text {th }}$ edition). Jossey-Bass.

Evans, G. E., \& Greenwell, S. (200o). Management basics for information professionals. ( $4^{\text {th }}$ edition). American Library Association.

Harvard Graduate School of Education. (2020, December 11). Leadership institute for academic librarians.

https://www.gse.harvard.edu/ppe/program/leadershipinstitute-academic-librarians

Morris, S., \& Roebuck, G. (2019). ARL statistics 2017-2018. Association of Research Libraries. https://publications-arl-org.proxyum.researchport.umd.edu/ARL-Statistics-2017-2018/

Wayne State University. (2019, September 19). Cruising with the provost:

Dean Cawthorne - Wayne State University [Video]. YouTube.

https://www.youtube.com/watch?v=Lht7griuszQ\&t

Wayne State University Libraries. (2020, November 15). Jon E. Cawthorne. https://library.wayne.edu/info/staff-directory/gmo6o6 


\section{"Living Well" \\ THE TRANSITIVE LEADERSHIP OF COURTNEY YOUNG \\ Maureen Jones}

Courtney Young's path through librarianship has been defined by transition in more ways than one. Transition, in the classic sense, has been regular. Permanence of position has not emerged as a facet of her career path, and she has been employed with a number of institutions, in a number of different capacities. While she transitions from position to position, she transitions the staff and organization with her-the status quo is to be challenged, not accepted. Her career has, by choice, been marked by changes: she facilitates diversification initiatives, encourages her staff to speak up where they are used to silence, and sets her own agendas. Perhaps most importantly, Young defies the limiting and stereotypical notions of what a library practitioner 'should' be and how a library practitioner 'should' behave.

This piece will discuss the various facets of Young's leadership style: what drives her, the shape her leadership takes, and her motivations. Organizational impact will also be noted, with respect to the changes that she makes in her workplaces, as well as the things that she deliberately refrains from altering. These aspects will be viewed through principles established by scholars in the leadership field, particularly through the four frames presented in Reframing Organizations: Artistry, Choice, and Leadership by Lee G. 
85

Bolman and Terrence E. Deal, as well as through concepts discussed in Drive by Daniel H. Pink.

\section{Background}

Young began her journey in the library sciences at a young age as a worker at her local public library. From those humble beginnings, she eventually climbed to the very top of the industry, serving as president of the American Library Association (ALA) from 2014-2015. This was a critical strategic planning year for the organization. Prior to serving as president elect, Young was involved with ALA operations dating back to 2003. These involvements included membership in the Executive Board, the Planning and Budget Assembly, and the Task Force on Electronic Member Participation, as well as filling positions such as the president of the New Members Round Table and Diversity Committee chairperson (President's Page [Archived], 2015).

In addition to her involvement with the ALA, Young has held a number of academic positions throughout her career. Her formal positions began in 1997 as a Diversity Intern Librarian at Ohio State University. Following her position there, Young became an Assistant Instruction Librarian at Michigan State University. After that appointment, Young began her 15-year employment with Penn State University. Her experience there included social sciences and reference and librarian positions at the University Park and Beaver Campuses, respectively, before being promoted to head librarian of the Greater Allegheny Campus. Throughout her time at Penn State, she was also an Associate Professor of Woman's Studies (Experience [Archived], 2015). Young's 
current position is University Librarian at Colgate University, and has been since July 2018 (Walden, 2018).

\section{“THE KEYS TO THE BUILDING”}

When discussing her workplace experiences, Young is quick to emphasize the importance of personal relationships in her successes. The relationships in question go beyond her superiors and the members of her department, reaching to different administrative offices, peers in other institutions and, ever importantly, the staff of her workplace. She goes out of her way to befriend the "people with the keys to the building," acknowledging their role in institutional function when they might otherwise have been overlooked. This particular trait was something that Young's mother, a college professor, instilled in her from an early age.

In addition to placing great value on interpersonal relationships when faced with managing a team, Young is drawn to others who share this value. According to her, the ideal leader both hears and listens- two concepts that are very distinct within her mind. She wants to know what the people around her think, and she readily inquires about their positions. In this vein, she emphasizes the importance of speaking to employees rather than at them. Even when delegating and instructing, she approaches from a place of camaraderie rather than as an authoritarian, which supports positive team dynamics and trust. Young's approach not only demonstrates care and appreciation for one's team, but allows her to gain a perspective she may not have previously considered. 
It is of the utmost importance to approach team members with respect and good intentions, and to carry those good intentions with oneself when faced with a situation where mediation is required. In both challenging situations and generally positive ones, language is incredibly important to Young. Language can be the difference between diffusing a challenging situation and fanning the flames, and it is critical for leaders to use their interpersonal skills to dig to the root of the conflict and guide the team to a resolution.

At the core of this view is authenticity. Honesty and integrity are two traits that Young values in others, and she is careful to maintain them herself. She remains inquisitive and ready to learn from those around her, in situations both positive and grim, and approaches them as experiences for growth. Language ties these things together, allowing her to connect to her surroundings and mediate conflict.

Interpersonal connections are one of the key aspects of the human resources frame as described in Reframing Organizations: Artistry, Choice, and Leadership. Organizations and managers that operate under this frame view employees as their most valuable asset, and acknowledge that the key to success is meeting the needs of their workers - they are more than just tools, they are people who must be nurtured and supported in order to do their best work. Libraries, particularly academic libraries, are often bound by a considerable amount of structure that may limit the effectiveness of employee input in favor of predictability. In that regard, Young combats the norm by treating peers and subordinates alike as individuals with something unique to contribute to the organization. This encourages growth, change, and new ideas, and prevents 
workers from becoming indifferent and disillusioned with their employment (Bolman \& Deal, 2017, p. 126).

In addition to improving morale and making employees feel listened to and respected, this leadership style can help boost productivity. Supporting employees, rather than stifling them, is shown to be beneficial to creativity and output. At academic institutions and large organizations like the ones Young has been affiliated with, there are structures in place that prevent total anarchy and ensure that accountability measures are in place. For that reason, there is no need to over-monitor employees-it is, in fact, counterproductive and likely to limit innovation (Pink, 2009, p. 35). The support of an understanding and flexible leader, paired with driving organizational goals, sets employees up for success (Pink, p. 43). Young's understanding of this is a critical component of her managerial style.

\section{Navigating Transition}

An unsuccessful transition can leave an organization "chaotic and fraught with uncertainty," hardly conditions that facilitate growth or institutional effectiveness (Dewey, 2012, p. 134). There are, of course, significant structural and procedural facets to leadership change that must be considered. After reflecting on the brief term limit and the fact that she would hold the position in a planning year, Young opted to refrain from starting a traditional president's initiative. ALA presidents will often create initiatives to tackle obstacles in the field or support particular trends, but Young thought that beginning 
anything new would subject the organization to "initiative fatigue" and take time and energy away from strategic planning efforts.

Rather than a sudden, abrupt upheaval of everything the ALA had been working towards, Young practiced restraint for the sake of a smooth transition. Focusing on the organization's needs rather than personal goals, Young used her time there to amplify the voices of others. ALA staff appreciated this approach, as it allowed them to tie up loose ends from previous presidential initiatives, such as her predecessor's "Declaration for the Right to Libraries" focus and left them prepared to begin new projects after her term. Of course, some were disappointed that she did not have her own initiative. But her decision ensured that her own transition into leadership went smoothly, in addition to setting up her successor for a smooth transition.

Additionally, her concern about "initiative fatigue" links back to her human resources-centered approach. Rather than overload her staff with duties on top of what they already had to be concerned with, a surefire way to breed resentment, she opted to support them in their existing engagements. Her actions support the global trend towards a "well-trained, loyal workforce" that has better output due to being treated with dignity and respect (Bolman \& Deal, 2017, p. 129).

Young's familiarity with the ALA was an advantage to her smooth transition-she already had connections to members and her staff, and knew of its daily functions. While this was greatly beneficial to her, she still had to establish credibility within the position in order to gain 
respect and solidify her social power (Dewey, 2012, p. 138).

Not all were immediately supportive of her: her opponent in the election had been a member of the association for 40 years, and the president before her had to run twice before being elected. Many members of the organization were library deans and other high-ranking members of their institutions, while she was still in a mid-level management position and was still an active library practitioner. There were some who underestimated Young due to her age, and as only the $5^{\text {th }}$ African American to hold the position, she had high expectations placed upon her.

Through hard work, Young was able to build her credibility within the organization. She was an active participant in shaping the organization without changing everything from the bottom up, and used her honesty and accessibility to make connections to her naysayers (Dewey, 2012, p. 139). Her perceived "inexperience" meant that she was in-touch with the needs of libraries and was still active in day-to-day library operations. She used her work on the Executive Board to her advantage, and her work on the Budget Analysis and Review Committee helped her make practical decisions about the budgeting portion of the strategic planning process.

\section{Changing Times}

Transitioning oneself out of one role and into another is a challenging ordeal, and it is no less easy to attempt to transition an organization into its future. Predating her positions with the ALA and Colgate University, Young was head librarian at Penn State's Greater Allegheny campus. 
Much of her work there involved auditing their collections and integrating more diverse viewpoints — this initiative existed before her time at the university, but it was something that she pushed forward. Though her efforts did not meet any overt criticism, there were skeptics. Many of her peers simply did not view the lack of diversity as an issue worth their time, specifically regarding the predominance of white male voices in the math and science collections. There was a reason that the project had not developed at the desired rate, and it was because the university needed Young's guiding hand.

There was much education to be done, and Young was the perfect candidate to fill that role. She developed a vision for the collection and was dedicated to making that vision a reality, even if that involved dismissing some outside recommendations that did not fit into the picture. She educated her staff on how to do the necessary work, again putting her skills of communication to work in order to align her team behind a shared goal and give them the support they needed to succeed. She acquired outside support in order to effectively stress their meager collection budget.

Still, there were always naysayers. Some felt that a diverse pool of experiences is not necessary in an academic library so long as it presents factual and accurate scholarly evidence. Others found Young's approach to be too active, and that the collections would naturally, and slowly, diversify over time. But Young is anything but passive in her professional life-a trait that she has sometimes faced criticism for. This is, of course, indicative of the prevalence of the "Angry Black Woman" stereotype in the modern era. 
Any pushback against the status quo labels Black women as aggressive and confrontational when they are anything but. Young has had to navigate situations such as those throughout her life, and has learned to advocate effectively for herself in the midst of conflict. She understands that people's perceptions of her "aren't really about her," but are indicative of sweeping cultural biases. Her approach has been described as "breakthrough leadership" for this reasonshe pushes forward and makes opportunities for herself, despite the obstacles that seek to limit her.

Ultimately, her efforts resulted in success. Supporting diversity initiatives has become an important part of her career and is something she has paid close attention to in subsequent positions. She attributes much of her success in this vein to her approach: rather than accuse the organization of failure or neglect, she shines a light on the good work that had been done thus far. It is easy to begin with criticism and negativity, but Young instead focuses on the potential of the collection. The goal is to move forward together rather than deepening divisions and breeding resentment.

\section{Moving Parts}

Young's career has not slowed since the end of her term as ALA president. She is still involved with the organization and is currently responsible for running the past presidents' luncheons at ALA meetings, though she has moved on to a full time position as University Librarian at Colgate University. 
Young's role at Colgate puts her in a decision-making role, in which she is responsible for things such as resource and budget allocation. Bolman and Deal's political frame is particularly applicable to this experience-while it is easy to assume that politically oriented institutions are full of nefarious plots and sinister machinations, that is far from the case. It has more to do with alliances, advocation, and bargaining to ensure that one's interests are represented (Bolman \& Deal, 2013, p. 184). That being said, Young's more human resources centered approach is still present in her decision-making process. She teaches her staff how to advocate for their needs so that they stand a fair chance at acquiring their fair share of sparse resources, encouraging them to collaborate with other groups to help strengthen their cause, and her willingness to build relationships strengthens her reach.

With respect to high-level decision making, it is critical to Young that she keep the greater picture in mind. One assumption of the political frame is that all actors within an organization are fighting for a limited number of resources, and as Head Librarian, Young is often the one to decide who is awarded those resources. Sometimes, cuts have to be made, and goodwill cannot propel an organization forward. She emphasizes the importance of flexibility in these circumstances; balance has to be found between enabling one's staff to be successful and enabling an organization as a whole to be successful. Being fair and practical in her decision-making, rather than being swayed by short-term gains and bias, helps facilitate trust in the organization, as well as in her leadership abilities. 


\section{Conclusion}

Throughout her lengthy career in the library sciences, Courtney Young has held a variety of managerial positions, all with their own sets of demands and challenges. From Penn State to the American Library Association to Colgate University, her flexibility and ability to embrace change have been critical to her success. At the root of her leadership style is a desire to connect with people. She does not just hear concerns and ideas, but listens to them. She does not talk at her staff, but to and with them.

Young believes that the mark of an unsuccessful leader is disrespect of one's peers and subordinates. Leaders who breed toxicity rather than growth have no place in her sphere of influence, and she actively works to maintain qualities that are contrary to that vision of an unsuccessful leader. At the core of her leadership style is the desire to support others and help them grow-she aims to teach her subordinates how to advocate for themselves, because this was a skill she had to develop on her own, without guidance from others. This level of empathy is a component of Bolman and Deal's human resources frame, in which an organization or a group within an organization uses familial energy and mutual support in order to facilitate productivity and growth.

Empathetic though she may be, Young is no pushover. A risk-taker by nature, she is always willing to confront the status quo. This can be a scary and challenging stance to take, but she feels the need to be authentic and understands the importance of speaking up for her own benefit. As a Black woman, simply existing and taking up space can be an 
act of defiance, but also one that draws criticism. She doesn not view her intersectional identity as a young Black woman in a white-dominated field as an obstacle, so to speak, but she knows how people view her. Her parents prepared her for this from an early age. But, despite the difficulties she may face as she transforms her industry, she remembers some wise words that her mother spoke to her: "Living well is the best form of revenge."

\section{Author bio}

Maureen Jones is a first-semester student in the University of Maryland iSchool pursuing a Master of Library and Information Science degree with a focus on Archives and Digital Curation. Jones graduated magna cum laude with a Bachelor of Arts degree from the University of Pittsburgh in 2017, having dual-majored in Political Science and History and minored in Museum Studies. Jones' research interests include visual culture, social justice, restorative archival practices, and museum archives.

\section{References}

Bell, S. J. (2016). Crucible moments: Inspiring library leadership. Mission Bell Media.

Bolman, L. G., \& Deal, T. E. (2013). Reframing organizations: Artistry, choice, and leadership. ( $5^{\text {th }}$ edition). Jossey-Bass.

Brundy, C. (2018). Critical views of leadership and the academic library.

Library Leadership \& Management, 32(3), Article 3. https://lib.dr.iastate.edu/libcat_pubs/70 
Courtney Young: ALA president. (2015). Internet Archive Wayback Machine. Retrieved December 7, 2020 from https://web.archive.org/web/20150605040648/http://courtneyy oung.org/service/experience/

Dewey, B. I. (2012). In Transition: The special nature of leadership change. Journal of Library Administration, 52(1), pp. 133-144. https://doi.org/10.1080/01930826.2012.629965

Pink, D. H. (2009). Drive: The surprising truth about what motivates us. Riverhead Books.

President's Page. (2015). American Library Association. Retrieved December 7, 2020 from http://www.ala.org/aboutala/presidents-page

Walden, M. (2018, May 9). Courtney L. Young named university librarian. Colgate University. https://www.colgate.edu/news/stories/courtney-l-youngnamed-university-librarian 


\section{Effecting Change \\ A PROFILE ON SUCCESSFULLY PROMOTING CHANGE IN THE WORKPLACE}

Jason Riggin

Timothy Hackman is currently the Associate Director of Public Services at the Albin O. Kuhn Library \& Gallery. He previously served for four years as the Director of User Services and Resource Sharing for the University of Maryland Library System, where he organized a complete restructuring of the Resource Sharing and Access Services departments, both in terms of physical space and construction as well as the departmental structure of the library staff.

His paper on the reorganization effort, Leading Change in Action: Reorganizing an Academic Library Department Using Kotter's Eight Stage Change Model, outlines the process that the library undertook, as well as highlighting key statistics that demonstrated tangible improvements to library performance after the change.

This paper examines his perspectives on successfully effecting a widespread change through the lens of various texts that have been influential on his leadership philosophies, as well as an interview conducted with him directly. 


\section{Literature Review}

There are voluminous mountains of literature written on the topic of effective leadership, but for our purposes we are going to focus on a specific handful recommended by Hackman. These are writings that he explained have specifically informed his leadership style and philosophies.

The first text we will examine is the only one not specifically recommended by Hackman, although he has stated he is familiar with it. We are casting Hackman's management perspective against the backdrop laid out by Bolman and Deal in Reframing Organizations: Artistry, Choice and Leadership. In this, Bolman and Deal define organizations through a series of frames which are outlined as the Structural, Human Resources, Political, and Symbolic. Together they outline a series of points of views that see organizations as machines, human collectives, competitions, and ritual processes respectively.

Of the writings recommended by Hackman, one of the most prominent is First, Break all the Rules, by Buckingham and Coffman. This extensive work uses decades of quantitative and qualitative research conducted by the Gallup Workplace Polls to try and get to the core of what makes great managers so effective. While they make no claim to a magic solution, they do highlight several very common threads that seem to tie together effective managers. Primarily, Buckingham and Coffman (2016) discuss managers as relationship and team builders, who are the most effective when they galvanize the talent that already exists in their staff, and who deal with struggling employees by trying to find a better fit for them, rather than trying to 
fix them: "The manager role is to reach inside each employee and release his unique talents into performance."

Buckingham and Coffman expand on this role significantly throughout the text, explaining the ways in which managers can most effectively turn talent into performance. While this approach leans heavily on the Human Resources frame, it does not shy away from some harsh structural perspectives, either. Buckingham and Coffman recommend managers spend most of their time with their best employees, rather than trying to help improve those who may be struggling. They also emphasize the importance of finding the correct fit for an employee and their talents, even if that fit is not with your organization. However, even when being brutally honest, Buckingham and Coffman never lose sense of the employee as a human: they emphasize the fact that every individual is different, and that the things that motivate one person might not work on another.

The second major text we will examine is Radical Candor, by Kim Scott. The titular concept explored in this book is centered around how to manage professional relationships by virtue of being compassionately honest with your peers. It examines in detail how to discuss difficult topics such as performance and to serve as a guide to your team. Scott outlines the three dangerous categories that juxtapose Radical Candor: Obnoxious Aggression, Ruinous Empathy, and Manipulative Insincerity. Each of these relationship types is defined as being lacking either in compassion or honesty, or in the final case, both. Scott uses this framework to outline a better and more effective way of managing a team. Like Buckingham and Coffman, Scott advocates for 
the effective manager to tailor their management style to the individual needs of the employee, in this case using her framework as a guide.

Finally, we will use Hackman's own paper, Leading Change in Action: Reorganizing an Academic Library Department Using Kotter's Eight Stage Change Model. This work outlines the 2015 reorganization of the University of Maryland Library's Resource Sharing and Access Services departments, which will serve as a real-life case study where these management philosophies were deployed effectively and used to ensure success of a substantial structural overhaul of a library organization.

Both Hackman and the texts to which he refers lean heavily on the Human Resources frame as described by Bolman and Deal. The unifying emphasis for this perspective is the creation and maintenance of trusting and effective relationships, and using them as the groundwork for an effective team.

\section{Interview with Tim Hackman}

I sat down with Mr. Hackman to ask him some questions about his management style and some of the things that have influenced him as a leader. In particular, I wanted to know what aspects of his management style made his transition at University of Maryland Libraries so effective, as well as what weaknesses were present. The transcript of the interview can be found in the appendix. In this section, we will highlight and summarize key responses only. 
101

When asked about the Bolman and Deal organizational frames, Hackman responded that he has a strong preference for the Human Resources frame, which closely aligns with the two primary readings we discussed, both of which are centered around management as a human element. Additionally, the critical need of building trust and establishing good relationships with staff make reoccurring appearances. When asked about how he established motivation within his team for the project, trust was front and center:

"Some of it was trust that I had built up with the team and the sense of teamwork that I had worked to establish. I had done a focus on shared values and shared priorities. So I think I had built up a pretty good level of trust with the staff, so that they weren't suspicious of my motives when I started reorganizing..."

Later on in the interview, similar concern for fostering those relationships resurfaced, when asked about handling the COVID crisis Hackman had this to say:

“...I never want to be the person who keeps information from somebody that they need to do their job. So I tend to over share, which isn't the default [at my current institution]. It's been sort of a struggle to get folks to understand that you need to tell people what's going on..."

This theme of caring personally for your employees and ensuring they have everything to do their best work is a common thread throughout much of the texts which we have examined, but is especially relevant in the listed texts by Buckingham and Coffman, Scott, and Sinek. In fact, as 
we previously mentioned, Care Personally is a crucial measurement for effective feedback as described by Scott.

This focus on staff as human members of the team that is prevalent in both Hackman's answers as well as in Buckingham and Coffman, reinforces this point of view's heavy reliance on the human resources frame of management.

When asked about some of the more difficult aspects of the project, Hackman stated that:

"There were a lot of moving parts, and some went together really well, but others didn't, so I had to constantly adjust the planning and try to figure it out. You would try one thing and try to figure it out, and if you put two things together it would break some other thing."

From this response it seems clear that one of the difficulties that can arise from leaning heavily on the Human Resources frame is that some of the more structural task design can become difficult to organize and plan. While this can present difficulties, it is important to remember that one of the most important aspects of an organizational overhaul is the upkeep of morale (Bolman \& Deal, 2013) and so it makes sense that these issues would be of secondary importance. Therefore, instead of working to eliminate the inevitable confusion that comes with a reorganization effort, this management style instead seeks to minimize the impact that such confusion will have on morale by ensuring that employees remain both motivated and committed to the effort. 
103

\section{A Case Study: The 2015 UMD Reorganization}

Restructuring an organization is a highly-risk endeavor with many potential pitfalls along the way. Bolman and Deal (2013) describe restructuring as "a powerful but high-risk approach to improvement," citing studies which indicate $50 \%$ or more restructuring efforts ultimately fail (p. 72 ).

Clearly, choosing to undertake a reorganization is far from a guarantee of success. However, using the techniques outlined by Hackman (2017), the University of Maryland successfully redesigned its Resource Sharing and Access Services departments; combining them into one larger User Services and Resource Sharing department centered around a single service desk system. This redesign was both organizational as well as architectural, as the entire physical desk layout of the library was recreated to reflect the new departmental structure.

However, in spite of these challenges, Hackman and the University of Maryland team were able to achieve an extremely successful reorganization. After the reorganization efforts, the University of Maryland library system reported faster turnaround times for reserves and ILL requests by an average of twelve hours, as well as a decreased reliance on student employee hours (Hackman, 2017).

They were able to do this by following Kotter's Eight Stage Change Model as outlined below, (as cited in Hackman, 2017, p. 1): 
1. Establish a sense of urgency

2. Create the guiding coalition

3. Develop a vision and strategy

4. Communicate the change vision

5. Empower employees for broad-based action

6. Generate short-term wins

7. Consolidate gains and produce more change

8. Anchor new approaches in the culture.

Hackman highlights the deployment of these stages from the perspective of the human resources frame, using each stage along the way to generate and reinforce buy in from his staff. By putting staff in charge of tasks such as sorting various responsibilities into logical groupings, and choosing the new name of the department, Hackman successfully shifted the perspective of the reorganization as something that the staff did collectively, instead of something that was being done to them.

By creating this staff buy in and making the project feel like it was something they were all a part of, Hackman was utilizing the human resources frame to lay the groundwork for Kotter's crucial 8th step: anchor new approaches in the culture. The best executed organizational changes will fall by the wayside if you cannot successfully embed them into the culture of the organization. Eventually, people tend to fall back into old habits. As Hackman (2017) explains, "No matter how much work goes into the change, it will not last unless the organization's culture, including group behavior norms and shared values, also changes to match" (p. 12).

However, Hackman manages to avoid this risk by firmly anchoring the redesign into the culture of the organization. 


\section{Conclusions}

Both Hackman himself and the texts discussed lean heavily on the Human Resources frame as presented in Bolman and Deal. This style of management is best summarized by Buckingham and Coffman, when they describe the talented manager as a catalyst for the talent within the staff member. From this point of view, a manager's primary job is to focus on their staff as humans first, and to help push them to be as effective as possible.

Several strategies on how best to do this have been discussed: moving staff to positions that best suit their talents, focusing on bringing out strengths rather than mitigating weaknesses, and fostering trusting, helpful relationships have all been pointed to as key tenants of this style.

The strengths of this style were demonstrated by the reorganization efforts of Hackman in 2015. A large scale, generally risky plan was successfully executed in no small part to the human relationships and trust that went into it.

The challenges of the frame were made clear as well: the human resources frame was less adept at handling the structural tasks required by the redesign, and at some points caused confusion. However, these issues were secondary to the primary goal of ensuring that the staff was involved and invested in the overall redesign of their organization. By emphasizing staff motivation over structural clarity, this management style managed to avoid most of the major complications that might come from such confusion. Based on the success we have seen, it is apparent 
that this heavily human-resources focused approach was the right frame for such a project.

\section{Author bio}

Jason Riggin is a first year MLIS student at the University of Maryland, College Park, where he focuses on information access and data security. He is employed by the Albin O. Kuhn Library at University of Maryland, Baltimore County, where he works in Interlibrary Loan.

\section{References}

Bolman, L. G., \& Deal, T. E. (2013). Reframing organizations: Artistry, choice, and leadership. ( ${ }^{\text {th }}$ edition). Jossey-Bass.

Buckingham, M., \& Coffman, C. (2016). First, break all the rules: What the world's greatest managers do differently. Gallup Press.

Evans, G. E., \& Greenwell, S. (200o). Management basics for information professionals. ( ${ }^{\text {th }}$ edition). American Library Association.

Hackman, T. (2017). Leading change in action: Reorganizing an academic library department using Kotter's eight stage change model. Library Leadership \& Management, 31(2), pp. 1-27. https://doi.org/10.13016/M2XZ7B

Scott, K. M. (2017). Radical candor: Be a kickass boss without losing your humanity. St. Martin's Press. 


\section{Appendix: Interview Transcript}

\section{Are you familiar with Bolman \& Deal's Organizational Frames, and if so, which one(s) do you feel you lean towards?}

I'm human resources all the way, I can do organizational and symbolic pretty well, I'm not particularly good at political.

\section{Can you describe the strongest team you ever managed? What made them so effective?}

The access services team at McKeldin; they had a group of really strong unit heads who complemented each other. Some people were very Type A and on top of every detail, and others who were more intuitive, and wanted to set up some frameworks and then wing it. Having a mix of approaches worked very well, because they supported each other very well. Nobody expected anything in return, the environment was focused on teamwork as the most important thing.

\section{What was the best manager you have worked under? What made the experience positive?}

My first library job, which was at the iSchool's departmental library. The manager was a librarian named Karen Patterson. It was just the two of us working there. What made it productive was that she genuinely cared about me and my development as a new professional. Also, she was pretty good at letting me do stuff on my own. She would set up parameters but then allow me to be creative within those perimeters. While she was pretty hands-off, I could also go to her when I needed more guidance. 
Kotter's Model recommends that the first step in facilitating a large reorganization effort is to establish a sense of urgency. However, in your writing, you indicated that in the case of McKeldin Library, very little additional motivation needed to be provided. Can you speak a bit about why that was the case?

Some of it was trust that I had built up with the team, and the sense of teamwork that I had worked to establish. I had done a focus on shared values and shared priorities. So I think I had built up a pretty good level of trust with the staff, so that they weren't suspicious of my motives when I started reorganizing.

After I had been there for a few years and we had let things run, then we got to the point where the cracks in the structure were starting to show. So people were kind of at the point where they could see that it needed to happen.

How would you have handled the situation differently with a less willing and eager staff?

I probably would have asked for more help from my own supervisor; I would have asked him to help me establish a burning need to do this. I would have asked for help in pushing the demand from a higher level, and creating a more external need for getting it done.

I was also able to let the staff work fairly autonomous[ly] in work groups, but, if I had less willing staff, I probably would have had to lean on them a bit harder with more deadlines, more check-ins, etc. 
109

\section{What do you see as the biggest organization and leadership challenges for the parts of the library you are responsible for in the COVID crisis?}

Most of my frustrations have to do with the library leadership above me, rather than the rest of the organization. It tends to be very reactive, and not as automatically transparent as I would be. I never want to be the person who keeps information from somebody that they need to do their job. So I tend to over-share, which isn't the default here. It's been sort of a struggle to get folks to understand that you need to tell people what's going on.

Lack of communication is even more exacerbated by COVID since we are not seeing each other in person regularly, so you have to be more intentional about it. So I have to make sure that whatever updates I get are being passed on to everybody that needs that information.

I don't think we've had much problem getting people to do work, everybody has been generally very eager to see how they can help.

\section{What was the most difficult part of the Access Services overhaul you conducted? How did you overcome it?}

Honestly it was just a very complex project. There were a lot of moving parts, and some went together really well, but others didn't. So I had to constantly adjust the planning and try to figure it out. You would try one thing and try to figure it out, and if you put two things together it would break some other thing. 
There were also personnel considerations, we had people who had some limits in terms of their individual skills with technology, or attention to detail etc. You can't fix individual people, you need to figure out what role best matches up with their abilities, rather than try to get their abilities to match where you want them.

So we had more high stakes spots where we needed people, than we had people to fill those spots. A lot of the positions were reliant on one another, and needed to be filled with reliable people.

\section{So how did you manage those people?}

We ended up splitting some of those people into different positions, so that they weren't all concentrated in one place, and it also served to create layers so that we had backups for everything.

\section{Buckingham and Coffman place significant emphasis on hiring the right people for the right job. Can you speak a bit on how you identify personal strengths and match them to the right positions, specifically during the hiring phase?}

For me, that starts with a really solid job description. I think a lot of times in libraries you're working with job descriptions that have been around a while, and over time they become way out of balance with what you actually need, both in terms of duties and also in skills. Every time that I've searched, I make sure the job description is updated to actually match what we actually need. 
111

I also did a stint as the library's equity admin, so I was a liaison to every search that went on, and made sure that committees were evaluating all candidates equally, and make sure that candidates weren't given preferential treatment. Part of that is making sure that you have very clear criteria for selecting candidates, that are derived directly from the job description.

I also think that making sure your interview questions are well-written, and get at the requirements for the job, and they get you sufficient information to make a decision on.

It's also nice to have different perspectives to help with the search. Having people who think differently from you. There were many times when we had completely different reads on people and I turned out to be wrong, so it's good to have multiple perspectives in the room. 


\section{Leadership in \\ Federal Service \\ SECTION III}


113

\title{
Lessons in Practical
}

\section{Macromanaging}

DR. JEFFREY REZNICK'S PERSPECTIVES ON

LEADERSHIP AND PUBLIC SERVICE

\author{
Miranda Downey
}

"I've always tried...to respect people along the way, listen to them, and bring them along as part of the team."

These words from Dr. Jeffrey Reznick embody how his personal beliefs on leadership have guided the way in which he has conducted himself throughout his twenty-year professional career in increasingly responsible leadership positions. Through his remarkable consideration for his coworkers, those below him and above him alike, he has taken it upon himself to be the kind of leader that people want to follow.

This paper endeavors to bridge Dr. Reznick's perspectives on leadership with literature on the subject, specifically leadership within libraries and archives. The Four Frame Model which was developed by Lee Bolman and Terry Deal and expanded upon in Reframing Organizations: Artistry, Choice E Leadership, will be referenced and referred to throughout as the components are exemplified by Dr. Reznick's viewpoints. These have been condensed into three key themes, which are the following: the 'golden rule', 
effective team leading, and staying flexible and goal oriented.

\section{Background}

Dr. Jeffrey Reznick is the chief of the History of Medicine Division at the National Library of Medicine, one of the twenty-seven institutes and centers of the National Institutes of Health. He received his PhD in History from Emory University in 1999, and following this he has held positions of authority in various federal, non-profit, and academic organizations. In his own words, he "fell into leadership," beginning in a more professional capacity when he created and led a history of medicine roundtable group at Emory University that gained traction until it eventually "became more like a formal seminar." As a self-professed extrovert, he has always enjoyed working with others, and his philosophies on the topic of leadership exemplify that.

\section{Perspectives on Leadership}

Following our email correspondence and interview conversation, I have devised what I believe to be the main three elements of Dr. Reznick's leadership perspective, and consequently the way that he uses these perspectives and philosophies in his work life-the 'golden rule,' macromanaging, and staying flexible and goal-oriented. His utilization of these philosophies has contributed to his success in leadership. 
115

\section{THE GOLDEN RULE}

Treating others how you wish to be treated-this is the core of the 'golden rule', a principle that Dr. Reznick finds to be of utmost importance in his role as a leader. Whether a coworker is above, below, or across in the organization, he endeavors to adhere to this rule by utilizing an approach that incorporates "several interrelated principles: listen, respect, learn, support, collaborate, and communicate clearly" (J. Reznick, personal communication, October 14, 2020).

The support and sensitivity central to this practice epitomizes Bolman and Deal's (2013) Human Resources frame, defined in Reframing Organizations: Artistry, Choice $\mathcal{E}$ Leadership as being built upon the assumption that "organizations exist to serve human needs rather than the converse" and that the people that make up the organization are vital to the overall success (p. 117); other key principles of this frame include investing in and empowering employees through the provision of "information and support" and by "[encouraging] autonomy and participation" (p. 140). As well, this practice shows adherence to the Human Resources frame by focusing on the worker's needs as a way to facilitate success and satisfaction.

A third frame can also be observed through this concept: the Symbolic frame. Though difficult to clearly define, the Symbolic frame is focused on meaning and the creation of myths or symbols that are used to "communicate unconscious wishes and conflicts, mediate contradictions, and offer a narrative anchoring the present in the past"; to facilitate this, culture is formed that "bonds an organization, 
unites people, and helps an enterprise to accomplish desired deeds" (Bolman \& Deal, 2013, p. 249). Through creating a culture of civility and respect, there is a story to be told about how this approach to people and the work they do demonstrates why the Symbolic frame can apply.

As the driving concept behind the rest of his perspectives, the practice of the 'golden rule' creates a foundation that demonstrates acute emotional intelligence and sensitivity to social awareness. This concept of emotional intelligence, defined by Martin (2019) as "the ability to monitor one's own and others' feelings and emotions, to discriminate among them and to use this information to guide one's own thinking and actions" (p. 1), is fundamental in the establishment of a healthy working environment.

An additional feature of emotional intelligence is social awareness, defined as "understanding and relating to people and the surrounding environment" and is fundamentally characterized by empathy, an important quality for leaders to demonstrate (Martin, 2019, p. 6). This critical, empathetic understanding of the needs of others is embodied in Dr. Reznick's belief that "one of the single most important things you can say to someone as a manager is 'I hear you'” (personal communication, October 14, 2020). By recognizing the efforts of others and creating a supportive environment, lines open to developing "clear and consistent communication", another vital aspect of emotionally intelligent relationships (Martin, p. 8).

\section{EFFECTIVE TEAM LEADING}

Taking a macromanaging approach is essential to Dr. Reznick's personalized concept of being an effective team 
leader. Considering himself as part of a team, not just someone giving directions from above, he exemplifies aspects that are a combination of Bolman and Deal's Human Resources frame as well as the Structural frame. As detailed by Bolman and Deal (2013) and demonstrated by Dr. Reznick, leaders observing the Human Resources frame should be discernibly supportive and unpretentious, visible and accessible, and conduct themselves in a people-oriented manner that makes it clear that the "workers have a stake in the organization's success" (p. 361). A particular technique that he has found successful in developing and reinforcing effective teamwork is "supporting the time and talent of each and every member of the team" so that when that goal is completed, they feel as if their work has contributed to a greater purpose (J. Reznick, personal communication, October 14, 2020). This approach is similarly reflected by Disney (2016), adding that goals, and by extension the greater good, cannot be met when there is preoccupation with short-term quandaries and a lack of teamwork (para. 1).

The Structural frame, as its name may allude to, gives itself to a definition more clearly distinguished than the former ones. In its most refined essence, the Structural frame falls under the assumption that "organizations exist to achieve established goals and objectives", which creates a further dependency on adequate framework to "increase efficiency and enhance performance through specialization and appropriate division of labor" (Bolman \& Deal, 2013, p. 45). Given that the National Library of Medicine is a governmental organization, it gives itself to the inherent rationality and formality associated with the Structural frame. Additionally, the need for being goal-oriented and 
necessary attention to efficiency and coordination are elements indicated in both. Be that as it may, through Dr. Reznick's rather empathetic leadership principles, it is clear that concern for the people within said structure ties back to the Human Resources frame. Although he personally identifies most with the two previous frames, I also was able to identify a measure of the Political frame present within his workings, such as the recognition that "organizations are coalitions of different individuals and interest groups" that require networking and "bargaining and negotiation" when allocating scarce resources and vying against the interests of others to achieve success (Bolman \& Deal, p. 209).

In opposition to instructing people on how exactly they should perform their jobs, Dr. Reznick prefers to take a more realistic and mutually-supportive macromanaging approach. "If I have to micromanage people," he says,

I'm doing their job, and if I'm doing their job...then I'm not doing my job, which is to lead an organization in cooperation with my team, valuing the talent and contributions of each individual who is a part of my team.

At the foundation of macromanagement is the concept of autonomy and, from that, trust in the accountability and motivation of the employees to do their jobs. As noted by Pink (2009) in Drive: The Surprising Truth About What Motivates Us, providing staff with autonomy creates a significantly positive effect within the workplace. In a research study conducted on the topic, it was found that greater job satisfaction and higher job performance resulted from bosses that "saw issues from the employee's point of 
119

view, gave meaningful feedback and information, provided ample choice over what to do and how to do it, and encouraged employees to take on new projects" (Pink, p. 89). As if more evidence was needed of the effectiveness of macromanaging throughout time, William McKnight, the chairman and president of 3M in the 1930's and 1940's was quoted saying in 1948 that "if [the workers] are good people, [they] are going to want to do their jobs in their own way" (Pink, p. 93). In endeavoring to meet the "grand challenge" of historical medical libraries and archives, which is to maintain relevancy in a society increasingly dependent on digital media, the need for these leadership skills becomes compounded (Reznick, 2014, p. 112).

\section{STAYING FLEXIBLE AND GOAL-ORIENTED}

When dealing with changes in the organization itself (such as working remotely in response to COVID-19), or dealing with smaller everyday challenges, the need for leaders to be flexible is an ever-present matter. As pointed out by Evans and Greenwell (2000) in Management Basics for Information Professionals, "successful managers operate on the basis of the precept "adaptability is essential for survival"' (p. 32). For the survival of the institution as a whole, Dr. Reznick (2014) believes that "every opportunity" should be taken to "demonstrate the relevance and value of historical medical collections" (p. 114). On a larger, institutional level, there is a need for staying flexible among times of great structural changes, such as the National Library of Medicine taking on a stronger role in the field of data science and placing more emphasis on supporting the NIH's mission, which is to "seek fundamental knowledge about the nature and behavior of living systems and the application of that 
knowledge to enhance health, lengthen life, and reduce illness and disability" (National Institutes of Health [NIH], 2017). All the while, the History of Medicine Division and the skills of the people that contribute to said mission must continually work to demonstrate the impact of their value to the progression of the entire institution.

A more common instance in which adaptability is absolutely necessary and where the 'golden rule' becomes invaluable is in situations where silos are at play. Silos, as defined by Kowalski (2017), are "workplace constructs and mindsets that isolate departments from one another through bureaucracy or rigid hierarchies. They are characterized by a lack of communication, information sharing, and collaboration" (p. 1). These silos can and oftentimes are compounded by a stricter adherence to approaches aligned with the Structural frame, as is inherent in government organizations.

When asked how he would combat silos when encountering them, Dr. Reznick gave an answer similar to Kowalski's (2017) solution of "keeping the big picture in mind" (p. 13), namely that

[T] he way out of silos is to look at the mission of an organization...in public service one of the best things you can do to break down silos is to say, "Well, who do we work for? We work for the public." (J. Reznick, personal communication, October 14, 2020)

In a generalized example of how he used this solution, Dr. Reznick spoke about how a silo created as a result of structural disconnections and personality differences between two subsections of the NLM disrupted workflows 
and threatened the completion of a major project that, when completed, would greatly benefit the patrons served. Through the continued efforts of being respectful (i.e., keeping the 'golden rule' in mind) and considering the end goal of the situation (to serve the public), the project was eventually finished even though the silo that jeopardized it was never fully broken down.

This solution to silos in itself demonstrates many aspects of Bolman and Deal's frames. The recognition of the need to achieve goals and the ultimate goal of serving the public, the need for coordination and efficiency, and the triumph of rationality over personal agendas are key features of the Structural frame. Attributes of the Human Resources frame include the idea that the purpose of the organization is to serve people and, to do so, there is a requirement of investment in the staff's abilities and continual empowerment to complete the project. The use of personal charisma and negotiation skills that allowed differing ideas to be temporarily relinquished are qualities regarded with the Political frame. While not as strong a connection, some of the Symbolic frame can even be seen in this, as the careful navigation of the situation shows a rise above the silos of bureaucracy to appeal to the culture created in the name of public service with the end goal of supporting people it serves, and working across silos is dependent on the understanding of different intrinsic unit cultures.

When considering goals, there comes a need for prioritization to remain effective. The creation of an "agenda for change" is essential when vying for productivity. This is broken down into "a vision balancing the long-term interests of key parties, and a strategy for achieving the 
vision while recognizing competing internal and external forces" (Bolman \& Deal, 2013, p. 209). If prioritization is not heeded and flexibility not kept within reason, burnout becomes a serious risk. Within the realm of library and archives, staff are known to be particularly vulnerable to burnout, as examined in Geary and Hickey (2019).

Regarding managers and leaders specifically, Dr. Reznick recognizes the need for prioritization on a daily and weekly basis, adding that "if a manager tries to do everything equally well, every day, burnout will happen” (J. Reznick, personal communication, October 14, 2020).

The necessity of prioritizing has been amplified within the past year, as the NLM has undergone changes as part of measures established in response to the COVID-19 pandemic. As the situation progresses and develops, and uncertainty remains as to when normal operations will resume, Dr. Reznick has recognized the need for flexibility and is taking steps to reduce additional stressors while conducting extended telework; primarily by making use of triaging, and channeling and conserving energy by “deciding what's important, what matters" (J. Reznick, personal communication, October 14, 2020). The end goal of serving the public must be kept in mind, and staying flexible in order to meet that goal is indispensable.

\section{Conclusion}

The virtues detailed above that are held in regard by Dr. Reznick meld together to create a case for a successful leader. These skills and techniques he has put to use as a leader, while intrinsic to his own philosophies, are mirrored 
123

in literature on leadership. Each of Bolman and Deal's Four Frames are exemplified in their own ways through Dr. Reznick's perspectives.

The Human Resources frame is indicated strongly in the assumptions of the 'golden rule'-being respectful, showing appreciation, and support. This empathetic support of coworkers and subordinates is also an important aspect of macromanaging, through providing the room to be autonomous and trusting in their accountability to keep the organization successfully able to remain serving the needs of its patrons. This orientation toward the people and accessibility as a leader plays into being a team player, and not just a superior giving out directions.

The intrinsic nature of the Structural frame is similarly discernable in macromanaging, in that the breakdown of labor into specialized roles are in support of the goals and objectives of the NLM itself. Additionally, the concept of prioritizing and the prevalence of rationality over personal agendas are both particularly favored in this efficiencyfocused frame.

The Political frame, while not as explicitly conspicuous, is evident in the ability to negotiate through the quagmire of interconnected interests of the organization itself and the contributing individuals.

The Symbolic frame is demonstrated by the creation of a workplace culture rooted in civility and support, as well as the establishment of the idea that the work being done by the History of Medicine Division, and by extension the National Library of Medicine, is all for the greater good and in service of the public. This symbolism carries on into an 
exemplification of adaptability - in the face of changing organizational structure, changing needs of patrons, even down to the way the regular workday is conducted.

This intersection of perspectives across multiple frames not only makes evident the inevitable connectivity of the frames themselves, but also gives insight to how observance of their concepts, whether intentional or not, is advantageous in the furthering success of a leader. Having been in leadership positions for twenty years, Dr. Reznick's perspectives and approaches to leadership have clearly been valuable and rewarding. Such is a necessity when it comes to the survival of historical medical libraries and archives dependent "upon informed and proactive leadership at all levels that can effectively navigate the digital world and corresponding factors of culture, economy, society, and politics" (Reznick, 2014, p. 120).

\section{Author bio}

Miranda Downey is a student in the University of Maryland's Master of Library and Information Science program under the individualized specialty plan. She holds a Bachelor of Science cum laude in Art History from Towson University. She is interested in art history and the history of medicine, primarily public and women's health from the mid-19 ${ }^{\text {th }}$ century to mid-20 ${ }^{\text {th }}$ century. After completing her MLIS, she plans to begin a career in a museum-affiliated library or archive, or in special collections. 


\section{Thanks}

The author would like to thank Dr. Jeffrey Reznick for his time, consideration, and the advice he gave. Also, thanks to Mary Lopez and Zahra Osman for their review of this paper.

\section{References}

Bolman, L. G., \& Deal, T. E. (2013). Reframing organizations: Artistry, choice, and leadership. ( $5^{\text {th }}$ edition). Jossey-Bass.

Disney, D. M. (2016, March 16). Collaboration doesn't mean consorting with the enemy. Government Executive.

https://www.govexec.com/management/2016/03/collaborationdoesnt-mean-consorting-enemy/126715/

Evans, G. E., \& Greenwell, S. (2000). Management basics for information professionals. ( $4^{\text {th }}$ edition). American Library Association.

Geary, J., \& Hickey, B. (2019, October 16). When does burnout begin?: The relationship between graduate school employment and burnout amongst librarians. In the Library with the Lead Pipe. http://www.inthelibrarywiththeleadpipe.org/2019/when-doesburnout-begin/

Kowalski, M. (2017). Breaking down silo walls: Successful collaboration across library departments. Library Leadership \& Management, 31(2). https://doi.org/10.5860/llm.v31i2.7202

Martin, J. (2019). Emotional intelligence, emotional culture, and library leadership. Library Leadership \& Management, 33(2). https://journals.tdl.org/llm/index.php/llm/article/view/7329

National Institutes of Health. (2017, July 27). Mission and goals. https://www.nih.gov/about-nih/what-we-do/mission-goals

Pink, D. H. (2009). Drive: The surprising truth about what motivates us. Riverhead Books.

Reznick, J. S. (2014). Embracing the future as stewards of the past: Charting a course forward for historical medical libraries and archives. $R B M, 15(2)$, pp. 111-123.

https://doi.org/10.586o/rbm.15.2.424 


\section{Change Management in Government}

\section{Information}

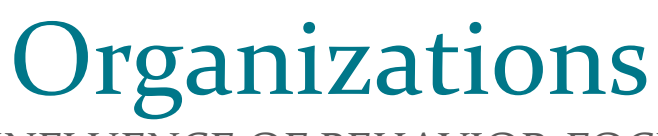

\section{THE INFLUENCE OF BEHAVIOR-FOCUSED}

\section{LEADERSHIP}

Bailey DeSimone

"I think [the Knowledge Services Group has] the most interaction with the larger Library [of Congress] because of the nature of our work. A lot of things cross over in terms of preservation, binding, or working together to purchase materials, things like that."

—Lisa Massengale, 2020

Government information organizations are valuable sources of primary information, serving the public as well as legislators and policymakers. The Congressional Research Service, a service unit within the Library of Congress, provides objective, authoritative, timely, confidential, and nonpartisan analysis and information services to members and staffers of the United States Congress, with which to create a more informed legislative body. An interview with 
127

Lisa Massengale, Head of Reference and Data Services of the Congressional Research Service's Knowledge Services Group, highlights the need for leadership to employ emotional intelligence in managing organizational culture. More specifically, technical services divisions within government information organizations should embrace flexibility in order to adapt to new developments and unforeseen changes in library operations. I will synthesize Massengale's perspectives on leadership in relation to literature that has shaped her point of view, as well as the leadership frames identified by Bolman and Deal (2017). Furthermore, I will examine the current issues facing the library community, and how behavioral-focused leadership can mitigate the negative impacts.

\section{Components of Profile}

Lisa Massengale's dynamic career in reference librarianship is characterized by the importance of building strong staff and public relationships. A third-generation librarian, Massengale earned her Master's in Library Science from the University of Pittsburgh and began her career in academic librarianship as a general reference librarian at Nova Southeastern University.

Massengale also attended the Minnesota Institute for Early Career Librarians, whose mission is to focus "on the development of library leaders from diverse backgrounds," mainly traditionally underrepresented groups. Here, Massengale learned about the National Library of Medicine fellowship program from a colleague, which she applied for in anticipation of specializing in a subject area. After two 
years as a fellow, Massengale served as a medical librarian as well as the head of a science reference department.

Afterwards, Massengale transitioned to the Library of Congress, where she served as the Head of the Science Reference Section for two years before moving to her current role in the Congressional Research Service.

Government organizations are bureaucratic in nature, characterized by detailed organizational charts and thoroughly documented workflows. Whereas many library organizations are public service or nonprofit organizations by nature, government libraries are unique in that they aspire to an ideal of nonpartisan information transparency.

The Congressional Research Service (CRS) exists as an independent research organization within the Library of Congress, with its intended audience being members and staff of Congress. Originally established in 1914 with the purpose of fulfilling congressional information needs, CRS increased its commitment to serving Congress in 1970 with the added responsibilities of performing research and analysis in support of the legislative process. With core values of confidentiality, authority, and objectivity, the Congressional Research Service aims to support the United States legislature "by providing comprehensive and reliable legislative research and analysis...thereby contributing to an informed national legislature." These fixed values and mission statement unify CRS while also identifying its unique purpose in the Library of Congress as a whole. 
129

\section{LEADERSHIP IN THE CONGRESSIONAL RESEARCH SERVICE}

Lisa Massengale now serves the Head of Reference and Data Services of the Knowledge Services Group, one of the research divisions of the Congressional Research Service. She oversees the work of reference staff and library technicians. Her interest in this role arose from "[CRS's] great reputation, working with Congress, and the different resources. It's a unique form of reference." Massengale explains:

We are charged with responding to Congressional information requests. We handle general reference questions in the field of humanities. We're also responsible for knowledge management, so that means we help to capture, organize and preserve institutional information and data to facilitate for future use. We are exploring better ways of ensuring that when somebody leaves or retires, we still have access to the knowledge that people have in their brain. We are trying to help facilitate processes that document knowledge in a way that doesn't interrupt people's work. We also look at how we ensure that information is preserved so people can access it in the future.

The balance of ensuring short-term successes with longterm strategies demonstrates Massengale's commitment to lasting change within her division. 


\section{ADAPTATION OF GOVERNMENT LIBRARIAN ROLES}

When asked if her position has changed in the time since she joined CRS, Lisa Massengale states that she:

[W] as initially the Head of Reference and GIS, but GIS moved into another division. Additionally, we implemented a data services program, which added an instruction component to my section. Data Services and Instruction are programs which have started this year, and it has been really exciting thinking about where we want to take those programs.

\section{LEADERSHIP IN GOVERNMENT INFORMATION SERVICES}

Evans and Greenwell (2020) describe management as the "art of getting things done through people" (p. 20). As the Head of her division, Lisa Massengale says, "I oversee the LaFollette Reading Room and the Jefferson Congressional Reading Room. I schedule the reference staff, oversee requests, and help with the collections for both of those reading rooms."

"Overseeing reference librarians, I still get to see the questions we get." Her direct involvement in the efforts of the reference team reflects the open communication and interpersonal nature of her group's organizational culture.

We ask ourselves, "Where would we even start to think about looking for that [information]?" Because of the nature of the questions we get, it is not 
131

usually "I want this article;" sometimes, we have to ask ourselves, "Who or what organizations would collect that, and are they collecting it systematically?" We often consult several different sources to find the answers.

\section{MANAGING RELATIONSHIPS EXTERNALLY AND INTERNALLY}

Congressional Research Service, and more specifically the Knowledge Services Group, rely upon consistent relationships with other divisions within CRS and within the Library of Congress as a whole to prevent the creation of silos. The Knowledge Services Group mainly provides technical services, which further emphasizes the need to promote interpersonal communication and organizational awareness.

Kowalski (2017) describes silos as "workplace constructs and mindsets that isolate departments from one another through bureaucracy or rigid hierarchies" (p. 1). The benefits of taking preventive measures against the creation of silos in an organizational culture are many-open communication leads to a decrease in competition, work efforts are not overlooked nor overlapped, and staff can instead focus on broadening their horizons and professional development. For government information organizations, working within a bureaucratic structure to ensure openness is essential.

Lisa Massengale explains her team's role in the daily operations of the Congressional Research Service: "Within Congressional Research Service, the Knowledge Services Group is one of the research divisions which deals with reference and humanities research in nature." In acquiring 
and locating information, library technicians assist reference staff. Technical services are essential components of library work that are often the frontline for staff interaction with library materials, as well as the workflows most vulnerable to crisis and change. The American Library Association (2016) identifies library technicians as support staff positions that perform "clerical duties" including circulating materials, answering general questions, and process new acquisitions. The amount of library technicians is expected to continue growing as digital tasks become more simplified, requiring fewer qualifications, and as funding for library institutions decreases. Thus, library technicians are an important population to consider when addressing library management.

\section{The Human Resources Approach}

Bolman and Deal's (2017) Human Resources frame assumes that "people and organizations need each other," and that when the "fit" between individuals and their collective organizations is poor, both suffer (p. 118). In the context of the Library of Congress as a whole, Massengale says:

Because of the nature of the work we do, in addition to traditional library services, we have a lot of interaction with the larger Library community. We sit on committees for collections policies or collection discovery groups; we're charged with acquiring monographs and e-resources, so we interface with the library in terms of collections. 
133

Information, autonomy, and engagement are three key needs identified by Bolman and Deal that staff should be able to access through participation opportunities (p. 144). In the Knowledge Services Group of CRS, Massengale empowers her staff along those principles.

Massengale's approach to leadership in framing her team within the Library of Congress as an organization is in line with the Human Resources approach, which Bolman and Deal (2017) describe as prioritizing "people's skills, attitudes, energy, and commitment" when measuring an organization's success (p. 117).

Massengale invests time and effort in engaging her staff with all levels of the organization. "With new people who come on board in Knowledge Services Group, we'll ask for them to take a tour of the Serials reading room, because a lot of our requests are for articles." The Serials Reading Room is a service unit within the Library Services division. "It's good to know who's there and what's available in the collections. We also participate in committees for other Library groups and organizations, like LC Labs"-being a division of another service unit, the Office of the Chief Information Officer.

Because of these intentional practices, Massengale's team is both aware of their individual contributions to the Library of Congress community and trained to confront unexpected changes in the workplace with a clear understanding of their responsibilities. Understanding shared and common goals across divisions strengthens connections and is especially valuable in anticipating organizational-wide change. 


\section{Library Leadership Adaptation in Times of Crisis}

The COVID-19 pandemic and resulting physical and social distancing requirements have resulted in library organizations adapting in efforts to bridge these new divides.

Massengale identifies a behaviorally focused approach that creates and maintains interpersonal staff networks:

I've been thinking about how I can best help facilitate those conversations between staff to keep each other in the loop, trying different conversation formats like round robins in meetings. We always have people in meetings who don't like to speak up, but we still need to hear what they have to say. It's just harder when we don't see each other, so that's been a challenge of the past six months.

Relationship management, is described by Martin (2017) as the process of building and maintaining internal and external relationships among an organization's people ( $p$. 8). By adapting to the individual needs of her staff, Massengale creates a healthy emotional culture that encourages open communication.

"I've been really focused on change management, because some libraries are definitely better prepared for advancing in technology," Massengale says. However, technological accessibility, especially in a period of distancing, is a concern of: 
[T] he people who have the most issues moving into a new way of thinking about how we're going to approach public service, especially because we are in a situation that we did not plan for. One day we were working onsite, the next day we all worked from home, but we still have to provide services.

Digital communications technology is a benefit to library organizations during the pandemic; however, the unprecedented shift in workflows exposed inaccessibility of these resources to library staff themselves. Technology is also identified by Bolman and Deal (2017) as a common obstruction to change (p. 372). Massengale addresses this dilemma by posing the question: "We're usually good about thinking about what the best tools are and how we train, but don't think systematically-how do we get people to embrace the thought of change?"

Massengale's behavioral approach to leadership is inspired by the analysis of change presented in Who Moved My Cheese?. Spencer Johnson's (1998) metaphorical narrative Who Moved My Cheese? demonstrates the importance of change management regardless of authority. Johnson's metaphorical characters, Sniff (change identifiers), Scurry (change-makers), Hem (change resisters), and Haw (eventual change embracers) represent varied instinctual and behavioral reactions to change. Change resisters to emerging technology in libraries, for example, rely on the familiarity and comfort of traditional practices, rather than embrace the ideas of improved workflows with new technology. As "Haw" experiences, leaving the comfort zone earlier results in an easier adaptation to change (Johnson, p. 49). 
While library technicians and paraprofessional staff may lack formal decision-making authority, they have control in how they react to change. Especially as library technicians tend to be on the frontlines for new workflow and technological developments, these individuals must prioritize flexibility in new situations to anticipate change, expect change, and seek it out (Johnson, 1998, p. 50-51). Bolman and Deal (2017) refer to shifting perceptions in the face of change as the "framing effect," a mental model that alters an organization's response to change (p. 39).

\section{AUTONOMY AND POLITICAL POWER IN APOLITICAL ENVIRONMENTS}

Government information organizations are characterized by nonpartisanship. In an effort to provide unbiased information, these organizations ironically must confront how their internal power sources support (or weaken) their values. However, this is not to say that these organizations are exempt from internal politics. I assess the concepts of power as indicated by Bolman and Deal as a core component of the political frame. Power, "the potential ability to influence behavior," manifests in autonomy and decision-making (Bolman \& Deal, 2017, p. 186). By identifying and addressing how these aspects drive the workplace through a behavioral lens, conflict can be prematurely mitigated.

Organizations empowering staff drive autonomy, described by Daniel Pink (2009) as one of the three innate human psychological needs (p. 78). Autonomy is a driving force for independent innovation, networking, and change. Expanding on her approach to supporting her staff, 
Massengale states, "I always encourage staff to come to me with a solution to any problem they want to discuss." Pink notes the increasing numbers of employees in the United States who work remotely-33.7 million at least once per month and 14.7 million daily_and how independent work decreases the need for direct oversight and encourages selfmotivation (p. 30). Although Pink theorizes that short-term goals "narrow our focus," Massengale's continuing encouragement reflects a long-term, sustainable workplace culture that facilitates autonomy (Pink, p. 48).

By encouraging the potential of her team members, Massengale embraces an idea that Kalil (2017) describes as "influence without authority" (p. 10). Massengale continues, "Even if their proposal is not feasible it's always a good starting point for a discussion about what is possible." Kalil addresses decision-making behaviors, a critical part of Bolman and Deal's (2017) Political Frame, in his endeavors to empower policy staff entrepreneurship during his time at the White House. Massengale displays a similar approach, in that she believes in the value of individuals within an organization, as staff from every level have the power to impact an organization, and therefore should be valued and supported.

Applying a behavioral approach to leadership, particularly in addressing workplace politics, is a healthy challenge to traditional hierarchies and fixed job descriptions. Encouraging innovation is crucial for government information organizations and should be prioritized by staff and stakeholders. To understand their changing environments, patron needs, and to connect with the meaningfulness of their work, individuals within 
government organizations should be actively encouraged to participate and innovate within their positions and beyond.

\section{THE HUMAN RESOURCES FRAME AND VOCATIONAL AWE IN TIMES OF CRISIS}

The ongoing COVID-19 public health crisis amplifies the role of libraries and their employees to quickly adapt to change. In addition to technological developments and changes in the time-sensitive needs of Congressional patrons, government information organizations like the Congressional Research Service must remain flexible to adjust to uncertain times.

Vocational awe, the term established by Fobazi Ettarh (2017), refers to the "set of ideas, values, and assumptions" held by library workers about themselves and the institution of librarianship (para. 3). Libraries have historically been symbolized as sacred spaces of salvation, resulting in library workers accruing intense burdens of labor with little preparation or compensation. Frontline library workers, often paraprofessionals in technical services and reference staff, are most vulnerable to the consequences of change, both societal and operational.

Ettarh states that "[m]any libraries open their spaces to the disadvantaged and displaced populations in the community such as the homeless or the mentally ill" (para. 6). In the wake of the ongoing COVID-19 pandemic, various types of library organizations have been tasked with responding to changing responsibilities. This includes, but is not limited to, limited access to physical materials, transition of events to virtual platforms, and new responsibilities to serve communities in crisis-often without appropriate resources. 
139

Without appropriate funding for training, livable wages, and appropriate staffing, library staff can quickly experience burnout. Workplace stressors, including emotional repression, leads to "less engagement and productivity" in a space that is expected to be self-sacrificial for social good (Ettarh, para. 15).

Massengale's behaviorally-focused approach to leadership in a library division consisting of technical services and reference staff is ideal for addressing these concerns. While CRS is primarily a resource for Congressional staff, the need to establish informed laws is ongoing. Balancing the emotional and physical well-being of staff (particularly those in paraprofessional, technical service positions) with the traditional obligation of libraries to provide service no matter the cost, is an example of how vocational awe can be a catalyst for burnout, and severely harm library staff.

\section{Conclusion}

Massengale's efforts to individually communicate with her team members and show respect to the needs and ideas of all, regardless of experience level and position title certainly alleviate such issues. As Kowalski (2017) states, change is a potential stressor in that "staff...are wary of how much [change] will affect their roles," and often react defensively as opposed to immediately embracing change (p. 3). By taking the initiative to communicate, not only does Massengale earn the trust of her team, but she also creates transparency throughout the organization's hierarchy. Such practices are crucial in maintaining a healthy workplace culture, particularly in ensuring that staff from all levels are 
aware and approving of decision-making processes that lead to long-term changes in the organization. In particular, I hypothesize that improving transparency through prioritizing communication and staff well-being will result in a safer decision-making process for government information organizations-especially for technical services staff that must continuously provide service even in times of crisis.

\section{Author bio}

Bailey DeSimone is a Library Technician (Metadata) with the Law Library of Congress's Digital Resources Division and is in her first year of her MLIS program at the University of Maryland's College of Information Studies. She is passionate about improving the accessibility of legal materials through storytelling and digital literacy.

\section{References}

American Library Association. (2016). Library assistants and technicians. http://www.ala.org/educationcareers/assistant

Bolman, L. G., \& Deal, T. E. (2013). Reframing organizations: Artistry, choice, and leadership. ( ${ }^{\text {th }}$ edition). Jossey-Bass.

Ettarh, F. (2018, January 10). Vocational awe and librarianship: The lies we tell ourselves. In the Library with the Lead Pipe. http://www.inthelibrarywiththeleadpipe.org/2018/vocationalawe/

Evans, G. E., \& Greenwell, S. (200o). Management basics for information professionals. ( $4^{\text {th }}$ edition). American Library Association.

Johnson, S. (1999). Who moved my cheese?. Vermilion. 
141

Kalil, T. (2017). Policy entrepreneurship at the White House: Getting things done in large organizations. Innovations: Technology, Governance, Globalization, 11(3-4), pp. 4-21.

https://doi.org/10.1162/inov_a_o0253

Kowalski, M. (2017). Breaking down silo walls: Successful collaboration across library departments. Library Leadership E Management, 31(2). https://doi.org/10.5860/llm.v31i2.7202

Martin, J. (2019). Emotional intelligence, emotional culture, and library leadership. Library Leadership E Management, 33(2). https://doi.org/10.5860/llm.v33i2.7329

Pink, D. H. (2011). Drive: The surprising truth about what motivates us. Riverhead Books. 


\section{Joe Puccio \\ THE POWER OF EMPATHY AT THE LIBRARY OF CONGRESS}

Laura O’Hanlon

One of America's most valuable institutions is the Library of Congress, a collection filled with over 170 million items that span across five buildings in the Washington, D.C. area.

The Library of Congress was founded in 1800 when Congress voted to allocate funds towards the purchase of books for the use of Congress. This initial collection was destroyed in a fire in 1814 when the British attacked Washington, D.C. during the war of 1812 (Cole, 2017). The collection was rebuilt years later when Thomas Jefferson offered to sell 6,487 books from his personal collection to the U.S. Government. The Library of Congress has grown to not only serve Congress but to serve the American people by "documenting the history and further the creativity of the American people” (Library of Congress, 2019).

Throughout the lifespan of the library, the collection has expanded to include five buildings. The Thomas Jefferson Building (1897), the James Madison Building (1981) and the John Adams Building (1938) are located on Capitol Hill in Washington, D.C. Other locations for the Library of Congress included the High Density Storage Facility at Fort Meade in Maryland and the Packard Campus for Audio Visual Conservation in Culpeper, Virginia. 
143

The collection contains an array of items and is not limited just to books, but also includes maps, manuscripts, and instruments. Some amazing treasures housed at the library included the Gutenberg Bible, the writings of the past presidents of the United States, and five instruments created by Stradivarius to name a few. This collection continues to grow through donations, acquisition purchases, and material acquired through the Copyright program.

The person who is responsible for managing, planning, and monitoring collection development within the Library of Congress is Joe Puccio, Collection Development Officer. Joe started at the Library of Congress as an intern in 1980's and has spent over 30 years in various departments.

Puccio's personal leadership style is guided by two principles, first to keep staff focused on the organization's mission and second, to take care of the staff. Through this profile I will examine how this personal leadership style developed and examine how Lee G. Bolman and Terrence E. Deal's four frames of leadership are used in modern information organization leadership.

\section{Background}

After completing his M.A in Library and Information Science at the University of South Florida, Joe Puccio started his career at the Library of Congress in 1984 as an intern. He then spent a few years in various departments such as the Congressional Research Service and the Serial \& Government Publication Division. 
His first supervisor role was in 1989 as the Public Service Officer for the Collection, Access, Loan and Management Division. In this position, he was responsible for 130 employees.

Following that role, Joe spent four years as the Assistant to the Director for Acquisitions \& Bibliographic Access Directorate before moving on to his current leadership position.

Joe has been in his current role as Collection Development Officer since 2012 where he is a responsible for managing, planning, and monitoring collection development. He also serves as a liaison to external groups and provides policy guidance to the Associate Librarian for Library Services and other senior managers.

\section{A History of Leadership}

I had the honor of interviewing Joe on a Friday in October of 2020, an unusual moment in time. Normally this interview would have been conducted in person, but due to the global pandemic of COVID-19, Joe was gracious enough meet with me over Zoom.

Before I met with Joe, he had given me his own personal leadership philosophy which is based on two principles: the first is to take care of the staff, and the second is to stay focused on the mission. This philosophy is something that Joe held for a long time and it started with observing his supervisors as from an early age. 
145

\section{STAFF ORIENTATED}

Joe started to develop his leadership style early in his career even before he entered the library field. Throughout high school he worked at Dave's Deli in Philadelphia, Pennsylvania. Danny, one of the co-owners of the deli, was an excellent leader who always put customers first, as they were "the life blood" of the deli. But even with all of this focus on the day-to-day operations, Danny still projected a sense of warmth and always had fun with his job. Joe also said Danny cared about him personally as an employee.

Joe's first leadership position at the Library of Congress came after five years as a reference librarian in the serials and periodical division. At this point in his career, he felt that he had hit a ceiling and the only way to move up was to apply for managerial positions. His first position was as the Public Service Officer for the Collection Access, Loan and Management Division, which was responsible for the general bound print collection. It was a huge division of almost 200 staff. The staff had oversight of the shelving and book service, which manages the library's closed stacks that have to be searched when a request came in. Sometimes a special search had to be requested if an item could not be located. Joe was ultimately the person who was responsible to patrons if a book could not be found.

One challenge that Joe expressed he had going into this role was that he knew that there was low morale among staff. To understand why this was, you have to look at the environment and culture that staff members were working in. Joe's portion of the division consisted of four section heads, Joe's direct reports, and about a dozen team leaders. Each team leader was in charge of a team of deck 
attendants. Deck attendants were typically low-paid and temporary, non-benefit positions.

The staff in the division was predominantly African American and there was a general feeling among the permanent staff and middle supervisors that they were being treated poorly, with low benefits and lack of professional development opportunities. These positions might not have been the most engaging, as they were responsible for some of the tedious work required in the library, such as shelf reading or shelving material. There were also divisions among deck attendant teams who formed cliques across the Jefferson and Adams buildings, separated by the day and night crews. All the while at the top tier of management were three white managers. Low morale was also caused by tension with upper management. The Chief at the time lacked empathy about helping staff; they were more preoccupied with finding individuals who were breaking the rules rather than helping them succeed.

Bolman and Deal alludes to these challenges that can be faced by leaders when looking at an organization through the human resources frame. This frame views challenges from the angle of relationships and human needs. Leaders in this frame are an image of empowerment, seeking to align the needs of the organization and the human needs of staff. Tension can arise when an organizational culture can lean towards a structural or factory model, which can be seen in the structure of the Library of Congress. Reliance on the structural frame can lead to low morale as seen in the example cited by Joe. 
To face the challenges Joe saw before him, he met individually with section heads and team leaders to gain perspective on the culture of the unit. During this process he found that staff were pretty bitter, with one team leader during this investigative process stating, "You are just another white man," which Joe found rather disheartening when trying to investigate a solution to this problem.

So how do you approach a cultural change in a difficult environment? Joe's response was to maintain his personal ethos: to stay positive and to believe in the staff that reported to him. Out of this difficult environment came many boundaries that were set up in between smaller groups in the library. Joe's solution was to develop a cross training opportunity for deck attendants. Additionally, a details program was created for staff members to try out a position at different divisions for four months. Both of these programs helped increase staff morale and helped staff to see the organization from different perspectives. At the same time, cultural factors changed to help the morale of staff, including an increase to the benefits package.

Although not often recognized, the psychological needs of staff are essential to the happiness and success of staff in the work place (Bolman \& Deal, 2013). Daniel Pink in his work Drive (2011) suggests that there are three drives for workers to be motivated and happy: autonomy, mastery, and purpose. In this example from the Library of Congress, Joe's solution to the challenge of motivating staff was to engage all three drives. Staff who have learning opportunities can master their work, be exposed to the purpose and mission of their work and organization, and develop autonomy by creating their own learning path. 
Joe said that the role of Public Service Officer was difficult, but in the end he learned more from this position than from any other. He still hears from some of his former staff, and a lot of them have moved up within the Library of Congress.

\section{MISSION-DRIVEN}

Staff are proud to work at the Library of Congress and feel that they work in a special place. They know that they work in a place where leading scholars, past and present, converge. An effective leader in a mission driven organization is aware of the power of this shared past and symbolism as it can be a powerful lens to view an organization. Bolman and Deal stress that when looking through this lens it emphasizes the meaning of cultural events and can help leaders understand what motivates staff. The library system has a large staff and each division is focused on a narrow slice of the mission of the library. With that in mind, it is a real challenge for management to let staff know where their piece is in the bigger puzzle and what the bigger picture is.

To help with this, the library started a New Employee Orientation program in Library Services. This program spans multiple days, so when staff at any level complete it they come into work with a few days of knowledge about what the library is all about. Having a leader, like the current Librarian of Congress, Dr. Carla Hayden, is integral. Her focus on the libraries' strategic planning and development of a mission statement and vision statement involved an 18-month process with multiple staff stake holders involved. Creating a clear, defined mission is an easy pointing place for leaders at every level to use as a reference for day-to-day work. 
In Joe's day-to-day work life, he supervises a staff of five who are, as Joe described, wonderful people and are very communicative and cooperative. When working with other units, inevitable tensions may arise for various reasons. In this situation, as a leader, Joe reminds staff that it is important to understand others' motivations to know that their heart is in the right place.

In the Library of Congress there are over 200 recommending officers or subject specialists that help develop the collection and make recommendations for purchases or material that are not being obtained through the Copyright program. Joe works closely with these stake holders to help develop the collection and collection polices. To remind the staff of the mission of the library, to obtain material that best suits its needs, Joe writes and develops policies. These policies follow the Library of Congress' style and scope to create fair and easy to follow guidelines to help those who are recommending material stay in line with the library's mission and goals.

Joe also stays true to the library's mission when there are issues related to budgets and resource allocations at work. Inevitably, every group in an organization is pushing projects or initiatives, but there is not enough funding to do all of them. All organizations can be viewed as political arenas. "Goals and decisions emerge from bargaining and negotiating among competing stake-holders jockeying for their own interest" (Bolman \& Deal, 2013, p. 184). An effective leader knows how to navigate this frame.

Joe finds that in this situation, one must step outside of their position and take a look at what the whole library's 
needs may be. He recognizes that the needs of other departments, like Information Technologies, may come before the needs of the collection. If there is a strong ask that he feels is important to his work, he will work with colleagues to make a stronger case.

When asked about his favorite collection, surprisingly Joe did not talk about something that he personally valued in the collection, but of his family experience with the collection. When Joe worked as the head of the Rare Books reading room, his mother-in-law, who was an English teacher, visited and he showed her the walking stick of Charles Dickens and a first folio from Shakespeare. The recognition of her joy and the joy of others through his career is an insight into Joe's leadership principle of focusing on the needs of others. Leading from a standpoint of empathy and human need while balancing the political, structural, and symbolic nature of one's work contributes to what makes an effective leader.

\section{Acting librarian of library services}

When Joe became Collection Development Officer in 2012, he made it to the zenith of his career. One day his boss, Mark Sweeney, came over to his office with an unusual ask. He asked him to take on the role of Acting Associate Librarian of Library Services as the library searched for a permanent replacement. Joe’s initial response was, "No, you don't want me to do this." After some convincing Joe agreed. 
151

On his first day in his role as Acting Librarian of Library Services, the head of facilities called him and said the Culpeper facility had an issue: there are copperhead snakes in the building, and staff are trying to save the snakes. All leaders over the course of their careers experience surprising and difficult challenges, including those that may be out of the scope of what they do.

It is hard to make a real impact with 1,200 staff in a temporary role, with a majority of that group being on the front lines and performing routine tasks. If Joe would have gone into the position permanently, he would have gone around to every division and met all the staff. He always said to himself that if he got into a positon like this within the library, he would do what he could to make everyone feel better. While in this position, Joe sent out a holiday message with a little update about the Library of Congress. This role taught him that if you can deal with the stress and aggravation that comes with this type of position, you can make a difference and change the culture of an organization. That said, when a permanent person was found for the position, Joe was happy to get back to just being a librarian.

\section{Perspective on COVID-19}

"It's a weird time." Joe and his team of five started off the pandemic working from home, and this has continued on until the Fall of 2020, the time of this interview. The big challenge with this shift for Joe and many in this position is the lack of human interaction. Joe had to present to the executive committee of the library on WebEx. Joe remarked 
that this can make it a little uncomfortable to present as you cannot really read the room.

For the team that Joe leads, there has been a bit of a change in workplace communication. Typically, those under him work in an open office and can have conversations throughout the day. With the change to work-from-home, Joe has been having one-on-one meetings each week with his staff, mostly to just check in to see how they are doing. The situation has helped staff come together. One challenge the team has had to navigate is giving briefings to large groups throughout the library. When mics are left on or screens are blank it can be difficult to give and get feedback on the effectiveness of a briefing. But overall, Joe finds that his team has been more productive working from home and that even he feels like he is getting more work done than usual.

Joe remarked that the pandemic has brought senior managers and staff closer together. Dr. Hayden has been sending out videos to the staff to highlight how the library mission continues and the administration has the safety and health of staff as a top priority.

\section{Conclusion}

Life's daily challenges rarely arrive clearly labeled or neatly packaged. Instead, they come upon us in a murky, turbulent, and unrelenting flood. The art of reframing uses knowledge and intuition to read the flow and to find sensible and effective ways to 
153

channel the incoming tide. (Bolman \& Deal, 2013, p. 399)

Bolman and Deal's Reframing Organization makes the argument that when leaders look at an organization's situations and workplace dynamics through multiple frames (structural, human resources, political and symbolic), they are better equipped to effectively navigate an organization through changes. Leaders who put this leadership theory into practice are prepared to make the most effective decisions by taking in the needs and wants of an organization and tailoring them to a specific challenge or goal.

Joe Puccio exemplifies all four frames that Bolman and Deal argue make an effective leader through the development of his own personal leadership philosophy and navigating the challenges he faces as Collection Development Officer at the Library of Congress.

\section{Author bio}

Laura O'Hanlon is a Master of Library and Information Science candidate at the University of Maryland. She currently serves as Acquisitions and Cataloging Supervisor at Loyola Notre Dame Library in Baltimore, Maryland. 


\section{References}

Bednar, M., \& Robbins, S. (2019). Using the start | stop | continue framework to improve library operations. Library Leadership $\mathcal{E}$ Management, 33(3). https://doi.org/10.586o/llm.v33i3.7351

Bolman, L. G., \& Deal, T. E. (2013). Reframing organizations: Artistry, choice, and leadership. ( $5^{\text {th }}$ edition). Jossey-Bass.

Brundy, C. (2018). Critical views of leadership and the academic library. Library Leadership E Management, 32(3). https://doi.org/10.5860/llm.v32i3.7254

Cole, J. Y. (2017). America's greatest library: An illustrated history of the Library of Congress. D. Giles Limited.

Evans, G. E., \& Greenwell, S. (200o). Management basics for information professionals. ( $4^{\text {th }}$ edition). American Library Association.

Miller, J., \& Alber, H. (2012). Heart at work: Stories and strategies for building self-esteem and reawakening the soul at work. Trafford.

Pink, D. H. (2011). Drive: The surprising truth about what motivates us. Riverhead Books. 


\section{Building the Future Through People}

A LEADERSHIP PROFILE OF PAMELA WRIGHT, CHIEF INNOVATION OFFICER AT THE NATIONAL ARCHIVES AND RECORDS ADMINISTRATION

Selena St. Andre

Passion is a driving force that most professionals within the library and information science field can agree compels people to enter the field. The passion that developed while completing research for a private consulting firm at the National Archives and Records Administration in Washington D.C. was a significant reason that compelled Pamela Wright to apply for a job at the National Archives. Nineteen years later, Wright is still enthusiastic about the work she does to further the goals of the federal agency in addition to now developing the leadership skills of the staff she supervises. Her leadership style and perspective serve as a strong foundation for moving the National Archives continually forward while keeping the staff that make it possible at the forefront of innovation and service to the public. ${ }^{1}$

\footnotetext{
${ }^{1}$ All direct quotes from Pamela Wright in this profile are from a personal interview with the author conducted on October 22, 2020.
} 


\section{Background}

Pamela Wright began her time at the National Archives and Records Administration (NARA) in Washington, D.C. in 2001, moving up in the ranks since then to her current position as the Chief Innovation Officer. Appointed to the position by David Ferriero, the current Archivist of the United States, in 2012, Wright became the first in her position and serves on NARA's senior leadership team. In her role, Wright directs the Office of Innovation, supervises 40 staff members, and leads hundreds of staff members in innovation projects throughout the agency. During her time at NARA, she has grown the organization's social media presence from a single blog to over 150 projects across 16 platforms, launched the Citizen Archivist Dashboard, introduced public crowdsourcing in NARA's Catalog, and developed the History Hub, a collaborative digital consultation and reference platform, among various other projects.

Throughout her 19 years with the National Archives, Wright has strengthened and developed her personal leadership style into one that values curiosity, accountability, honest, open communication, and, most of all, creating a strong workplace culture. This paper will dig into Wright's leadership philosophy while connecting it to various qualities of management as well as issues that leaders may face. By analyzing her management style with a solid backing of theory, focusing on frameworks in which to view leadership and the role that managers undertake in supporting their staff, we can present one potential model of successful leadership in the library and information science profession. 


\section{Radical Candor}

We as humans are programmed from an early age to be fearful or otherwise hesitant about authority and how we approach those in powerful positions with difficult conversations. This lack of willingness to be open about our concerns can lead to a harmful work environment and create unnecessary tensions between management and staff. Often, uneasiness with authority results more from the power that is associated with a position, rather than with the exact person in that position. This positional power, as Bolman and Deal (2017) referred to it, is a source of power that may not necessarily be tied with authoritative power. Yet it often comes with another power source, the ability to control rewards, which can impact how employees interact with a manager with positional power (p. 192). In addition, when something goes wrong, staff members may believe their manager is placing the blame for the failure on them personally. Likewise, a manager may not have the tools or experience to communicate to their employees that any wrongdoing was not their fault-or worse, they may not be able to see the bigger picture and the root of the problem and will indeed place primary blame on their staff.

These all-too-common complications between management and staff result from poor communication skills. Wright understands the inherent difficulties that come from simply being in a position of power saying:

I don't feel like I'm a very intimidating person, but you realize as you go up that your position becomes intimidating to people. No matter how down-to-earth you feel, the people that 
are working for you have a hesitancy to tell you what you don't want to hear.

This is something Wright has actively attempted to address in developing her personal leadership style. With the help of a wealth of resources, she has strived to develop relationships with her staff that places a high value on open and honest communication, including helping staff become comfortable having difficult conversations with her personally. Much of this success is tied to Kim Scott's (2017) book Radical Candor. The book focuses on the concept of radical candor as one that can both build strong relationships between managers and employees and create an environment where people enjoy their work and colleagues. The idea of radical candor is simple: create, nurture, and maintain an environment that allows a manager to talk frankly with their staff and for staff to talk frankly with their manager in return.

\section{"IT WAS CRITICAL TO DEVELOP A RELATIONSHIP WITH STAFF WHERE THEY FELT LIKE THEY COULD TALK WITH ME AND WOULD NOT BE PENALIZED FOR TELLING ME THINGS I DIDN'T WANT TO HEAR."}

Wright has instilled this concept so clearly into those reporting to her that those in her office will "invoke the principles of radical candor" whenever they want to begin a difficult conversation so that each party is able to get into the right mindset for the conversation. Wright has found that this ability to lead a team that is clear and direct in their communication has been incredibly valuable to her as a leader and manager. 
159

The idea of radical candor is also one that can serve as a strong foundation for a strong leadership style. By giving staff the ability to speak their minds, there are many other barriers that can be broken down in the divide between hierarchical structures and the power imbalances that result from those structures. In addition, the ability for a manager to be able to be frank with their employees leads to another important theme of Scott's guide. Managers that are actively open with and investing time in giving constructive feedback to their reports have an opportunity to take an active role in ensuring that those staff members are given the chance and space to continue to developing their individual leadership styles in order to advance their careers. In addition to crafting her own leadership style, Wright has also taken this idea to heart.

\section{Leadership Development}

While the ability to lead can be innate to some, most often it is a skill that one must learn through trial and error. Learning how to lead can also come from listening to experiences others have had or through specific leadership development courses. Most importantly, leadership is a skill that one can never master as leading deals with unique situations from the people and organizations around us that continually impart new strategies to include in our knowledge base.

For Wright, being in management was an unintentional role that happened as she moved up in rank at NARA, all while gaining new knowledge and experience. In the library and information science field, being an accidental manager is 
common, as very few entering the field come in wanting to be managers (Evans \& Greenwell, 200o). However, with her ability to see the bigger picture and guide her staff towards broader goals, management was perhaps a good fit for Wright. But simply seeing the bigger picture is not all leadership entails. It includes the ability to have an understanding and grasp on emotional intelligence, ease into new situations with an open mind, be able to delegate effectively, and foster the development of leadership in one's team by sharing knowledge and experience.

Like the ideas of radical candor, the concept of emotional intelligence is one that can have an enormous impact on workplace culture. First coined by Peter Salovey and John Mayer in 1990, emotional intelligence is the ability to be aware of oneself and others in order to handle emotions and build strong relationships. By preventing burnout and fostering innovation, emotional intelligence as a skill often holds more value for leaders than technical skills (Martin, 2019, pp. 1-2).

This is an ability that Wright has developed over the years in listening to her staff and seeking out ways to strengthen relationships within her office. Wright recognizes the importance and impact of emotions within the workplace. She stresses to staff, and especially to her reporting managers and supervisors, that one of the most important things they can do for themselves and the organization is to take care of themselves by identifying their personal boundaries and being aware of signs of burnout, which is especially commonplace in the library and information science field (Geary \& Hickey, 2019). Even with the best intentions, self-care can be difficult in a profession that 
161

demands constant innovation and progress for the sake of public good. To this Wright reflected, "[It can be] hard to take the time to take care of yourself, so you must be really conscious of it." By having this type of foresight to understand that self-care can keep staff energized in their work and relationships, Wright has demonstrated how emotional intelligence can be just as valuable a skill to have as any technical knowledge.

\section{“THAT FEELING OF 'HEY! I WANT TO GIVE THAT A TRY,' YOU NEVER WANT THAT TO DIE. AND FOR WHATEVER REASON, IT NEVER DIES IN ME."}

One of the most telling qualities of a good leader is their ability to step into new roles-often roles that increase their responsibility load and supervision duties-and succeeding by building upon their previous experiences. The ability to transition into new positions and understand that it will be impossible to be perfect in a new role overnight demonstrates leadership that is comfortable with being uncomfortable.

As the inaugural Chief Innovation Officer at NARA, Wright knows a little bit about transitioning into completely new territory. Although transitioning to a new role almost always comes with more work than originally imagined, Wright expressed her thoughts about how transitions have a human impact saying, "...having to go through that work, you come out a different person.” By coming out as a different person having done the hard work of being in a state of discomfort, one is able to push themselves to continually develop their personal leadership style, something that Wright has learned over her 19 years at 
NARA. One way she has been pushed to develop her skills has been in understanding the importance of effective delegation of work to her staff. When she was appointed to her current role, Wright struggled with delegating, often feeling like she was asking her staff to do her job for her. Except, in a hierarchal structure like the one NARA is built on, this is exactly why delegation is important, because one position or person cannot possibly do everything. Over time, with the help of mentors, Wright realized that by doing work that could have been delegated, she "was losing that time to do the more complex and important work that I should be doing" and "not delegating meant robbing myself of time to do what I was hired to do." This led her to get better at effective delegation. By developing this knowledge, it led to an understanding of management continually moving towards the bigger picture and spending less time focusing on detailed tasks, thus resulting in one of the principles of management that Wright has realized over the years, "As you rise up in management, you don't just prepare yourself, you get people to prepare you because you can't do everything."

The idea of preparation is reciprocal. Investing in a team is important in creating an engaged workforce that can lead to a well-rounded organization with committed and talented employees (Bolman \& Deal, 2017). One way to invest is to encourage individual leadership development while on the job. For Wright and her team, this takes the form of seminars, webinars, and occasional group reads. This year, 2020, Wright intentionally invested in her team by contracting a team of coaches to work with her entire management staff individually, including herself. She credits this experience with increasing their ability to 
effectively communicate with each other, harkening back to the importance of communication that radical candor stressed. A leader never works alone, so it is important to be aware that by encouraging talent and leadership development in staff and colleagues, an organization can only continue to progress towards their ultimate goals.

\section{Organizational \& Professional Challenges}

Leadership is not without its challenges. These challenges can come from various places and in many ways. How one deals with those challenges is what is important in strong leadership. Challenges can be internal and external, each playing a significant role in the overall success of the organization. From two examples, we can learn how challenges can spark further organizational innovation.

Internally, the concept of silos plays a large role in overall communication and effective team work to reach overarching goals. Silos, or different functional areas such as departments, have had a long lifespan in the profession by serving the basic needs of an organization. Instead of working collaboratively between these areas, silos have historically been synonymous with rigidity, isolation, and bureaucratic hierarchies that stifle communication, collaboration, and positive morale throughout the whole organization (Kowalski, 2017). On the other hand, silos can provide meaning, purpose, and comfort for employees, providing a kind of internal glue between staff and the organization (Bolman \& Deal, 2017). 
As well as being a structural element, silos also serve a symbolic purpose in team building by providing a way to make sense of work in a way that only members of any particular silo are allowed to create. The symbolic function that drives close relationships and a higher sense of purpose makes it difficult to eliminate silos. Most people naturally gravitate towards grouping themselves together in some way in order to make sense of their role within a larger institution. As Wright puts it in discussing silos at NARA, "The reason there are silos are [because] people are trying to make sense out of [and] order and structure out of blobs. [There are] 3,00o of us-we have to figure out some way to organize [ourselves].” This makes sense. An organization working with thousands of employees that lack set responsibility or expertise is bound to quickly become chaotic. Still, silos, although necessary in an organizational sense, can limit the progress of institutions by allowing employees to get too comfortable.

In breaking down silos and actively encouraging crossdepartmental collaboration, leaders must move slowly and utilize a well-connected network and trust building strategies to be successful. Wright has implemented these approaches in combating silos at NARA. In addition to doing little things like asking people to lunch, giving positive praises about them to others, and setting up regular check-in meetings, she also developed a larger system at NARA called the Internal Collaboration Network. This network allows every employee at the National Archives, from the lowest hourly employee to the Archivist of the United States, to post a discussion to the entire staff and discuss it as openly as they want. Reponses can come from across the agency, so the Archivist can respond directly to a 
165

lower-level technician. This network, according to Wright, has opened communication between the geographic and hierarchical silos present in the agency. This network also supports Wright's belief that the symbolic meaning of silos deserves to be treated with empathy when anyone attempts to break them down, since they often start as a wellintentioned way to provide structure. However, Wright also stresses that silos are good to break because "[you are] really making people uncomfortable, which is a good thing, and the beginning of innovation is that discomfort." Discomfort leads directly to growth, but it is important to acknowledge that discomfort is not easy and can be scary for many people.

\section{“ONLY WHEN YOU ABSOLUTELY CANNOT CONTINUE THE WAY YOU'RE WORKING WILL YOU FINALLY LET IT GO AND TRY SOMETHING DIFFERENT."}

Externally, the one challenge that all information institutions are bound to face is that of limited budgets and the politics surrounding resources. Although the National Archives is a federal agency and is entrusted to safeguard federal and general national documentation for the good of the public, it faces the same issues as any organization that must continually demonstrate its importance to stakeholders. As Evans and Greenwell (200o) sum it up, "Money is the underlying resource upon which everything else in the library [or archive] depends. A managerial leader's role is to utilize those resources effectively" (p. 256).

Although Wright oversees an annual budget of several million dollars, innovation and progress is not cheap and 
there is always the constant push to develop the next best thing for the institution. As a federal agency, NARA's innovation initiatives change with different Presidential Administrations, which can limit the budget the office has to work with for ongoing projects not connected to a particular administration. While Wright strongly believes that limited resources fuel innovation by forcing staff and management to think outside the box to make progress happen, those limited resources can become crippling to deal with from a quality-of-life standpoint when stretched to the absolute limit.

This paralyzing effect has had direct influence on NARA's digital Catalog, one of the parts of the agency Wright has been most dedicated to during her years at the National Archives. While general upkeep and maintenance falls in the Office of Innovation's budgetary discretion, larger projects, such as upgrading the system, require federal approval and money. The last time NARA was allocated money to upgrade the Catalog was in 2014. In a broad view, that may not seem all that long ago, but technology has experienced rapid growth in the last six or so years. Since 2014, the digitized collection has also grown from 300 thousand to 120 million items without a major upgrade. Instead, the money has been funneled towards continued digitizing, which is important to increase accessibility of NARA's collections, but is that the best use of money if it means the system that holds those digitized files lags behind current technology? Wright expresses it best by stating that their team has a vision for what the Catalog could be and that they are "sitting on a gold mine" but because of the lack of funding "have not made [the Catalog] as easy as it could be for the public to use." 
While the Office of Innovation has a mandate to lead the National Archives through change and useful transformation, they must balance this responsibility while ensuring a high level of maintenance to their collections and access for the public. This maintenance work is continuous and often performed in invisibility, until something goes wrong and there is an uproar (Arnold, 2016). However, maintenance is only a steppingstone to a better solution and its "primary aim and value is not to uphold stasis" (The Information Maintainers et al., 2019, p. 11). Maintenance, although critical work, should not be viewed as an end goal and Wright and her team understand that maintenance will always be important, but there is only so much maintenance to be done when the world and technology are consistently advancing. The politics of the bureaucracy that support the National Archives has directly created an organizational challenge for the agency that has required innovative thinking to maintain the National Archives' value to the nation by ensuring that the Catalog remains a resource that is available to the public despite a lack of adequate funding.

Innovation as the introduction of something new can be challenging to defend. In a large organization, it is important for everything to relate back to the mission and goals senior management has established. The National Archives has four goals as laid out in their 2018-2022 Strategic Plan (2018): Make Access Happen, Connect with Customers, Maximize Value to the Nation, and Build Our Future Through Our People. With these goals in mind, Wright and her team must connect their projects to these. However, Wright often does not have trouble making the projects fit into one specific goal. Instead, they usually come 
up with new projects by discussing ways to support the goals or, as discussed in the next section, new ideas naturally connect with the goals. So, while some challenges might be difficult and others may be minor, the ability to effectively address those challenges is a key skill for a leader in any capacity to be comfortable with and this ability can lead to a better workplace because of that learned comfort.

\section{Intrinsic Motivation}

If management, as defined by Mary Parker Follett in 1941 (as cited in Evans \& Greenwell, 200o), is "the art of getting things done through people" (p. 5), then management can sound harsh. Although the definition boils down the function of management simply, it fails to take into account that good management should also have an obligation to be encouraging of the people that get things done. This obligation has increased as jobs have slowly increased in complexity, involving more tasks and responsibilities that are not simple or monotonous and continue to move towards a more self-directed model (Pink, 2011). People have increasingly looked for jobs and careers that are selfdirected and creative rather than the once standard practice of reward-motivated work (Pink, 2011). Innovation, by its very nature, demands creative talent and self-motivation. By allowing employees to work on ideas spurred from this notion, Wright has supported incorporating intrinsic motivation into the workplace.

To demonstrate this, a particular instance that Wright highlighted works well. One the most popular forms of engagement for the National Archives comes from their 
Today's Document ${ }^{\underline{2}}$ social media accounts that have accumulated tens of thousands of followers. Today's Document selects a new item daily from NARA's holdings to highlight and give context about for the public. The selected documents are generally tied to anniversaries of the document or current events. In order to "breathe some life" into the program, Wright asked one of her staff members to work on the platform. As a member of the web staff, who has worked at NARA for years, they love history and are skilled at searching through NARA's Catalog. Through seeking out interesting documents that made Today's Document a more dynamic program by featuring items that were comical and exciting as well as combining his web technology skills, this employee started to create animated GIFs (Graphics Interchange Formats), moving images that developed new-found popularity in the 2010's with the rise of social networking sites, from NARA's visual collections. GIFs have grown so large in popularity that they are often used in quickly expressing reactions, allowing people to "simultaneously express their mood, sense of humor, and identity in a low-effort way like no other digital medium can” (Yao, 2018, para. 18). Utilizing this growing, popular digital technology, the GIFs soon led to a higher level of engagement and intrigue from the public. In response to the popularity they were amassing, the employee came to Wright with a new idea: start a GIPHY channel. At the time, Wright was unfamiliar with the GIPHY platform, which is one of the largest online databases of GIFs and allows agencies to store all their GIFs in a central, public library, but encouraged them to work on this project. Individually, and in their spare time, they developed NARA's GIPHY

\footnotetext{
${ }^{2}$ https://www.archives.gov/social-media/todays-doc-app.html
} 
channel. ${ }^{3}$ As of December 2020, the channel has over 800 GIF uploads that have been viewed 2.7 billion times, averaging over a million views per day (Ferriero, 2020). From this one innovative idea by a single employee, the National Archives has been able to reach new audiences by keeping up with modern digital culture.

“WHAT IS THE THRILL FOR ME IS NEW IDEAS.... [WHEN STAFF] SAY, 'YOU KNOW, THIS PROBABLY ISN'T ANYTHING...' AND TELL ME ABOUT A TECHNOLOGY AND HOW IT COULD CONNECT TO WHAT WE'RE DOING...THAT'S HOW ALL OUR GOOD PROJECTS START-[BY] REALLY LISTENING TO STAFF."

To Wright, this is one of the best parts about her role. The ability to allow staff to come up with their own ideas to move the needle of progress further is a driving factor in keeping not only Wright invested in her work, but her staff as well. By fostering a culture that values intrinsic motivation as a way to create results, Wright exemplifies what Pink (2011) labels as Motivation 3.o. According to Pink, the innate drive to be autonomous, self-motivated, and connected to others allows people to "achieve more and live richer lives" (p. 71).

Motivation 3.0, as opposed to Motivation 1.o (the biological drive to survive) and Motivation 2.o (an "if-then" rewards and punishment drive), is governed by the principles of autonomy, mastery, and purpose. The motive of purpose sets this type of motivation apart and in the Office of

\footnotetext{
${ }^{3}$ https://giphy.com/usnationalarchives
} 
171

Innovation this belief of contributing to something greater in the grand scheme of the historical record is an idea that Wright champions in her staff, as exhibited in the GIPHY channel example. By encouraging that staff member to revitalize a program that, although popular, lacked personality, she allowed them to develop their own ideas for how the agency could connect with their customers. On how the autonomy her employee had to innovate sparked positive results for them and the agency, Wright said, "It [was] something he was interested in, so his life [became] interesting [(outside of his daily work)] and we wind up with really great results.” Dozens of other successful projects have begun this way according to Wright and has allowed staff to feel more comfortable about suggesting new, personally appealing ideas that draw from and hone their skills or expertise. This in turn feeds into a continuous cycle of self-motivation that leads to long-term enjoyment of one's work.

\section{Conclusion}

The ideology and qualities of a leader play an important role in how they are perceived and if they are successful in the long-term. Although the idea of management has scorned generations over time by coming off as "coercive" or "authoritarian" (Evans \& Greenwell, 2000, p. 5), management can be encouraging, helpful, and a positive force in workplaces. Pamela Wright showcases just how that is possible. Wright's leadership style, supported by management theory, demonstrates a successful way to lead a library and information science organization. 
The key element of her style comes from her focus on creating a welcoming, collaborative culture among her staff. By encouraging radical candor and a certain amount of autonomy, Wright wishes for her staff to take an active role in innovation for the National Archives. That role requires staff to feel comfortable in offering critical feedback and in their own personal ability to work on projects outside of their normal positional scope. Creating this culture also means that Wright must be hyperaware of the importance of reinvesting in her staff to contribute to both staff and organizational long-term success. By encouraging personal staff development and allowing staff to explore a sense of purpose, Wright taps into the increasingly crucial role that emotional intelligence plays in effective leadership.

During her almost two decades at the National Archives, Pamela Wright has not only strengthened and developed her personal leadership style, but she has also created a culture that in turn has allowed her staff to do their best work and succeed in their own right. Passion for the work may have driven her to begin a career at the National Archives, but that passion has expanded to motivating and encouraging her team's ideas and development, leading to a belief that innovation happens not by simply "getting things done through people" (Evans \& Greenwell, 200o, p. 5) but by building the future through people. 


\section{Author bio}

Selena St. Andre is a MLIS graduate student at the University of Maryland's iSchool with a focus on Archival and Digital Curation. She also holds a BA in History from James Madison University. She plans to pursue a career in archives and is interested in increasing accessibility and knowledge of archives as well as expanding the archival record to be fully inclusive and address past injustices of excluding marginalized communities. After graduating, Selena is interested in working in a historically based academic or government archives.

\section{References}

Arnold, H. (2016, August 2). Critical work: Archivists as maintainers. Hillel Arnold. https://hillelarnold.com/blog/2016/o8/criticalwork/

Bolman, L. G., \& Deal, T. E. (2017). Reframing organizations: Artistry, choice, and leadership. ( $6^{\text {th }}$ edition). Jossey-Bass.

Evans, G. E., \& Greenwell, S. (200o). Management basics for information professionals. ( $4^{\text {th }}$ edition). American Library Association.

Ferriero, D. (2020, October 15). Animated archives: Meeting people where they are. The National Archives: AOTUS Blog. https://aotus.blogs.archives.gov/2020/10/15/animated-archivesmeeting-people-where-they-are/

Geary, J., \& Hickey, B. (2019, October 16). When does burnout begin?: The relationship between graduate school employment and burnout amongst librarians. In the Library with the Lead Pipe. http://www.inthelibrarywiththeleadpipe.org/2019/when-doesburnout-begin/

Kowalski, M. (2017). Breaking down silo walls: Successful collaboration across library departments. Library Leadership \& Management, 31(2). https://doi.org/10.5860/llm.v31i2.7202

Olson, D., Meyerson, J., Parsons, M. A., Castro, J., Lassere, M., Wright, D. J., Arnold, H., Galvan, A. S., Hswe, P., Nowviskie, B., Russell, A., 
Vinsel, L., Acker, A., et al. (2019). Information maintenance as a practice of care: An invitation to reflect and share. Zenodo. http://doi.org/10.5281/zenodo.3251131

Martin, J. (2019). Emotional intelligence, emotional culture, and library leadership. Library Leadership \& Management, 33(2). https://journals.tdl.org/llm/index.php/llm/article/view/7329

National Archives and Records Administration. (2018, February). 20182022 strategic plan. https://www.archives.gov/files/about/plansreports/strategic-plan/2018/strategic-plan-2018-2022.pdf

Pink, D. H. (2011). Drive: The surprising truth about what motivates us. Riverhead Books.

Scott, K. M. (2017). Radical candor: Be a kickass boss without losing your humanity. St. Martin's Press.

Yao, R. (2018, April 5). The surging popularity of gifs in digital culture. Medium. https://medium.com/ipg-media-lab/the-enduringpopularity-of-gifs-in-digital-culture-54763d7754aa 


\section{Beyond Libraries \& Archives SECTION IV}




\section{Marvin Pinkert}

\section{A LIFE IN MUSEUMS}

Ellen Goodman

Few people I know have their childhood dreams come true. Most children have an idealistic vision of what they want to do with their lives, and then get a reality check once they are out in the real world. Not so for Marvin Pinkert. Growing up in Chicago, his parents would drive by the Museum of Science and Industry (MSI) every week and he would visit it whenever he could. He even went to summer camp on the grounds, spending rainy days in the museum. He fell in love with the place: the exhibits, the hands-on aspect, the learning outside of the classroom, the technology, all of it. When asked what he wanted to do when he grew up, he said "work at the MSI!" Even as a young child he served as a "guide" for his extended family of 35 first cousins.

After getting a BA in English from Brandeis University in Boston, an MA in Japanese Studies from Yale University, and an MBA from Northwestern University in Nonprofit administration, Pinkert eventually talked his way into a job in strategic planning at the museum he had dreamed of working for. Once on board, his combination of ambition, creativity, nonprofit management background, and experience was the perfect mix to enable the museum to become the gold standard for science museums across the country. Many of the exhibits for which the museum is known today - the train, airplane, coal mine, submarine- 
177

were installed or expanded under his watch. Some were temporary and have come and gone, but a large number have shown staying power. As the technology of the 1980's gave way to the major electronic advances of the $21^{\text {st }}$ century, some things have stood the test of time, especially those of a historical nature. Others became traveling exhibits, so people all over the country could experience them.

\section{The Winding Road to the Dream}

Pinkert has a knack for making connections, getting things done, finding the right people to make it work, and finding people and other resources who are willing to fund his projects. This skillset, honed over many years at multiple institutions, has grown and improved over the years as Pinkert took on jobs with more and more responsibility. Pinkert is passionate about museums as an important part of the infrastructure of society. They both preserve the past and teach it. Museums come in many shapes and sizes, with the common theme of being a collection of artifacts of cultural or historical importance. Often, but not always, these are focused on a specific geographic area or a certain topic. A city could have a different museum for every ethnic group present in the community. Preserving cultural artifacts is a tangible way to preserve the past for future generations and to understand where we came from.

While working at the MSI was his childhood dream, he did not necessarily think it was realistic. The road to the MSI took several detours. He was an English major and received an MA in East Asian Studies from Yale, and started his 
career in foreign service in Korea. His first experience in creating an exhibit was at the American Cultural Center in Seoul. Returning to the States, he worked briefly at the EastWest Center in Honolulu and as the first microcomputer salesman at ComputerLand in Hawaii, before heading to the East Coast to work for Brandeis and Long Island Universities. At both colleges he served under the mentorship of the Dr. David Steinberg. Dr. Steinberg was a mentor his entire career, and when Steinberg moved from Brandeis to the Presidency of Long Island University, Pinkert followed him as his assistant (Steinberg, 2020). This role gave him in-depth and invaluable experience in managing a nonprofit educational organization, raising money, working with people, enacting institutional change, and making connections.

He returned to Chicago to be closer to family and attend Northwestern University MBA School to get a degree in nonprofit management, with the intention of continuing his academic career. The MSI got a new director at that same time, and he convinced the director to hire him in an untitled strategic planning position in 1988 (Schlegel, 200o). Finally, he could see his dream come to fruition. Using his university and foreign service experience and his Northwestern degree, he was able to make lasting changes in the museum's outreach and the quality of its exhibits, setting it apart from other museums with similar mission and resources. His reputation gained traction beyond the borders of the MSI, and soon he was in great demand by many museums for his skill in creating interactive exhibits.

Using the lessons learned from Michael Spock who was one of the leading experts on interactive museum exhibits, 
179

Pinkert figured out how to bring authentic examples of modern technology to the museum, rather than replicas. The impact Spock had on the museum's exhibits and programs gained nationwide recognition. Spock spent 20 years at the Boston Children's Museum, followed by a 10year stint at the Field Museum in Chicago (Chicago Tribune, 2018). Spock was one of the founders of the Boston Children's Museum in its current form, a hands-on experience with interactive exhibits. It was at the Field Museum that Pinkert and Spock became collaborators and colleagues. Spock was an important mentor, on the cutting edge of hands-on, interactive museums. He revamped the Boston Children's Museum into a major cultural institution, and elaborated about how a museum director is responsible for many moving parts (Spock, 2013). After Spock left the Field Museum, he stayed on in Chicago at Chapin Hall Research Center, so Pinkert still had access to his invaluable expertise. The mission of the MSI is "inspiring the inventive genius in everyone." By using the example of geniuses who came before him, Pinkert had a blueprint for creating interactive and enlightening exhibits that would hold the attention of young and old alike.

Another invaluable resource was The Museum Experience, revised as The Museum Experience Revisited, by Falk and Dierking (200o). This has become the "bible" for museum educators, in order to better understand why people attend museums, what they are looking for, what they enjoy most, what they would like to see improved, and how they would improve the experience if it were up to them. The book emphasizes that museums have become a necessity in society rather than just a nice perk, and it is important that museum staff create the most meaningful possible 
experience for visitors. Many visitors include museums as part of their vacation itinerary, while locals will often spend as much time as possible there in their free time. Museums have come to play a crucial role in modern society because they cover so many topics and appeal to so many groups of people. Having first encountered Falk at national museum conferences while still at MSI, during his years in D.C., Pinkert was fortunate to strike up a personal friendship him.

Starting with the MSI, every position Pinkert has had until his current one was custom-created for him. He did not advance his career through existing vacancies. His reputation for leadership, fundraising, managing people, connecting, creative exhibits, and easily switching between frames as the situation dictates, made him a sought-after leader in the field of museum management. He has mastered the art of networking, which can be crucial in a field like this which is notorious for having few upper management vacancies at any given time. He applies the human resources frame on a regular basis in his work, as it is important for leaders to have good people skills in order for them and their organizations to succeed (Bolman \& Deal, 2017).

I got the impression Pinkert was implying, "It's better to be recruited than to interview." Understanding the structural frame is essential in addition to the human resources and political frames. As the director of programs for the MSI, he had almost infinite flexibility to curate any event, exhibit, and program within reason that fit the mission and structure of the museum. Creativity and collaboration played in important part in the success of both permanent 
181

and temporary exhibits and public programs. Pink (2009) touches on how these skills are essential for being a Type-I manager: Autonomy (being responsible for your own projects and decisions), Mastery (being very good at what you do, in this case curating hands-on exhibits), and Purpose (which is well-suited to a museum career). Rather than just trying to turn a profit, GLAMS managers often feel that they have a calling, a purpose for a greater good. Give people of all ages an exciting experience where they will learn something, understand the world around them, and be inspired. Pinkert definitely feels that the cultural heritage field is his calling. He remained Vice President of the MSI until 1999.

\section{Beyond the Dream}

After relocating to Washington, D.C. and an interim stay at what became the National Children's Museum, Pinkert took on the role of Director of the National Archives Experience at the National Archives in Washington, D.C. Here his impact was profound. He took on a role that did not exist to create something that did not exist-a museum within an archive. Many organizations have archives, holding the recorded history of the organization. The National Archives is a standalone institution that holds the recorded history of the whole United States. It was never originally intended to be a museum; its mission was and still is to be a repository of documents of events, people, and companies that form the record of the United States. But Pinkert and the team that hired him realized that the National Archives held certain documents that the public would want access to, and it would behoove them to put them on display. 
Displaying historic documents on parchment or paper requires a lot more effort than displaying indestructible steel equipment, for example. They must be in secure, protective displays with low light, so the material does not disintegrate.

Turning the National Archives' first level into a publicfacing museum was no easy task. It required a great deal of political maneuvering and looking hard through the symbolic frame. Some of these are transformational documents: The Constitution, Declaration of Independence, and the Bill of Rights, among others, that have longstanding symbolic significance to the founding of our country (U.S. National Archives, n.d.). This transformation also touched on the structural frame, because the institution was changing the way it operated completely.

Prior to this re-imagining, the Archives was basically an office where federal workers managed important documents pertaining to US history, individuals, land, events, treaties, and so forth. Though more than one million visitors came to the Rotunda to see the Charters of Freedom each year, management had viewed them as a necessary but regrettable distraction from the real work of the Archives. Turning the first floor into a public-facing museum meant increasing awareness of the Archives core mission to the public, while maintaining strict preservation guidelines for the displayed objects. Looking at this transformation and the resulting museum through all these frames enabled Pinkert to approach museums and transformation from different perspectives and adjust his approach accordingly. 
183

As an employee of the National Archives, Pinkert's responsibilities included giving tours to incoming senators and Members of Congress. One of these was Maryland's Senator Ben Cardin. During this tour, Sen. Cardin brought his daughter, Deborah, who worked at that time as Director of Education for the Jewish Museum of Maryland (JMM). This chance encounter would lead to a professional friendship and a heightened awareness of the potential of the Museum, that six years later would lead to Pinkert applying to be Executive Director. Though the institution was smaller, the position involved even greater autonomy than the National Archives, and in Pinkert's view "a chance to make a real difference in the future trajectory" on the institution.

Pinkert realized it would be a good fit and took the position in 2012, where he remains to the end of this year. At that time, he will finally retire from a long and fulfilling career in museum management. It was Pinkert's position at the JMM that initially caught the author's interest, and I contacted him with no knowledge of his prior experience at the Archives or MSI, or that he attended my alma mater. Upon learning this history and seeing his resume, I realized I was speaking to someone who knew how to make connections and use all available resources to turn his visions into reality. Pinkert has an innate ability to connect to people and resources. The JMM fills a specific niche and caters to a certain target audience, but he has proven that his uncanny ability to transform cultural heritage institutions is not confined by physical size, budget, mission, collection size, attendance, or any of the other variables unique to individual institutions. 


\section{Leadership Style and Philosophy}

Pinkert explained that the best way to lead a cultural institution effectively is to know the right people and be able to make your case convincingly. At the JMM, there is a permanent exhibit about the history of the Jewish community in the Baltimore neighborhood where the museum is located, adjacent to Little Italy. There is not much of a Jewish community there anymore, but the Greater Baltimore Jewish community is still thriving in the suburbs, creating a built-in target audience. There is a changing exhibit space as well, and this is where Pinkert's people and networking skills are most apparent. Once the temporary exhibit topic is determined, he wastes no time finding the right people, the right funding sources, the right designers, and the best curators for that particular exhibit. Some of the staff for an exhibit are full-time staff of the museum, but others are hired specifically for their expertise on the topic of the exhibit.

Pinkert has mastered the art of negotiation. He does not make final decisions about what the temporary topic will be. This is determined by team consensus, availability of resources, staff members' personal knowledge or interest in the topic, and potential of interest to the public (Pink, 2009). Ideally it should have local relevance and it must be somehow related to Jewish culture. Some are traveling exhibits, but with a local twist. Some are built from the ground up at the museum.

Any Jewish museum, or museum specific to a culture, is going to rely heavily on the symbolic frame. The symbolic frame is what brings a group together and differentiates it 
185

from other groups, provides a sense of belonging, and tries to bring order out of chaos. Meaning, belief, and faith are its central concerns. Museums are places to keep objects of significance to whatever the topic or mission of the specific museum is. In the case of a Jewish Museum, the objects relate to the culture in some way. The JMM's mission is not only culturally but geographically specific. As the Executive Director, part of Pinkert's job is to make sure the items in the collection relate to both the Jewish community and the state of Maryland in some manner. Because a culturespecific museum like the JMM relies on the symbolic frame so heavily, it is important that the museum and its exhibits thoroughly explain the symbols of the culture to the public. The symbolic frame can apply to both the public facing aspect of a museum or library or the employee side.

As Bolman and Deal (2017) discuss, many well-known corporations have a long symbolic significance in culture. The symbolism affects public perception and reputation of the company and its products. They mention many such companies: Ford, Amazon, Apple, Zappos, etc. The reputation may be related to the product they sell, or the importance placed on customer service, or what it is like to work there.

In the case of culture-specific museums, the collection is going to be inherently symbolic. Knowing that many visitors the JMM will feel a symbolic connection to the collection, Pinkert has emphasized on its importance. Thus the museum took on a major challenge when it was created, initially to preserve the history of the Jewish community of the immediate surrounding area, and gradually expanding to represent the history of the Jewish community of the 
entire state. It also manages the two adjacent synagogue buildings. One is vacant and used for programs; the other is functioning and one of the oldest still in operation in the country.

Over the years, Pinkert also wore several other hats. He served as Vice President, Greater Baltimore History Alliance and member of the Executive Committee of Historic Jonestown, Inc as well as a member of the Tourism Subcommittee of the Greater Baltimore Committee (that city's chamber of commerce). These roles enabled him to connect professionally with the larger community and use his platform to benefit the neighborhood the museum is trying to preserve.

Symbolism in Judaism is not only about objects, however. Ritual and values also play an important role. The symbolic frame inherent in a Jewish museum also spills over to its leadership. Decisions-such as what exhibits to show in the temporary space and what to include in those exhibits, what to keep in the permanent collection and what to put on display, how detailed to make exhibit captions-all those day-to-day decisions, affect the symbolic frame. Jewish museums, including the JMM as well as the Jewish Museum Milwaukee and the Maltz Museum of Jewish Culture in Cleveland, among others, often serve multiple purposes. They are places to preserve historical artifacts from a bygone community and introduce the symbolism and ritual to those who may be unfamiliar with them, as well as provide a living lab to share how life has evolved for that particular culture. 
A good leader at a museum like this needs to find the balance between explaining artifacts so an unfamiliar visitor can appreciate them, and not be condescending to those already familiar with the culture. In this type of situation, the human resources frame plays an important role. It is virtually impossible to be the executive director of a museum or library and use only one frame. In Pinkert's case, he is managing people and money, making exhibition decisions, coordinating the collection, delegating responsibility, and using connections to find the right experts for the right programs. The political frame is all about connections and allocation of resources. Running a cultural institution is very dependent on the political frame. Directors of libraries and museums need to be skilled at doing more with less. Relying on grants, donations, and admissions makes budgeting unpredictable and challenging.

With nonprofit organizations, the goal is not to make as much money as possible, but rather to create the best organization for the mission you have chosen and ensure you have the funds to make it happen. Limited resources are a fact of life for these institutions, which means one must make decisions every day about how to best use the resources one has. Pinkert has always been good with raising the funds needed to succeed with his projects. Even though a development role involves asking for donations rather than selling a product, it is necessary to act as a salesman in addition to your other responsibilities. The director needs to make a case for his institution in such a way that donors believe it is worth funding. 
Pinkert is very skilled in navigating the political frame and understanding how to wield power so that you can stay in control of your institution without alienating your staff. This is a crucial skill for leaders. Throughout history, we have seen how power unchecked can result in a dictatorship. The first thing that comes to mind when most people hear politics is government, at any level. But all institutions have governing bodies, which can assert any level of power and control, depending on how leaders approach the political frame. Having no parameters can result in chaos but having an oligarchy can result in oppression.

Leaders need to find the balance between exerting too much and not enough power. Pinkert has found that balance where he has gained the respect of his peers without being so laissez-faire that the staff feel directionless. This skill, acquired over years of experience creating exhibits, finding funding sources, hiring experts, and convincing upper management to agree to out-of-thebox thinking on many occasions, has enabled him to create the kind of museum he would be excited to visit. He might throw out a suggestion for a temporary exhibit, and get feedback as to who might have contacts in that area that could provide expertise.

He does not pretend to know all the answers. The JMM is small by museum standards, but it has a robust development office and corporate sponsorship that enables it to thrive in its niche. Unlike other institutions that took a hit during the COVID-19 pandemic, The JMM took it as an opportunity to improve its digital content and had no furloughs or layoffs, due to grants and loans. It reopened in 
189

July 2020 and had a new temporary exhibit, "Jews in Space," by September 2020.

Museums dedicated to a specific culture or group of people are almost by definition going to have a more symbolic and cultural focus than a traditional history museum. History museums, such as those of the city in which they are located, will often put emphasis on events and milestones and the city's participation in national events such as wars and natural disasters. Culture-specific museums, on the other hand, focus more on everyday life, using individuals as case studies for what the typical lifestyle looked like, with artifacts such as clothing, photos, maps, event programs, and other ephemera that mark the passage of time. It might look at how national events such as wars affected individual families, rather than entire communities. A major challenge that all cultural institutions wrestle with every day is: What is important? Museums usually serve the dual purpose of education and research. Museum managers have to continually ask these questions: What gets collected?, What gets displayed?, What gets discarded?, What gets stored offsite?

While the JMM has a fairly narrow focus, items pertaining to the Jewish community in Maryland, the form those items might take is very broad. It could be a program from a synagogue confirmation ceremony or a shofar, a ram's horn blown at the Jewish holy days, a photo of a butcher shop that used to be the heart of the neighborhood, or an old kiddush cup (a ritual wine cup). Is the goal to have a large collection of a certain ritual items to show the variety, or just one or two to give examples of the types of ritual objects the community used? Collection sources can be 
estates of people who want to leave their entire collection to the museum, even if much is not relevant. How to manage space, how to manage and preserve collections, how to manage people, what a new exhibit should look like-these are all part of the "what is important" question.

A good leader realizes that what is important is subjective and can be a matter of opinion. Getting consensus on this issue is part of the political frame. It is important that good leaders listen to their colleagues and be open to new ideas and change. Kowalski (2017) addressed change, how difficult it can be, and how important it is to get buy-in from colleagues in order to break out of the silo mentality. With a museum, there may not be constant overhaul of the entire system, but every time there is a new exhibit, the director needs to get buy-in from the staff. Every temporary exhibit requires an almost endless number of decisions unique to that specific topic. Each individual item is curated to ensure it fits in with the rest. These are all political decisions and therefore viewed through the political frame.

What might be important to one person may be of passing interest to another. The museum and its staff act as representatives of the collection to the public. Sometimes, to demonstrate the whole story in a temporary exhibit, it is necessary to acquire items temporarily from outside sources. Ideally, this means borrowing it from another institution. In order to facilitate the smooth transfer of items in these situations, it is important that all parties cooperate, compromise, and agree to the terms of the lent item. In an ideal world this would be straightforward, but organizations can be understandably protective about their collections and hesitant to let them go. This is when 
191

political negotiating skills are especially important. Pinkert has demonstrated time and again his skills in convincing partner institutions to lend him what he needed pull off a comprehensive exhibit.

Pinkert has shown the qualities necessary to be a good leader in a cultural heritage institution throughout his long and successful career in museum management. He has reinvented himself as he reinvents the organizations he has been responsible for. He has gone above and beyond to create meaningful experiences that patrons find rewarding, educational, and informative. Using every resource available, he has put together exhibits of lasting significance, providing insight that visitors remember for years to come. Along the way he has made important connections with experts in the field, inspired generations of museum goers to expand their horizons, and changed what it means to have an interactive experience.

Unanticipated obstacles such as COVID-19, rather than being a deal-breaker, gave the museum time to regroup, fundraise more, and prepare a stronger exhibit for when they did reopen in the summer of 2020 . What could have been a liability became an unexpected gift of time they were able to use to mobilize additional funds and prepare.

Another quality that Pinkert has consistently demonstrated is his ability to cross generations and make museums accessible to all ages. Jerry Seinfeld once said, "There is no such thing as 'fun for all ages." Pinkert would respectfully disagree. His philosophy has always been that people of all ages enjoy learning in a hands-on environment. Freed from the constraints of tests, grades, and studying, all generations 
have something to learn from understanding how things work and how we got here. The museums Pinkert has worked in have not, for the most part, been specifically for children, but it is important to him that children benefit from them as much as adults. This can be a difficult balance-presenting information in such a way that children are interested, and parents and adults are not bored. Having the leading expert in children's museums as your mentor ensures that the exhibits will appeal to children, and Pinkert's experiences at the Archives and MSI gives him the background to make displays interesting for adults as well.

\section{Author bio}

Ellen Goodman is a first-year student in the MLIS program at the University of Maryland. She received her BA in anthropology from Brandeis University and holds a Master's in Urban Planning from UCLA. She is planning a second career in archives and records management. A native Marylander, her roots in Jewish Baltimore go back over 100 years.

\section{References}

Bolman, L. G., \& Deal, T. E. (2017). Reframing organizations: Artistry, choice, and leadership. ( $6^{\text {th }}$ edition). Jossey-Bass.

Chicago Tribune. (2018, December 25). Michael Spock.

https://www.legacy.com/obituaries/chicagotribune/obituary.asp $\underline{x} ? \mathrm{n}=$ michael-spock\&pid $=191078788$ 


\section{3}

Falk, J. H., \& Dierking, L. D. (200o). Learning from museums: Visitor experiences and the making of meaning. AltaMira Press.

Golster, M. (2014, April 2). The life of a retired LIU President. The Pioneer. http://liupostpioneer.com/the-life-of-a-retired-liu-president/

Hackman, T. (2017). Leading change in action: Reorganizing an academic library department using Kotter's eight stage change model. Library Leadership E Management, 31(2), pp. 1-27. https://doi.org/10.13016/M2XZ7B

Kowalski, M. (2017). Breaking down silo walls: Successful collaboration across library departments. Library Leadership \& Management, 31(2). https://doi.org/10.5860/llm.v31i2.7202

Museum of Science and Industry, Chicago. (2021). About us. https://www.msichicago.org/explore/about-us/

Pink, D. H. (2009). Drive: The surprising truth about what motivates us. Riverhead Books.

Schlegel, C. (2001). Having a ball: Marvin Pinkert '84 redefines museum management. Kellogg World: Alumni Magazine. https://www.kellogg.northwestern.edu/kwo/winoo/facultynews /pinkert.htm

Spock, M. (2013). Boston stories: The children's museum as a model for nonprofit leadership. Boston Children's Museum.

Steinberg, D. J. (2017). Preface to the future: A history of LIU through the turbulent sixties. http://www.davidjsteinberg.com/en/bio

U. S. National Archives. (n.d.). Creating the public vaults of the National Archives. Google Arts and Culture.

https://artsandculture.google.com/exhibit/\% $\mathrm{C}_{2} \%$ Aocreatingthe-public-vaults-of-the-national-archives-u-s-nationalarchives/4wLio7dH4zb7JQ?hl=en 


\section{Management \\ Through Alignment}

A PROFILE ON THE CAREER OF TOBY

PEARLSTEIN, PHD

Rebecca Fink

Being a manager is like living; you are always learning and always changing and always adapting to the things happening around you. This paper takes a hard look at that lifelong learning through the career of Dr. Toby Pearlstein, a retired information professional with a long career in managing information services, both in a state-level government library and in the private-sector in a global organization, and her philosophy on managerial success.

Dr. Toby Pearlstein is a lifelong information professional with a Masters in History from the University of New Hampshire, a Masters in Library Science from Simmons College (now Simmons University), and a PhD in Library Science from Simmons College (now University). She has written/edited multiple articles and books on handling and managing different specialized libraries often supported by a network of professional colleagues as well as her own experiences in adaptability and alignment with her organization's mission.

This profile will break down her professional career as revealed through an interview, starting with her introduction to information management as an archivist 
195

and records manager, and will emphasize her journey as a lifelong learner and her overall take away on management styles to best succeed in an information institution. This paper will use managerial framework definitions and break downs from the 2013 textbook, Reframing Organizations: Artistry, Choice, and Leadership, as the foundation for comparing Dr. Pearlstein's own understating of management and the emphasis she places on certain aspects of the job. I will also include references on management styles and function in information management settings concerning Dr. Pearlstein's understanding of the shift in managerial priorities in the current professional atmosphere.

\section{Becoming a Manager}

Dr. Toby Pearlstein did not start her career wanting to be a manager. Yet as she grew in her career handling day-to-day tasks and operations, as well becoming a leader in her field, being able to articulate the vision of the organizations in which she worked and supporting that organization's success, became the foundation on which she stood (Matarazzo \& Pearlstein, 2016). Dr. Pearlstein started her career like many librarians, attempting to do something else. Her original goal was to be a historian, and with an MA focusing on Black History, she found that there were not many opportunities available to her. Through sheer luck, while working in an interim job at University of Massachusetts/Boston supervising a computer lab, she was introduced to the idea of library school as a good way to put her history degree to work. While she had used archives for her Master's, it had never occurred to her until then that it 
would be a good application for her history and research background. After completing an informational interview at Simmons College on the subject, she found this track to be a perfect fit for her career aspirations.

Dr. Pearlstein entered Simmons in 1976 and went through the standard Master's program for librarians at the time. The nine-course program provided a broad introduction to library work in all types of organizations, though she chose not to specialize in a specific type of library, rather exploring a variety of possibilities and, honestly, just wanting to get a job in the field. In 1977, with an MLS in hand, Dr. Pearlstein got a job as a Survey Archivist working for the Archives of the Commonwealth of Massachusetts. When she started, everything was a learning experience. She (2020) describes her time there as working "with great people. 'Roots' had just burst on the scene and there was a lot of genealogy research I got to do, along with a lot of other reference and research as well as records management experience." Dr. Pearlstein got a well-rounded education, not just in archival work but also in records scheduling, data capture, and how to collect and manage records through their life-cycle.

During our interview, Dr. Pearlstein told me a story about a difficult man who worked directly under the Curator while she was at the Archives. This was her first step in helping to develop her ideas about how someone became an information professional and what skills people had to gain and offer in a library or archives setting. With little background in what made a good manager (except by observing how her manager worked), this was the start of her managerial journey. After working there for two-and-a- 
half years, she became frustrated with governmental politics and transferred to a more specialized library-centric position, also in the public sector.

\section{Working in Transportation: Government Agency Librarianship}

Dr. Pearlstein's next job as a solo librarian at a local regional planning agency in Boston continued to expand her understanding of the role of a manager. As the person in charge of the department, Dr. Pearlstein had to do everything from cataloging and reference to research, outreach, and agency communication. Dr. Pearlstein was in charge of it all. To her, this was one of the best jobs she had in terms of broad experience. She learned every skill one needed to run a library. It was a great education for managing library services. It was the first time she had to take full responsibility for all facets of the service. She was in charge of managing the schedule and task for herself and one other person on the team; she was in charge of budgeting; she was in charge of reaching out to other libraries and organizations the agency was trying to work with.

This was her introduction to being a manager. She learned vital skills of managing upwards, which would become fundamental in her managerial style and beliefs later on in her career. Managing upwards is a skill attuned to the Political framework of management. The Political framework, as defined in Reframing Organizations: Artistry, Choice, and Leadership is "the process of making a decision 
and allocating resources in a context of scarcity and divergent interests" (Bolman, \& Deal, 2013, p. 179). Extrapolating outward is the foundation of any organization in terms of how it functions at varying levels. Most organizations manage downward with upward political management being reserved for pitch meetings surrounding budgeting and project projections. When it comes to a library, especially in a governmental setting, being able to influence and persuade those above you is essential to acquiring resources not just to manage but to maintain the department/service you are representing. Dr. Pearlstein believes that being able to connect with and converse with those above you is instrumental in a library setting. This skill was instrumental in Dr. Pearlstein's ability to run her library and played a huge role in her continuing career, specifically in the positions she would later fill.

Through her work in this regional agency, Dr. Pearlstein created a network of people in state government and especially in the cabinet-level Executive Office of Transportation and Construction. This began to build credibility for the role of an information professional serving Transportation agency employees. At this same time, the Executive Office was building a new centralized "Transportation Building" to bring under one roof all the transportation agencies. Part of the vision of the Secretary of Transportation was the creation of a new, centralized library absorbing several disparate agency information collections into one facility. Dr. Pearlstein was hired in 1983 to be the Chief Librarian and Archivist to create this new centralized library from the ground up. She was in charge of everything from understanding, merging, and organizing these different collections to figuring out how this new 
199

library was going to operate (what services were needed, who was going to work there, what types of people and positions were needed, who were these people going to work for, who was going to fund them, what was the collection going to be, how would it be cataloged, etc.)

Several projects had to be accomplished to get this library up and running. The biggest downside was the fact that the library space was created by architects, not librarians. Dr.

Pearlstein mentions how this was a good learning experience for her as she had to learn how to deal with architects, contractors, building management, and so on. Learning to coordinate and best utilize people external to the library as resources was a type of practical learning she would continue to build upon throughout her career. It is this pragmatic, on-the-job learning, especially how to deal with different people and conflicting priorities that helps one succeed in managing an information service in any organization. Management of a facility depends on flexibility as the space one is managing will change over time, and its original conception is not what it will always be used for as the institution settles and grows (Evans \& Greenwell, 200o). This is also one of the first times Dr. Pearlstein started to be aware of the power of network connection and credibility when it comes to competence and intra-institution cooperation.

The Secretary of Transportation fully supported this centralized library and that went a long way in the creation of this multi-agency endeavor. Dr. Pearlstein was in charge of both the creation of the new services and the day-to-day operations, which led to much coordination between different departments and agencies. Everyone was funded 
under different agencies, so there was a blend of powers that led to an interesting dispersed hierarchy. If taken from the idea of a Structural frame, that of dividing work between people and coordination in management and productivity, the specific all-channel network that was created around the central library was a delicate yet effective dance that led to an interesting dispersal of power (Bolman \& Deal, 2013). Dr. Pearlstein reported daily to the person who managed the building, not the agency who directly employed her, and those who reported to her were in positions funded by various agencies. Despite the complexity of the system, it all worked well, and she spent ten years running the facility that way.

Throughout her tenure at the State Transportation Library, the staff grew to include a professional cataloger, a law librarian, a handful of uncredentialled (no MLIS degree or equivalent) people with focused research skills, i.e., transit history. In turn, Dr. Pearlstein began to master managing a team with diverse capabilities and learned how to utilize their skills to get the best work out of them (Matarazzo \& Pearlstein, 2016). This concept was a hard one to fully embrace but turned out to be one of the most useful dynamics in successfully managing her team. Once again, we turn to Bolman and Deal and their definition of the Human Resources frame to best understand the benefits of learning how to utilize employees. This lens emphasizes the importance of understanding those working in a company as people, not just workers. Their textbook stresses the impact of investing in the skills of your people and how that can lead to better returns for the company overall (Bolman, \& Deal, 2013). 
In hindsight, her experience at the Archives as well as at the Transportation Library led Dr. Pearlstein to understand the importance of working with the people and resources you have. You should not wish that they are something or somebody else. Rather, you need to learn how to effectively work with who they are and the skills they have to get the most out of them for the overall benefit of the team and to achieve success. She remarked that this is something she wished she had understood more at the moment, but instead that knowledge came slowly to her. Making sure those working under you do not just feel like they are a member of the team but truly are being included in the group, can go a long way in maintaining your department and getting things accomplished. The Structural frame says, "Suitable forms of coordination and control ensure that diverse efforts and individuals and units mesh" (Bolman \& Deal, 2013, p. 48). This is something Dr. Pearlstein is not disputing. Yet, just like many other managers, understanding those individuals is the best way to create the cohesion that allows for the type of coordination required to manage a group of individuals successfully.

Three years into her work at the Department of Transportation, Dr. Pearlstein said she realized she did not have enough managerial experience. If she wanted to continue moving forward in her career, she needed to go back to get her doctorate. At that time, Simmons offered a doctoral degree focused on management as opposed to scholarship. This is where the idea of lifelong learning solidified for Dr. Pearlstein, and she makes a point to inform the information professionals she mentors or connects with that to best succeed as a manager they must take steps to continue and expand their professional 
education. Getting her PhD helped expand her network across different organizations and countries, allowing her access to differing ideas and resources. Working on her $\mathrm{PhD}$ provided her the ability to write about her work at the Transportation Department and figure out how to manage this new library to best bring all their collections together and provide information services to both the agencies and the public. Since this library was a new resource for the intended audience, this was a big hurdle in her job and she spent a lot of time trying to market the benefits of the services being offered.

Any librarian can tell you that they spend many hours on outreach, making sure people know what benefits their services could provide, and Dr. Pearlstein's institution was no exception. Dr. Pearlstein participated in a wide range of programs across the agencies outside the library as well as sponsored activities that highlighted library services. She worked on raising the library's profile and did anything she could to get people in the door of the library and utilize its services. Her doctorate was a multi-purpose degree in the end. It helped Dr. Pearlstein learn to be a better manager in terms of practical management styles; and through the creation of a network of industry professionals she could call on and utilize, it also raised the standing of the Transportation Library, increasing the organization's creditability as a serious institution. The doctorate also served as a personal career achievement for Dr. Pearlstein and also had a significant impact on the target audience of agency employees by creating an understanding in them of the education it takes to provide an effective information service. The Symbolic frame work of Bolman and Deal tells us that the Image or perception of an institution, both from 
the outside and within, can go a long way in motivating and supporting the organizations mission and success (Bolman \& Deal, 2013). Bettering yourself for the organization can help build that image and create an atmosphere of importance, both in terms of your job and the overall work your organization does.

One of the biggest problems Dr. Pearlstein sees in many information professionals today is a lack of ambition to take on management responsibility as well as a lack of understanding on how to market themselves and their services as being professional. Continuing one's education as a manager or higher up in the library field can benefit the organization as much as it can the individual. Joining professional associations like the Special Libraries Association (SLA) and gaining resources through network connections for the benefit of your own growth and for your employer are crucial. They can help demonstrate the library's contributions, especially when the credibility or relevancy of the services are called into question. When Dr. Pearlstein got involved in SLA, for example, she immediately had people to call on as resources locally, nationally, and internationally for the benefit of her organization and in turn, could be a resource to them.

For her personal and professional growth, this is where and when she decided that she wanted to take a bigger role beyond her "day job" and get more involved in managerial positions in SLA. Getting involved in leadership roles at SLA was a great opportunity to learn how to interact as a professional and experience how to manage on a higher level. None of these associations ever have enough people to volunteer, so this allowed her to seek positions that led to 
her continuing education in managerial skills in a nonwork, but still professional, environment.

All of this being said, Dr. Pearlstein was very clear about how, though she had to be aware of and deal with politics in her work environment, she had no patience in constantly fighting for the relevance of the library's services. Working in government meant that her job was at the whims of those who were elected to office, and just around the ten-year mark in her time at the Department of Transportation a new Governor was elected. Anticipating an increasing lack of support for the library, Dr. Pearlstein realized it was only a matter of time before the library might be written off, politically speaking. Some of the best advice Dr. Pearlstein provided when on the topic of external support of libraries and information services goes as follows: "No matter how good a manager you are and no matter how good the services are that you offer, someone who is not attuned to the value that vetted information can provide them is never going to be supportive" (Pearlstein, 2020). She would go on to learn two very important managerial skills that would attune people to the importance of that work, skills that she credits with being key to successfully managing a library within an organization.

\section{Bain \& Co., Inc. and the Corporate Library World}

Speaking again to the value of networking, through a Canadian colleague/friend she had made in SLA, Dr. Pearlstein received a call that would take her out of 
government work and into the private sector. Bain and Co., a global management consulting firm, was looking for someone to help build a world-class information services operation. As it turned out, Dr. Pearlstein's credentials and work as the Chief Librarian and Archivist of the Transportation Department made her uniquely qualified for the position. Now for the first time, she was working with someone who had a vision for what Bain Information Services needed to become and was also willing to be educated on and supportive of what it would take to make it happen. While Bain already had a large library in its global headquarters in Boston, and a few small libraries in offices elsewhere in the U.S. and Europe, they wanted a manager who had had experience working with disparate groups to mesh them into a centralized service that would become a global resource. Though this was one of the reasons they wanted her, the drawback was that Dr. Pearlstein had never worked in a business library before. The headquarters library had suffered cutbacks in the early 9o's, and Bain wanted to rebuild and branch out. The good news was that they knew the value of a professional librarian and the services that could be offered.

The move to Bain meant Dr. Pearlstein had to learn not only how to be a librarian specializing in business, but how to be a librarian in a private company, and how to manage on what would potentially be an international scale. Adaptability in her role became key as she went from an annual acquisitions budget of $\$ 5$, ooo (does not include personnel or non-acquisition costs) to a budget of millions of dollars, with an experienced professional research team and organizational expectations for growth as Bain stretched out its services internationally. This was the pre- 
Internet/desktop era, so competent research by Information Services was instrumental to the firm's success. As the manager of the Boston team, Dr. Pearlstein had to both manage the researchers and learn to be a business researcher at the same time. She was the leader in connecting the different offices and bringing in resources that could eventually be shared across those offices. That started her on a path to learning how to negotiate with vendors, journal providers, and the like, and learning how to interact with all levels of consulting staff. Learning to interact with research staff who were more skilled than she was, and most importantly learning how to communicate in all directions (especially regarding budgeting) in an organization that was very different from a government agency setting was crucial.

Budgets represent three basic ideas: "planning, coordinating and control" (Evans \& Greenwell, 2000, p. 256). Library budgets work through dispersal as the amount of money is decided prior to the allocation of the fund. Proper allocation of money and the ability to negotiate for more funding is a big part of running a library. Limited funding is the biggest challenge (Evans \& Greenwell, 200o). You can learn to understand the fundamentals of a budget, but until you get into an organization and understand their form of budget and their form of performance reviews, you cannot be able to properly work within the expectation set for your department.

Over her 15-year tenure at Bain, Dr. Pearlstein and her team took the whole library operation global. During that time the Information Services team grew from about 15 people across less than eight offices to 65 researchers across 35 
offices - all of whom were focused on developing and providing information services that would contribute to the success of the firm's work with its clients. One of the most important lessons she says she learned during that time was that without a great team of people supporting and working with you toward the same goals, hashing out disagreements and different philosophies and styles, something on this scale could not have been accomplished.

This is where the philosophy of "Alignment" comes in as a management technique. The concept and philosophy of alignment became a byword for special libraries in particular as a result of a significant study conducted by the Special Libraries Association that identified a disconnect between what the customers of special libraries wanted and what their librarians/information professionals believed they needed. This disconnect was identified as an overwhelming threat for special libraries. So, alignment is what Dr. Toby Pearlstein lives and dies for in terms of her managerial philosophy and preferred style of operation. Through my entire time talking with her, and within almost all of her published writing, this idea that information managers must engage with their stakeholders to ensure that they are using the scarce resources they have to provide services where they can do the most to benefit their organization's goals has always been present (Matarazzo \& Pearlstein, 2014; 2016).

There is no point in creating an information services department or division or organization if you don't know who you are supporting and what they need and what they prefer. You can create something in a bubble, or a vacuum, thinking 'I know what they 
need or I know better than they do,' and then no one comes to use you or nobody comes to support you because there is a disconnect between the two. (Pearlstein, 2020)

This is where many libraries falter. Their mission and goals are not always clearly defined and more often than not do not represent the mission and goals of the parent organization. If your services and what you do are not 100\% aligned with the goals of your parent organization, you will not succeed. That is a hard lesson for people to learn but it is a necessary one, especially today where many libraries are having a hard time justifying their relevance to their organizations. It was stated by Dr. Pearlstein that convincing someone who does not believe in the importance of vetted information is a pointless endeavor, but if you can convince someone of your contribution to the organization in terms of their mission and success, then minds can be changed. Dr. Pearlstein was clear to point out that the firm lost several highly skilled researchers when information services was going global because they could not get behind alignment and felt they knew better than their customers, the consulting staff, and what was needed.

"Now having said that, as a manager, you never want to relinquish your professional responsibilities, capabilities, and credibility" (Pearlstein, 2020). You still need to be able to advocate for what you think is the right thing to do or the right way to do things. You just do not always get your way. This is why managers must find "champions" in their organizations. Unlike the Symbolic frame's "hero," leaders who support the organization's image or brand (Bolman \& Deal, 2013), champions fall under the Political frame as 
people being used, usually through a network connection to lower management to help lift those on lower tiers for political assistance.

Dr. Pearlstein worked under one such champion and they were able to accomplish a lot because, as an upper-level manager, he supported the library and the work being done. In many organizations, there is no champion, no person willing to go to bat for information services, and that is how numerous libraries get marginalized and services reduced. Dr. Pearlstein specifically stated that "when some services switched to the consultant's desktop, the arguments of 'why do we need professional researchers, can't we just Google it" came into play. "Why do we need a professional, became more and more prevalent" and is still a question that many librarians are trying to answer as funding gets tighter and services diminish (Pearlstein, 2020). Especially in a highpower environment like a corporate library, for librarians the idea of outsourced information research becomes harder to justify when their clients can just "Google it." People who are not trained researchers are being asked to do that work, while the professionals are being stripped of their resources, making it harder to provide the valuable services that lead to credible and reliable information results. The librarian and their services lose their reputation as symbols of a reliable information source. This all leads to a shift in the Human Resources frame of managing a library. Managing an information organization became more difficult after the economic downturn in 1991-92. Budgets were tighter, expectations were higher. In many settings, especially as the Internet became more ubiquitous and everyone fancied themselves a "researcher," it was no longer sufficient for the professional researcher to simply provide a 
"data dump" rather than actually going through the research results and providing the most relevant results, becoming a real problem in many organizations. It is not an insignificant challenge today to convince some experienced researchers to accept that change in responsibility for what they are producing as research results.

The rapid advance of information service (IS) related technologies, transition of some services to the customer's desktop, and the need to develop new skills such as Big Data management, makes continuing education (CE) even more critical. End user training had to fold into the services already being offered, leading in turn to another managerial shift. The question now became how do you support your team's lifelong learning in order to keep them up to speed with new techniques and research developments and the need to become trainers. How do you encourage them to go to conferences to network with people, and take the initiative to grow with the changing environment? All of this impacts not only the budget but each individual's professional development and the ability of your department to be successful in meeting the needs of the organization.

This is how and where Dr. Toby Pearlstein finished her career in 2007, working towards creating this global organization, traveling and doing regional and global meetings, and working with the managers under her to discuss the issues forming around the Internet age to best achieve what the firm wanted from them. As each service level expanded, going from the local office, to regional services, to continental services, to global services, her management style had to reflect all of these changes. 
There is no training or trick to a single management style: you just have to learn and adapt to the situation. This is where Dr. Pearlstein's management philosophy solidifies. "You realize that working with all of these diverse groups, you have to be an open person, the kind of person who is willing to be creative or at least accepts someone else's creativity" (Pearlstein, 2020). She admits she was not always the best practitioner of this idea. The pressures of providing what needed to be provided in a short time often affected her managerial style. But when it came down to it, it was a team environment and despite some ups and downs and anxiety, they worked very well together. Even now, years after she has retired, the Information Services operation of the firm is sustainable because it continues to grow and adapt to the needs of the organization.

Dr. Pearlstein retired in 2007 followed by the 2008 recession hitting everywhere. Unlike a lot of other library operations, Bain did not lay anyone off from Information Services. The biggest management success and service success from Dr. Pearlstein's time working at Bain was embedding the value of Information Services into the organization. She utilized the Political frame by advocating for the resources her library needed to grow and be successful for the parent company, and through that accomplishment firm management continued to believe in the overall importance of Information Services as a contributor to the organization's success. So, nobody, though they might have questioned the amount of money they were spending, questioned whether or not they should have information services in the first place. Many institutions and organizations are not that fortunate. A lot of libraries closed or were consolidated because of the recession, and this is 
where that idea of alignment comes into play again. It is not always successful, but you need to be able to say what you are contributing to whatever your organization defines as success, and if you cannot do that, or you do not think it is your job to do that, you are already on the edge of a cliff.

During Dr. Pearlstein's tenure at Bain outsourcing was touted as a way to save money or to more effectively provide library services. Just about everyone in Information Services globally saw this as a potential threat to their positions. As a manager it is your job to be calm in the face of what are very real fears and ensure that what you are telling your team is true and honest to the extent it can be based on what you as a manager know. If you have managed your team well and created the right kinds of relationships where people trust you, you can work together to figure out how to respond in a professional way. This is by far not the only challenge an IS team will face. Of course, there are daily problems and different management challenges, but relationships and alignment are the bottom line for success.

\section{Management, Alignment, and Working for your Organization}

When Dr. Pearlstein left the public sector to work for Bain it was a huge shift; the expectations were completely different. It was really like night and day. She was terrified at the new challenges before her but she knew that she had accomplished all she could at the State Transportation Library and took the leap. After she got the job, she started to receive invitations to vendor advisory boards and 
213

meetings of a wholly different nature from what she had experienced on the government side and this enriched her career tremendously.

Thus it was that Dr. Pearlstein learned to become adaptable in her management style in terms of responsibilities and job expansion. Dr. Pearlstein's management style matured once she moved to Bain. When she was with the State, she knew the organization and how it worked. She also knew the people, so it was very congenial outside of the politics. Her network was very important, and that greatly affected her management style. Networking is a very important aspect of Dr. Pearlstein's managerial career and throughout our conversation, it was repeatedly stressed as one of the most beneficial things to do when moving up in the field of Information Services. It was how she got the opportunity to apply for the job at Bain; it continues to be a resource and an opportunity to share knowledge. Bolman and Deal talk about networking with their political framework of managerial structures (Bolman \& Deal, 2013, p. 180). The Political frame is the strongest in terms of managing upward and utilizing people as resources when working within an institution, and that, along with the Human Resources frame, became the foundation for Dr. Pearlstein's managerial experience (Bolman \& Deal, 2013).

Though Dr. Pearlstein worked within the Political frame she had little patience for the power struggles within the organization. Yet, when it came to the networking of relevant and potential resource relationships, she understood the value those links created in continuing one's lifelong learning journey as a leader. "My management style was very upfront, meeting clients, and trying to support my 
team to be very service-oriented" (Pearlstein, 2020). When it comes to management styles, it is important to think about what kind of service model works for your organization, determine what service model or combination of models fits your organization. Dr. Pearlstein defines these service models as the roles that an information professional takes on when handling and dispensing information, roles that must be adaptable, whether "gatekeeper" or "intermediary" or "facilitator" (Pearlstein, 2020). When she moved to Bain, Dr. Pearlstein found herself in a situation similar to the Transportation Library though there were many more resources, where the library role was that of gatekeeper. There were no desktop services, so users had to come to the Library to use the print collection, CD-based resources, or computers with one or two online services. A user had to come in, have a reference interview, and a Librarian would provide them with whatever information or resources needed.

As things progressed, the service model had to change and that is a huge management decision. The researchers were both gatekeepers for high-end expensive or sophisticated resources and users could be somewhat self-sufficient because of desktop services. Your management style needs to change to fit that new way information is deployed, as well as advocating for whatever extra resources and training might be needed. Well-trained and experienced researchers would have been there for over 10-15 years in some cases, so when a consultant came looking for certain information or asking certain questions, there was a high chance that the researcher had come across this question before or even knew the question better than the consultant, thus coaching the consultant in thinking about the question 
differently or reworking their information seeking behavior. Service models are typically dictated by the information resources available and by how the organization defines success. "What is the best way to use the resources I have to contribute to the success of the organization, and how do I create one or more combination of service models to achieve that goal?" (Pearlstein, 2020). This all fits back into alignment: understanding where you work, your limitations, and shaping yourself and your services to best fit the whole.

Alignment is the key. Any organization you work for, whether public, academic, corporate, or other is still beholden to someone or has some reason for existing. Any mission can be clearly stated. No matter the organization, their mission needs to be aligned with that of the parent organization. For example, a college's mission might be to make sure the students graduate or learn certain information to gain employment, and the college library has to reflect that goal (Pearlstein, 2020). That was certainly true at Bain, where the overall mission was to make their client companies, all Fortune 500 companies, profitable. The role and mission created for the library were created to mirror that mission. Many libraries do not have mission statements or a set of values or goals, and even those that do, do not pursue alignment with their organization's reason for existing (Matarazzo \& Pearlstein, 2018). Once that disconnect forms between the organization and the library, the latter is in danger of marginalization. This is when upper-level management and funding sources start to see libraries as expendable, the services as replaceable, and the libraries find themselves having to justify their existence to the parent organization without the foundation of corresponding goals. 
Seeing opportunity at any point along the Information Continuum gives information professionals the ability to align their skill set with what their organization overall or an individual requester might need at any point in time. The Information Continuum model, or the Records Continuum, is a model created in 1997 to help people understand record-keeping in multiple contexts over time and space (Schauder et al., 2005). Dr. Pearlstein emphasizes that the continuum is the best way to understand that one never knows where the information needed to satisfy the requester is going to come from. Understanding that an answer might be found outside the library is using the concept of the continuum. For example, a requester looking for research on the management of a Human Resources Department might be best served by referral to the organization's own HR group or someone looking for how a specific type of situation was addressed in the past might be referred to the organization's archives. Understanding the beginning and the end of the continuum provides one with a much more informed context to do the research, whether it is primary research or third-party research. For an information professional, expanding the scope of information management to consider how best to answer a request, whether with library resources or some other resource within the organization, can be more efficient, cost-effective, and time saving for the requester.

Adaptability and alignment are the foundation for successful management in a library. Yet many librarians think their job is just to be a librarian and do not think about the overall organization they are working within. That inability to reorganize your service model with the goals of the organization greatly affects everything in the 
model. Service models need to be nimble/adaptable to match what your organization needs at any given time. To be able to do that as a manager, you need to be able to manage both upward, sideways, and downward in the organization. Understanding where people are in the hierarchy relative to you and gaining access to them is how you can build credibility and earn their trust to best support what your staff needs from them so they trust what you say.

Once you are adaptable you can manage downward to your team and make sure your team has the resources, ensuring they can do the job they are asked to do. With the advent of Big Data, data management and analysis over the past five to seven years, adaptable specialized librarians may find their jobs taking a different but more successful path. Pressure is being put on researchers to be more involved in making a qualitative judgment about what are the best research results to turn over to the client (Pearlstein, 2020; Matarazzo \& Pearlstein, 2018).

With the increasing capability of an organization to purchase raw data, it is often the Market Research Group that is responsible for both vetting the provider of the raw data and figuring out what is needed. It is also the responsibility of the librarian to be familiar with what is being purchased so as to pass along the knowledge of which departments hold the data a requester might be looking for. It can be the IS manager's job to provide all concerned with the resources and training to better transition them through this process. Younger Library Science students are taking data classes for exposure to this growing area of necessary expertise, but in organizations where the researchers have been there over 10-20 years, it is a hard management task to 
realign them to the new responsibilities (Matarazzo \& Pearlstein, 2018). This is one of the biggest problems modern libraries face when technology continues to evolve and people are still not up to speed in the new roles librarians now play in dispensing credible information. "People might not always need libraries but they will always need Librarians" (Matarazzo \& Pearlstein, 2013).

Understanding what it is people need from libraries and reforming information services to reflect that is the only way they are going to be sustainable. Working from both the top and the bottom to successfully implement ongoing changes is a critical part of a manager's role in an organization and instrumental in moving into the future of library services.

\section{Conclusion}

You never stop learning as a manager. One's management style is relative to their audience. One of the first things Dr. Pearlstein learned when honing her managerial skills was to speak the language of her organization. Library-speak does not translate to upper management; you need to learn to represent what you need or want in the way the organization expects it. Budgeting and funding can go wrong when libraries try to advocate for resources. Whether it is prose memoranda, a 9o-second elevator pitch, or a PowerPoint presentation, a manager must learn how to make those changes or no one is going to listen and you cannot even get in the door to talk to the person holding the purse strings (Pearlstein, 2020). Learning to communicate in the way your organization expects is what you need to do to be a successful manager. This, again, fits 
into the idea of shaping your management style to fit the organization's expectation, not just how you believe things should be done. To be a good manager you must utilize both the Political and Symbolic frames, as Dr. Pearlstein did, by both advocating for the library and its services while at the same time framing it in a way that resonates with the institution's stakeholders. We see this again and again in her career as she tried to grow her libraries within the parent organization, intertwining them into a solid cooperative force.

All of these lessons come with the understanding that one, no matter their education level or job title, is never done learning. One of the issues in many libraries today is that they are so pared back and lean that there is little organizational support for continuing professional education, and you see many people not willing to move forward at their own expense. The organization used to support extended education, such as paying for registration fees and travel for conferences that help librarians expand their networks. A lot of people feel that if their organization is not going to pay for professional association dues or attendance at a conference then they are just not going to participate.

Support for professional education is no longer always forthcoming yet it is important to continuing the vitality of your skill set. As a manager, you want people on your team to see it as important. It's critical to their success in their jobs. (Pearlstein, 2020) 
You need to be able to convince them it is important. To be a manager one needs to have the broad experience in what is being managed and the support of others to best succeed in any situation. Adaptability is a skill honed by experience and must be encouraged.

Together, adaptability, alignment, networking, and life-long learning combine to create the type of manager who can help solidify the ability of information services to contribute to their organization's success. As the mass of information that must be managed continues to grow exponentially, new expectations are being set for information professionals in all types of organizations. The way managers react and realign themselves will make or break the relevance and sustainability of their careers and services.

\section{Author bio}

Rebecca Fink is a current MLIS student at the University of Maryland, with a BA in English literature and minor credentials in book studies and religion. Rebecca has previously worked in an academic library as a circulation manager for four years, as well as having experience working in the special collections library at the United States Holocaust Memorial museum. Rebecca has volunteered at local public libraries and worked in interlibrary loan distribution. Rebecca's current aspiration is to become an archivist at a religious institution. 


\section{References}

Bolman, L. G., \& Deal, T. E. (2013). Reframing organizations: Artistry, choice, and leadership. (5 ${ }^{\text {th }}$ edition). Jossey-Bass.

Evans, G. E., \& Greenwell, S. (2000). Management basics for information professionals. (4 ${ }^{\text {th }}$ edition). American Library Association.

Matarazzo, J. M., \& Pearlstein, T. (2014). Corporate libraries: A confluence of forces pressing on their future. Journal of Library and Information Sciences, 2(1).

Matarazzo, J. M., \& Pearlstein, T. (2016). Leadership in disruptive times. IFLA Journal, 42(3), pp. 162-178.

Matarazzo, J. M, \& Pearlstein, T. (2018). The emerald handbook of modern information management. Emerald Publishing.

Matarazzo, J. M., Pearlstein, T., \& James, S. M. (2013). Special libraries: A survival guide. Libraries Unlimited.

Schauder, D., Stillman, L., \& Johanson, G. (2005). Sustaining a community network: The information continuum, e-democracy and the case of vicnet. The Journal of Community Informatics, 1(2), pp. 79-102. 


\section{Toward A More \\ Equitable Future SECTION V}




\title{
A Library Freedom
} Dream

IN CONVERSATION WITH FOBAZI ETTARH

\author{
Zahra Osman
}

"I think my freedom dream as it relates to libraries is about living up to the socialist ideals it purports to value."

\section{-Fobazi Ettarh}

Creating success in organizations is incredibly difficult, so much so that whole disciplines (organizational design/leadership) have been created to understand how best to achieve success. Although there are various headwinds to organizational success, one significant headwind is that organizations naturally incorporate, metabolize and in turn actively prop up harmful ideological frameworks that inhabit society at large. For example, ideologies such as white supremacy, colonialism, and patriarchy are foundationally embedded in American institutions and often actively harm the people that these organizations purport to serve (de jesus, 2014). Considering this, persistent leadership and collective action are required to rework and, in some cases, rebuild these institutions so that they actively countermand these ideologies as much as possible. 


\section{In Conversation with Fobazi Ettarh}

Fobazi Ettarh is currently the Undergraduate Success Librarian at Rutgers University and the creator of the concept Vocational Awe (Ettarh, 2018). Ettarh is also a blogger and important voice in librarianship and critical pedagogy via her blog WTF is a Radical Librarian, Anyway? (Ettarh, 2020). When Ettarh is not doing her full-time job and contributing to the discourse on Critical Librarianship, she is graciously spending time giving interviews with MLIS students covering her perspectives on leadership within library settings.

This essay seeks to examine leadership and challenges in achieving organizational success within the context of information organizations. To this end, this essay utilizes an interview with Fobazi Ettarh and Reframing Organizations: Artistry, Choice, and Leadership (Bolman \& Deal, 2013) as counterbalancing narrative guides.

\section{Leadership in Organizations}

How and why do some organizations succeed while other organizations fail? Some texts devote time to exploring the impact of individual mindsets (Dweck, 2006) or how teams working together more effectively contribute to mission success (McChrystal et al., 2015). In Reframing Organizations: Artistry, Choice E Leadership, Lee Bolman and Terrence Deal (2013) argue that there are four distinct decision-making frameworks that leaders use on a day-today basis. These four frameworks: the Structural Frame, the Human Resource Frame, the Political Frame, and the 
225

Symbolic Frame each provide their own lens on scenarios and result in differing solution sets. Bolman and Deal argue that each of these frames serve their own purpose and the ability to reframe a particular situation using one of these four frames is critical to appropriate decision-making and ultimately organizational success.

Bolman and Deal place emphasis on shrewd decisionmaking as a major factor differentiating leaders from managers. Although Reframing Organizations focuses on decision-making, they argue that this ability is an important factor in effective leadership.

If decision-making is only one part of the formula; what differentiates people from being able to affect change in an organization? The answer comes down to leadership. What then, is the difference between a leader and a manager?

In their explanation of the difference between leaders and managers they borrow from Bennis and Nanus: Managers do things right. Leaders do the right thing (Bennis \& Nanus, 2007). An aphorism often referenced in the U.S. Armed Services is that you lead people and manage things, not the other way around.

When asked about whether she considers herself a leader and what influences her leadership and management practice, Fobazi answered:

Well firstly, I think it is important to separate the words manager and leader. While managers can be leaders, and vice versa, there are plenty of leaders who aren't mangers, and the reverse equally true. And so to answer your question, I do consider 
myself a leader, but I do not consider myself a manager. (F. Ettarh, personal communication, October 30, 2020)

This distinction that Fobazi makes between leadership and management is important. Leaders affect change while managers uphold the status quo. In the world of information organizations, this ability to make change is particularly important. Leadership, not management, is required to address issues such as burnout, low wages, and job creep.

\section{Visible and Invisible Structures}

In Reframing Organizations, Bolman and Deal describe the Structural Frame as a model that focuses on achieving "established goals and objectives" by "enhance[ing] performance through specialization and appropriate division of labor" (Bolman \& Deal, 2013, p. 45).

This model heavily relies on each member of the organization performing their task, as assigned, for the unit to function. This organization of tasks, or "specialization," lends to efficiency, but also creates separated groupings of people or silos. Additionally, a manager provides oversight of individuals to ensure tasks are being completed on time and appropriately. This adds a vertical layer to the organization on top of the specialized silos that sit side by side each other.

The combination of these vertical layers and horizontal categories is what comprises a standard organizational chart for many organizations. This type of structure, particularly 
for larger organizations, tends to be hierarchical and requires leaders to use a system to maintain control vertically and coordinate across the organization horizontally.

Although more prevalent in larger organizations, hierarchical structures are not the only types of organizations. When asked whether creating a functioning organization without hierarchy was possible, Fobazi replied:

I have worked in highly hierarchical organizations and 'flatter' organizations, and they both come with their pros and cons. In my experience, both types of organizations can lend itself to a lot of red tape and 'solving' things via committee. (F. Ettarh, personal communication, October 30, 2020)

However, not all structures are visible on an organizational chart. Organizational charts show who are in positions of authority, but do not show other dynamics whether they are internal (relational dynamics) or external factors (sexism as a result of patriarchy, anti-black racism as a function of white supremacy, etc.).

As an example of how this shows up in libraries, nina de jesus (2014) argues that:

[L]ibraries do, in fact, embody enlightenment values, but/and that enlightenment values are themselves steeped in and reinforce white supremacist settler state ideologies. To the extent that libraries do embody enlightenment values, they likewise contribute to ongoing colonization and 
thus are reasonably seen as sites of violence and oppression.

In the conversation with Fobazi, she identifies that awareness of how white supremacy shows up in an organization is the first step.

I don't think that it is possible to create a functioning organization absent of hierarchy, but I do believe that by being aware of the white supremacy characteristics (Jones \& Okun) and using the antidotes as well as being transparent about the decisions being made that a healthy organization can occur. (F. Ettarh, personal communication, October 30, 2020)

\section{The Human Element}

In Reframing Organizations, Bolman and Deal describe the Human Resource Frame as a model that believes that “organizations exist to serve human needs" (Bolman \& Deal, 2013, p. 117). Consequently, the Human Resource (HR) Frame is principally concerned with what humans in an organization need, what motivates them to excel and ultimately perform in a way the organization needs.

Leaders who utilize the HR Frame tailor their decisionmaking based on who they are interacting with and their understanding of how best to motivate that person. Zooming out, the HR Frame looks at the relationship between the organization and the humans that comprise the organization. This includes a focus on talent management: hiring the best people and finding a way to 
retain them at the organization by keeping them engaged, motivated, and happy.

Emotional intelligence is a skillset that helps leaders motivate their teams. In Emotional Intelligence, Emotional Culture, and Library Leadership, Jason Martin (2019) writes that:

Emotionally intelligent leaders excel at many things, but perhaps their most important skill is the ability to effectively facilitate change in an organization. Their ability to recognize, manage, and influence emotions helps make those in the organization more responsive to and comfortable with the change taking place. (p. 2)

If the HR Frame considers how a leader, or organization, needs to treat people to achieve success, then it is important to state that the way we treat people is influenced by societal constructs like race, gender, class, and ability. How do concepts like emotional intelligence play out when we live in a gendered and racialized society?

If emotional intelligence is the ability to recognize and influence emotions, then emotional labor is the performance of emotion in service of maintaining someone else's emotional state.

In Behavioral Expectations for the Mommy Librarian, the authors contemplate that "although librarianship is predominantly female, the scholarly literature has yet to consider the role of gender in our expectations for emotional performance as librarians and in our experiences of emotional labor" (Emmelhainz et al., 2017, p. 30). 
Awareness of how societal structures seep into organizational leadership is a necessary first step for leaders. When asked whether there could be more to be done to harness emotional intelligence for "good" while avoiding pitfalls such as emotional labor, Fobazi replied:

No, I think that there is no concept that can be used without avoiding pitfalls because we are all human. We've created a racialized and genderized society, and even if we were to create a new one, there would still be the mistakes of humanity within it. The best way is to acknowledge and embrace that pitfalls will happen, and using context, do the best you can to remedy the situation with as little harm to as many people as possible. (F. Ettarh, personal communication, October 30, 2020)

\section{Symbols as Tools}

In Reframing Organizations, Bolman and Deal describe the Symbolic Frame as a model that relies on organizational symbols to create an organizational culture. These symbols may include myths, metaphors, traditions, and other rituals that communicate an organization's values and core beliefs. Bolman and Deal (2013) write that "culture forms the superglue that bonds an organization, unites people, and helps an enterprise to accomplish desired ends" (p. 248).

Leaders who leverage the Symbolic Frame seek opportunities to create these common bonds, with the goal of getting people to perform their jobs. The end goal is always to achieve the ends required by the organization. 
231

One way the Symbolic Frame shows up in organizations and institutions is the role of the myth in the organizational/institutional origin story.

In Fobazi Ettarh's (2018) groundbreaking article Vocational Awe and Librarianship: The Lies we Tell Ourselves, she writes that the earliest libraries were those of religious orders. This origin in religion is causally related to why libraries are seen as sacred places, librarians are seen as "priests/priestesses," and their service is thought of us as a duty.

These symbols, however, do not operate in a vacuum. Symbols are tools and they are often used for a particular institutional purpose. In Vocational Awe, Fobazi discusses how the symbols of vocation and duty are weaponized to convince library workers that they should work harder and longer in the name of the "calling" of librarianship.

This weaponization of the calling to librarianship, shows up in a few different ways. When discussing how silos show up in libraries, Fobazi weighed in:

For libraries, Vocational Awe plays a big role because of the martyrdom aspect. Since librarianship has created a culture that suffering equals a higher level of service, it disincentives collaboration because the best suffering happens to one person or a few people rather than a large group. (F. Ettarh, personal communication, October 30, 2020)

The combination of Vocational Awe working in conjunction with governments not properly funding other institutions (i.e. homeless services, mental health) creates a situation 
where libraries are providing social services beyond its original intent of information services. This “job creep," or continual expansion of duties, is another way library institutions ask library workers to do more with less under the guise of the symbols prevalent in libraries.

\section{Politics as Change Making}

In Reframing Organizations, Bolman and Deal paint organizations as being a place where competing ideas and agendas require skillful leaders to navigate the landscape and work with people to elevate their own agendas. Leaders who leverage the Political Frame understand that resources are finite and that they must build coalitions and networks to help them secure their resources. Bolman and Deal compare this frame to being in a jungle where battles over power and resources take center stage.

Although the organizational space is an arena of sorts in the Political Frame, the battles that take place do not necessarily need to be filled with conflict. In fact, a major tenet of the Political Frame is the ability to: a) understand the power landscape (who has power and what kind of power) and b) creating networks and coalitions with people who will help you in our efforts.

To simplify: the Political Frame seeks to answer how to get things done when other people have competing priorities. In some instances, the institution itself does not want you to work together and build coalitions. In an interview on the Imagine Otherwise podcast, Fobazi Ettarh discusses how Vocational Awe makes library workers take on work 
233

themselves instead of going outside of their unit and asking for help because they think that it is their duty to solve a problem (Hannabach, 2020). In this example, Vocational Awe is actively working against any attempts to build networks and create change.

Fobazi offers a potential option for combatting the isolation made prevalent by Vocational Awe:

Despite the rhetoric, libraries never really were about access to all. But I think they can be if we work together with other failing social institutions such as community centers and social services to create a healthy network of places for people to go without a capitalist agenda, instead of the current model of libraries desperately trying to be the catchall for all of the failing social services.

\section{Asking the Right Questions}

Bolman and Deal's four organization frameworks (Structural, Human Resource, Political, and Symbolic) provide a solid starting point for understanding how best to solve problems and lead. However, as a stand-alone strategy, it lacks appropriate societal context to address the deeply rooted, systemic issues that plague organizations (and society at large). Although Bolman and Deal discuss themes like gender and race, it is often mentioned as a footnote instead of positioning them as foundational frameworks that fundamentally drive interpersonal and organizational dynamics. 
Bolman and Deal's work is just one example of scholarship in management and organizational theory that minimize the role of race, gender, and class and corresponding societal constructs. Instead of conducting critical examination of these themes, much of leadership and management literature instead orient their recommendations on how to best problem-solve within the existing set of operating rules and assumptions. These works, including that of Bolman and Deal, create solution sets that do not adequately consider existing systems of oppression and how to overcome them. Consequently, the proposals they put forward end up reinforcing the societal status quo and miss significant opportunities to contemplate how we may affect change within our own organizations.

Contrastingly, Fobazi Ettarh's work pushes us to directly challenge the existing set of operating rules and assumptions inherent in the Library profession. In Vocational Awe, Fobazi begins by reviewing long accepted concepts of "duty" and "sacredness" in librarianship. She (2018) asserts that:

$[B] y$ deconstructing some of these assumptions and values so integrally woven into the field, librarianship can hopefully evolve into a field that supports and advocates for the people who work in libraries as much as it does for physical buildings and resources. (para. 3)

In this way, Ettarh prompts us to ask broader questions on why and how our organizations work the way they do. If typical leadership and organizational management 
235

literature gives us tools to mop up a wet floor, works from Ettarh and de jesus ask us to look up and see the giant hole in the roof.

\section{Library Freedom Dreams: A Conclusion}

How then do we begin to change these organizations and achieve Ettarh's freedom dream? How do we combat patriarchy, white supremacy, ableism, and symptoms of those ills that manifest in things like Vocational Awe?

\section{Acknowledge the problem.}

In order for us to create futures where organizations can counteract systems of oppression and harm, we must first address how these systems show up in our organizations. In Vocational Awe, Ettarh argues that the starting point is awareness and acknowledgement of how these phenomena manifest and live in our realities.

In White Librarianship in Blackface: Diversity Initiatives in LIS, April Hathcock (2015) argues that we must first understand how whiteness dominates LIS before we can effectively address diversity within the profession. However, whiteness along with other pernicious societal constructs, often mask themselves in "invisible normativity" (Hathcock, para. 6). In other words, these constructs are deeply embedded in our societies/organizations and have been operating for so long as to be assumed as "normal." This normalization is exactly why certain works in leadership and organizational management (i.e., Bolman \& Deal) fail to acknowledge and question them. 
As an example of normalization, the term "diversity problem" and "diversity issue" is incredibly common when discussing diversity within libraries. Hathcock references the framing of diversity as a problem instead of as a solution to issues created by racism, classism, sexism, etc.

Collins (2018) furthers this idea by examining how language "establishes normative practices...and reinforces a kind of institutional reality" (p. 44) within libraries. Language is a powerful normalizing agent and, in this instance, can cause harm without being appropriately examined.

A pivot from accepting normative systems to a more questioning attitude also requires building sufficient understanding in the history of systems of oppression and how harmful ideologies are embedded in our institutions. For some, this step requires stepping outside of one's default perspective and examining lived experiences for people with less privilege. Scholarship in the spirit of Collins, Hathcock, Ettarh, and de jesus help us acknowledge the problems we face specifically within the library profession.

\section{Complex problems require imaginative, complex solutions}

Using one mental model to solve problems like Vocational Awe is not going to work. Bolman and Deal's reframing/multi-frame solution is a good start. It also requires thinking outside of what we have experienced and imagining what could be.

In an article for Vogue, activist Tourmaline (2020) writes, "Freedom dreams are born when we face harsh conditions 
not with despair, but with the deep knowledge that these conditions will change-that a world filled with softness and beauty and care is not only possible, but inevitable" (para. 1).

When asked about her freedom dream as it relates to libraries as an institution and a profession, Fobazi replied:

I think my freedom dream as it relates to libraries is about living up to the socialist ideals it purports to value. Education and access for all is a noble ideal, one that was tainted from the beginning with the shifting goal posts surrounding all. First 'all,' meant all white, rich men, then all white men, then all white men and women, then all white men, women, and children, and so on. And so, despite the rhetoric, libraries never really were about access to all. But I think they can be if we work together.... My dream is that the library stays strong by trimming the fat and doing what it does best: providing information and referral services. (F. Ettarh, personal communication, October 30, 2020)

Ettarh's freedom dream for libraries acknowledges the systemic issues embedded within the profession while highlighting a path forward through collaboration and refocusing on the original intent of the library. In Systems Thinking for Social Change, Stroh (2015) acknowledges that this departure from the original intent of the system is a common problem that plagues organizations (p. 16). To bring an organization/system back to its original intent (i.e., equity and information access for library patrons), Stroh 
argues that we must zoom out and understand how all the component parts of the system are working with each other.

Where traditional problem-solving is concerned with fixing one component part, systems thinking forces us to reckon with the dynamics between components and how those relationships ultimately contribute to the health of the system (Stroh, 2015). It comes to reason then, that solutions aiming to make libraries true places for information access for all (and not some), require consideration of the ecosystem in which libraries operate. Seeing how the system works is just the first step; effective problem-solving also requires collaboration and action across component groups or "silos" (Kowalski, 2017).

Structural issues such as white supremacy, ableism, and patriarchy are deeply rooted and protected within our institutions. Combatting these constructs, including within the library profession, requires leaders who can acknowledge the problem and craft systems-minded solution sets. Although, the library freedom dream will not be easy to achieve, Tourmaline (2020) leaves us with a benediction of sorts:

I want you to know that your freedoms dreams can be immediate.... I want you to know that it's not frivolous to have dreams about seemingly small or pleasurable things; it is vital. 


\section{Author bio}

Zahra Osman is a first semester graduate student pursuing her MLIS degree after spending time in government and financial services. When she isn't taking long naps, she is freedom dreaming of liberation.

\section{References}

Bennis, W. G., \& Nanus, B. (2007). Leaders: Strategies for taking charge. Harper Collins.

Bolman, L. G., \& Deal, T. E. (2013). Reframing organizations: Artistry, choice, and leadership. ( $5^{\text {th }}$ edition). Jossey-Bass.

Collins, A. M. (2018). Language, power, and oppression in the LIS diversity void. Library Trends, 67(1), pp. 39-51. https://muse.jhu.edu/article/706987/pdf

de jesus, n. (2014, September 24). Locating the library in institutional oppression. In the Library with the Lead Pipe. http://www.inthelibrarywiththeleadpipe.org/2014/locating-thelibrary-in-institutional-oppression/

Dweck, C. (2006). Mindset: The new psychology of success. Ballantine Books.

Emmelhainz, C., Seale, M., \& Pappas, E. (2017). Behavioral expectations for the mommy librarian: The successful reference transaction as emotional labor. Library Juice Press.

https://escholarship.org/uc/item/2mq851mo

Ettarh, F. (2018, January 10). Vocational awe and librarianship: The lies we tell ourselves. In the Library with the Lead Pipe.

http://www.inthelibrarywiththeleadpipe.org/2018/vocationalawe/

Ettarh, F. (2020, June 5). WTF is a radical librarian, anyway?. https://fobaziettarh.com/

Evans, G. E., \& Greenwell, S. (200o). Management basics for information professionals. ( $4^{\text {th }}$ edition). American Library Association.

Hannabach, M. (Host). (2019, October). Imagine otherwise: Fobazi Ettarh on the limits of vocational awe (No. 98). [Audio podcast 
episode]. In Imagine Otherwise. Ideas on

Fire. https://ideasonfire.net/98-Fobazi-Ettarh/

Hathcock, A. (2015, October 7). White librarianship in blackface: Diversity initiatives in LIS. In the Library with the Lead Pipe.

http://www.inthelibrarywiththeleadpipe.org/2015/lis-diversity/

Jones, K., \& Okun, T. (2001). From dismantling racism: A workbook for social change groups. ChangeWork.

https://www.thc.texas.gov/public/upload/preserve/museums/fil es/White_Supremacy_Culture.pdf

Kowalski, M. (2017). Breaking down silo walls: Successful collaboration across library departments. Library Leadership E Management, 31(2). https://doi.org/10.5860/llm.v31i2.7202

Martin, J. (2019). Emotional intelligence, emotional culture, and library leadership. Library Leadership \& Management, 33(2). https://journals.tdl.org/llm/index.php/llm/article/view/7329

McChrystal, S., Collins, T., Silverman, D., \& Fussell, C. (2015). Team of teams: New rules of engagement for a complex world. Penguin Random House.

Stroh, D. P. (2015). Systems thinking for social change: A practical guide to solving complex problems, avoiding unintended consequences, and achieving lasting results. Chelsea Green Publishing.

Tourmaline. (2020, July 2). Filmmaker and activist tourmaline on how to freedom dream. Vogue.

https://www.vogue.com/article/filmmaker-and-activisttourmaline-on-how-to-freedom-dream 


\section{Can Anyone Be a Storyteller? \\ EQUITY, DIVERSITY, AND INCLUSION IN CULTURAL HERITAGE}

Tannaz Motevalli

"In the West, and in places that have styled themselves after the West, we value the idea of bestowing power to one trustworthy person because it will somehow bring order to chaos. And we do so knowing that some people's voices will get lost in the shuffle...We don't want to imagine what would happen if there wasn't a person leading us."

\section{- Kevin Whiteneir}

In the wake of a recent and historic United States election, the spectrum of ideas for what makes a good leader is broad, complex, and it is extremely clear that our country is divided. Whether we wish it or not, our leaders are also the gatekeepers of the stories we value. Cultural heritage institutions, the maintainers of these stories, have great power in shifting narratives and thus the values we uphold. Recent activism from a transformative justice lens asks many of us to think more critically about how our core values influence the way we view power and leadership. Are those core values being met in the leaders leading us today? What are those values? When we think about the history of our country from this perspective, we find the past 
repeating itself_-old models of management and leadership repeated although they continue to fail us while new models do not manage to make great structural change. Cultural heritage institutions are no less subject to this vicious cycle.

This essay seeks to uncover some of the reasons why storytelling has been left to the hands of few and the many barriers to change within cultural heritage institutions, both structurally and from individualized perspectives. Key opportunities for how library and information science (LIS) professionals and leaders can begin to encourage social change through leadership and management within their communities and organizations, are also discussed.

\section{Speaking with Kevin Whiteneir}

Kevin Whiteneir, currently the Technical Services Associate at the Ryerson and Burnham Archives and Research Center at the Art Institute of Chicago, came to the LIS field after pursuing a career as an interdisciplinary artist and art historian. My initial interaction with him was during my years in undergrad at the School of the Art Institute of Chicago (SAIC) (2013-2017). I spent many hours in the library where he worked as a staff member while pursuing his Master's in Art History, Theory, and Criticism. Though I did not know his name at the time, years later, I still remembered his face. Our next, though still indirect, interaction was this year in a Zoom Happy Hour hosted by the ALA's Office of Diversity, Literacy, and Outreach Services for fellow Spectrum Scholarship recipients as I was joining the 2020 cohort. Whiteneir, a recent alum of the scholarship program, began speaking, and after a brief 
Google search, I knew Whiteneir was the person I wanted to interview for this paper.

I continue to be struck by Whiteneir's dedication to equity, diversity, and inclusion throughout his career both in the arts and LIS. With the knowledge that many of the systems we participate in and enable are still very much colonial and oppressive, I was keenly interested in hearing how Whiteneir navigates spaces as another POC LIS professional and encourages change in his respective environments and communities. As an artist who left the industry to work more specifically in LIS, there are certain elements of Whiteneir's perspective on leadership and management that come directly from his experience in the arts which are insightful and can be extremely useful for thinking about social change in cultural heritage institutions.

\section{From the Arts to LIS: Persistent Problems}

By age 14, Whiteneir wanted to pursue the arts, particularly dance, and was met with great encouragement from those around him. Passionate at a young age, Whiteneir discusses how many pushed him to pursue a career in the arts fostering a belief that being an artist was a viable pathway for his future. Like many, including myself, Whiteneir found himself burned out and disillusioned by a field which failed to provide a sense of deeper nourishment that we felt, in many ways promised, while pursuing the arts as young people. 
Just like every other system in some ways, it's not really about your creative practice, but how much you can crank out a year. It's about keeping up with the Joneses, a lot of competition, and never really continuing to foster that kind of, creative spirit or that artistic spirit. (K. Whiteneir, personal communication, October 17, 2020)

\section{THE ARTIST AND THE LIBRARIAN}

Whether you are in the arts or in any other community or industry, we assume that most people's long-term career goals entail working in a role one finds genuine joy and purpose in, or dare I say, passion for. This assumption is especially strong in the arts. The notion of being a working artist often conjures the "starving artist" narrative. As Whiteneir and I discussed, in our experience of being artists from young ages, the mythos of the passionate and starving artist is often intertwined in that initial desire to pursue a career in the arts. It led us to inevitably excuse the exploitation of our labor and personhood.

In Lee Bolman and Terry Deal's (2013) book, Reframing Organizations: Artistry, Choice, and Leadership, the symbolic frame explores how organizations, and in some cases industries more broadly, use myths and symbols to instill core guiding values that communicate what that organization or industry adheres to ideologically (p. 243). As Whiteneir and I discussed our time in the arts, it became clear that much of our disillusionment with the arts came from no longer believing in the myths that the arts could serve our own deeper purpose (Whiteneir, 2020). The minute the symbols that uphold our beliefs in the systems 
we partake in no longer hold meaning, the flaws within that system become much easier to see.

And much like artists, librarians and other information professionals struggle with a constant negotiation of the symbols attached to that position and trade. In Vocational Awe and Librarianship: The Lies We Tell Ourselves, Fobazi Ettarh (2018) defines the term of vocational awe as "the set of ideas, values, and assumptions librarians have about themselves and the profession that result in beliefs that libraries as institutions are inherently good and sacred, and therefore beyond critique" (para. 3). Ettarh explains the formation of vocational awe by looking through the history of librarianship and how the profession has fastened itself to pseudo-religious symbols of service, duty, and goodness. Whether this is true or not, passion becomes a prerequisite for entering the field, much like the arts. "The problem with vocational awe is the efficacy of one's work is directly tied to their amount of passion (or lack thereof), rather than fulfillment of core job duties" (Ettarh, para. 23).

The symbolic frame as explored by Bolman and Deal in conjunction with Ettarh's insights on vocational awe show us how symbols and myths not only help us find meaning in the work we do, but, like any other signifier, are capable of being exploited if they take precedent over the lives of those impacted by them.

\section{To Degree or Not To Degree}

Whiteneir worked in the Chicago Public Library system since the age of 14 . When he decided to make a more 
serious career shift towards librarianship, not having a Master's degree in this field greatly limited his job prospects-yet another barrier, much like the one he faced when determining whether or not to continue on to a $\mathrm{PhD}$ in Art History. This is a story of old for many fields and LIS is no different. Like many people who have worked in libraries as volunteers from a young age to later become staff members, the push to a degree in order to gain any more upward movement in your chosen field becomes more and more urgent.

In an industry that continues to suffer from underfunding and budget cuts, burnout, and fast-paced technological changes, the division between degreed librarians and nondegreed library staff only continues to grow larger. This kind of division creates deep rifts and harms employees through limiting workplace effectiveness, morale and comradery, overall communication across the organization, and the motivation for change and innovation (Kowalski, 2017, p. 2).

When we bring identity in the mix, the problem becomes even more dangerous than unequal and divisive workplaces. Historically, the most diverse staff is found at the bottom of the pay scale (Whiteneir, 2020). Looking at art museums specifically, statistics show that, while the field grows more diverse in certain sectors of the workforce, leadership demographics across the board continue to remain largely homogenous (The Andrew W. Mellon Foundation, 2019). 


\section{The Storytellers}

"Power is often in a ladder structure. We put the power of storytelling in the chief storyteller's hands. That's not real.

Storytelling is not done by one person. But the way museums and cultural heritage institutions currently work is that you have many people working on a process or product, but at the end of the day it comes to a director or president to put the stamp of approval on it. I think that this is dangerous. It makes it seem as though storytelling needs to be authorized. And we know 92\% of directors in cultural heritage institutions are white, which means all storytelling is being approved by one white person, most likely a white man at the top of the ladder."

\section{- Kevin Whiteneir}

There is ample evidence throughout the history of librarianship showing the institutional frameworks of libraries and other cultural heritage institutions continue to sustain the colonial ideologies of their founding that in turn contribute to our ongoing societal acceptance of white supremacy (de Jesus, 2014; Ettarh, 2018). One of the most persistent ways this is done is through keeping power within communities and identities of privilege, from having majority white, male leaders to underfunding or not funding the collection and preservation of cultural materials generated by minority and marginalized communities. As Whiteneir and I discuss why we think this happens, one big question comes up-why are the people at the top of the institutional ladder so untouchable? Are they really, or are we sustaining the belief that they cannot be moved when, in fact, there is a way? 


\section{INESCAPABLE HIERARCHIES}

"Libraries as institutions were created not only for a specific ideological purpose but for an ideology that is fundamentally oppressive in nature. As such, the failings of libraries can be re-interpreted not as libraries failing to live up to their ideals and values, but rather as symptoms and evidence of this foundational and oppressive ideology"

$$
\text { -de jesus, } 2018
$$

The insidious nature of systemic oppression makes it so that any institution within our society is not only capable of functioning from a "foundational and oppressive ideology," but also provides both micro and macro pathways for that oppressive ideology to take root into the fabric of our culture. nina de jesus' article, "Locating the Library in Institutional Oppression," specifically addresses ways the library as a fixture within our society engages with systemic oppression. These ways include, but are not limited to, enlightenment values, moral codes used to bolster racist ideas about identity and intelligence, the myth of the neutrality, and the pillars of white supremacy as dictated by Andrea Smith. de jesus (2018) shows us that systemic oppression is in fact deeply rooted to the foundational elements of librarianship in ways that feel almost inescapable. As a result, the triangulation of power, in which storytelling is dictated by the few individuals at the top, creates both the illusion and the reality of impenetrable power. Libraries' and other cultural institutions' reliance on these structural and hierarchical models of management and leadership only lend themselves to the continuation of systemic oppression and white supremacy. 
History shows us that time and time again we find comfort in following individuals who have been given leadership status. Whiteneir points out that even in the history of social movements, there has been plenty of evidence to support this need and desire for leaders. He brings up the 6o's and the Civil Rights era stating that "when MLK was assassinated, we saw the petering out of a lot of those efforts" (K. Whiteneir, personal communication, October 17, 2020). He suggests that, even while he believes we can work together through collaborative exchange, people resort to being guided and lead by one individual. This is especially the case when that individual shows characteristics many find to be of leadership quality, such as charisma and confidence. This is especially the case in times of great crisis and division (Bolman \& Deal, 2013, p. 253).

In another bottom-up fight for change, Bolman and Deal (2013) briefly reference the Occupy Wall Street movement from 2011 in Chapter 11: Organization of Political Arenas and Political Agents (p. 221). While some successes came out of the Civil Rights Movements, Occupy Wall Street in particular petered out largely due to its increasingly nebulous and leaderless approach. Bottom-up approaches for motivating change and calling for action within organizations have been done time and time again, yet topdown approaches are the most common and default methods of organizing power in cultural heritage institutions. 


\section{LATERALIZING THE HIERARCHY AND REORGANIZING POWER}

While many cultural institutions function with clear and seemingly impenetrable hierarchies, Whiteneir argues for the importance of dismantling hierarchies within as many spaces inside the organization as possible (K. Whiteneir, personal communication, October 17, 2020). Giving employees the power and autonomy to determine their work flows and chose how their delegated tasks can be done is an important step in doing this. But more importantly, having members of all levels of the hierarchy have a say in how the organization functions is paramount for making a more egalitarian workplace. This is especially important when strategizing any organization-wide change initiatives, and even more so for diversity and inclusion initiatives (Hackman, 2017).

While studying female led spaces, author Sally Helgesen coined the term "web of inclusion" to articulate the organization of power which was non-hierarchal, but rather circular, building out from the center (Bolman \& Deal, 2013, p. 83). At the time, Helgesen believed that future successful organizations would benefit from this model, but still many cultural heritage institutions are stuck with top-down and triangular models. From Whiteneir's perspective, models like this which focus on communal experiences of power help, but currently only exist in small team management, not organization-wide management and leadership (Whiteneir, 2020). 
251

\section{REDEFINING LABOR}

One lesson Whiteneir learned in the arts and now uses as a way to navigate the LIS field, is the act of working against definition and continuing to redefine labor. Whiteneir specifically spoke to me about methods of redefinition that allow for hierarchies to be lateralized and power to be redistributed in the workplace (K. Whiteneir, personal communication, October 17, 2020).

In thinking about the symbol of the artist vs. the librarian, as discussed earlier, meaning-making in the arts is often more flexible and more "creative," for lack of a better word. Artists do not need to make a bibliography or do literature reviews to make bold statements. Artists are also expected to work against the grain, push the needle, and aggravate the status quo. Whiteneir (2020) finds value in these notions and argues this more "rabble-rouser" attitude towards systems, structures, and norms can be helpful for LIS professionals who want to fight for social change in their organizations. But how does that attitude translate into the LIS field? How can we redefine our labor and reorganize power by changing the way we make meaning and the things we use to make meaning? Resistance to these ideas feels inevitable and provides an added layer of emotional labor to the work we do (Whiteneir, 2020).

In recent years, some writing has been published on how the archives and archival practice in particular erases the labor of those working within them (Arnold, 2016; Williams, 2016). A discipline known for its employees being chronically underpaid and understaffed, archival labor is still delegated only to the most credentialed who often are white and/or have the privilege of access to multiple levels 
of higher education. This is especially dangerous as it furthers the role of the archives as a way of gatekeeping stories and histories that may literally never see the light. As a specialist working in an archives, Whiteneir interrogates archival labor even further by asking who is allowed to do this labor and who is allowed to have a say in that labor? And when we make that labor more visible, who is still left out of the conversation?

\section{Building Sustainable Change}

Cultural heritage institutions participate in systemic oppression beyond the simple fact that they were made to do so, but also because efforts to reorganize and restructure institutions forget that the work to be anti-oppressive is constant. No amount of finite restructuring will eliminate the existence nor the pervasiveness of racism, ableism, ageism, sexism, xenophobia, transphobia, queer-phobia, prejudice, identity-based discrimination, and any other form of oppression. While this is true, it is our duty as maintainers of storytelling to fight for a decolonization of our institutions.

\section{WHITENEIR'S STEPS TO CHANGE}

Towards the end of our conversation, Whiteneir discusses some preliminary thoughts on concrete steps institutions should take to be more anti-racist, diverse, equitable, and inclusive at all levels:

Being truly and deeply honest about the way these institutions have marginalized minority communities in the past and the fact that they will continue to do so. 
Doing the work to reach marginalized communities that are shut out. Building new and equal partnerships with those communities.

Actively hiring members of marginalized communities. Making hiring accessible to minority and underrepresented LIS professionals and strategically reaching out to minority and underrepresented LIS professionals.

Providing ongoing and consistent trainings on allyship and anti-racism within and outside the institutional structure.

Diversifying visitor-ship and viewership. Making the viewer/visitor experience inclusive and accessible to all while actively welcoming communities that have previously not felt welcome within these institutions.

In efforts to address growing discontent and pressure to eradicate systemic racism within cultural heritage institutions, many organizations move quickly to anti-racist and bias training, building internal coalitions and committees, and pushing diversity hires. Yet, as Whiteneir points out while articulating his suggested steps to change, the work to be anti-racist, the work to be more inclusive, the work to be anti-oppressive, all require deeper and more involved efforts that include reallocating how power has been traditionally allocated between the institution and the communities which have been harmed (K. Whiteneir, personal communication, October 17, 2020). Efforts that do not recognize the deeply rooted harm cultural heritage institutions may have caused certain minority and marginalized communities can exacerbate the problems. 
Diversity hires that are not done intentionally or under the leadership of diverse individuals can lead to tokenism and tribal divisions across identity within organizations.

Organizations that hire diverse professionals but do not attempt to mitigate or eliminate a harmful and discriminatory workplace only serve to make "the problem of diversity" worse (Hathcock, 2015). Poorly planned outreach can lead to the further exploitation of minority communities and thus further isolate these communities from engaging with cultural heritage institutions. Whiteneir specifically encourages a concerted effort to build trust and listen to communities. "They (cultural heritage institutions) need to be honest about what their relationships with those [minority and marginalized] communities are. Because they've been poor...[t]hey have not cultivated relationships with us" (K. Whiteneir, personal communication, October $17,2020)$.

The disconnect between cultural heritage institutions and marginalized communities is evident not simply in the homogenous workforce but also in visitor-ship of these institutions. Five years ago, the Museum of Fine Arts (MFA) in Boston, MA surveyed their visitors and found $67 \%$ were women, $75 \%$ were 45 -years-old or older, and $79 \%$ identified as White (Shea, 2017). While their efforts largely included diversifying their workforce and leadership in particular, the MFA also addressed the need to be honest with what this did to storytelling. As a result, the MFA began working on "broaden[ing] the scope of their storytelling" by curating works by minority artists and art communities (Shea, 2017, para. 22). While hiring is important and helpful, bringing the power of storytelling to the communities and individuals often forgotten by cultural heritage institutions 
255

requires constant and simultaneous cooperation and coordination of many of these steps to change in order to be truly effective.

\section{TAKING AND MAINTAINING CARE}

In April Hathcock's (2015) article, White Librarianship in Blackface: Diversity Initiatives in LIS, she specifically highlights the ALA's Spectrum Scholarship Program as one of many diversity initiatives that struggle to make meaningful difference. As a Spectrum scholar himself, I asked Whiteneir to share his thoughts on how the program has the potential to change the game, or not. While he has only been in the program for two years now, Whiteneir says the Spectrum community feels more close-knit and active than many other affinity groups he has been a part of over the course of his career. He especially calls out the way the program is pushing organizations that may have a history of saying "well there just aren't that many diverse people in the field" (K. Whiteneir, personal communication, October 17, 2020). Programs like Spectrum give institutions a vetted pool of diverse professionals whose goals align with some degree of social change, but is that enough? The idea that diverse and non-white professionals need to be vetted by an institution for other organizations to see their worth in the hiring process is inherently racist. So while Whiteneir sees potential for sustainable community building and nonwhite multicultural allyship, Spectrum cannot change the game on its own.

In discussing Spectrum, a much larger issue of how we maintain our own will to change in the face of a seemingly endless and immovable problem appeared. As actors and agents of various institutions and as individuals in the 
world, we must reconcile with our own ability to harm others and the likelihood that we will continue to do so in our attempts to stop. No one individual and no one system is exempt from this. In accepting that we do and will harm others, and especially the communities with which we promise to serve, we become more capable of a sustainable path to change, yet many leaders and managers struggle to understand their contributions to their organization's more unsavory impact (Stroh, 2015, p. 22). However, this internal work needs to be done, and to be done thoughtfully and thoroughly, in order to garner lasting effects.

Harm reduction and care ethics serve as excellent models for moving through the many complex changes and shifts necessary for decolonizing our institutions and organizations. More recently maintenance theory provides us with a compassionate lens with which to understand our roles in society as cultural heritage workers (Information Maintainers, 2019). By aligning our work with care and repair, we may be able to better shift our labor from a colonial paradigm to a most sustainable exchange with the communities we serve and whose stories we preserve.

To continue our work, we too need to be thoughtful of the emotional labor that goes into fighting for change. To end my conversation with Whiteneir, I ask my final question: "how do you take care of yourself?" Whiteneir recognizes that to push for change we often have to put ourselves in uncomfortable positions, cause trouble, and often get a target on our back (K. Whiteneir, personal communication, October 17, 2020). And as POC LIS professionals, there can be a lot of fear in doing that, but it is still worth it: 
Finding the people who will cause the trouble with you is great, because you can tag-team. You can say, "Hey, you guys, I need to take a break. Otherwise, I'm not gonna make it.” ... That's the way these places disenfranchise us, keeping us separate, and keeping us feeling alone and like we're the only ones with a problem. And that's why it is the hardest and most rewarding part because you really got to put yourself out there. (K. Whiteneir, 2020)

Talking with Whiteneir makes it clear that while there is so much change that needs to happen, there is still a lot of hope that together we can make a difference for one another. Together, we can become storytellers.

\section{Author bio}

Tannaz Motevalli (she/they) is a MLIS student at the University of Maryland with special interests in health sciences librarianship, museum studies, and community outreach. Prior to entering the LIS field, Tannaz worked as an interdisciplinary artist and arts administrator. Tannaz received a BFA from the School of the Art Institute of Chicago in Studio Art.

Currently, Tannaz works as the Exhibition Coordinator at the National Library of Medicine in the History of Medicine Division's Exhibition Program. Tannaz is also a member of the 2020 cohort of the ALA Spectrum Scholarship Program, which actively recruits and provides scholarships to American Indian/Alaska Native, Asian, Black/African 
American, Hispanic/Latino, Middle Eastern and North African, and/or Native Hawaiian/Other Pacific Islander students, to assist them with obtaining a graduate degree and leadership positions within the profession and ALA.

\section{References}

Arnold, H. (2016, August 2). Critical work: Archivists as maintainers. Hillel Arnold. https://hillelarnold.com/blog/2016/o8/criticalwork/

Bolman, L. G., \& Deal, T. E. (2013). Reframing organizations: Artistry, choice, and leadership. ( $5^{\text {th }}$ edition). Jossey-Bass.

de jesus, n. (2014, September 24). Locating the library in institutional oppression. In the Library with the Lead Pipe.

http://www.inthelibrarywiththeleadpipe.org/2014/locating-thelibrary-in-institutional-oppression/

Ettarh, F. (2018, January 10). Vocational awe and librarianship: The lies we tell ourselves. In the Library with the Lead Pipe.

http://www.inthelibrarywiththeleadpipe.org/2018/vocationalawe/

Hackman, T. (2017). Leading change in action: Reorganizing an academic library department using Kotter's eight stage change model.

Library Leadership \& Management, 31(2), pp. 1-27. https://doi.org/10.13016/M2XZ7 B

Hathcock, A. (2015, October 7). White librarianship in blackface: Diversity initiatives in LIS. In the Library with the Lead Pipe. http://www.inthelibrarywiththeleadpipe.org/2015/lis-diversity/

Kowalski, M. (2017). Breaking down silo walls: Successful collaboration across library departments. Library Leadership \& Management, 31(2). https://doi.org/10.586o/llm.v31i2.7202

Olson, D., Meyerson, J., Parsons, M. A., Castro, J., Lassere, M., Wright, D. J., Arnold, H., Galvan, A. S., Hswe, P, Nowviskie, B., Russell, A., Vinsel, L., Acker, A., et al. (2019). Information maintenance as a practice of care: An invitation to reflect and share. Zenodo. https://doi.org/10.5281/zenodo.3236410

Shea, A. (2017, June 7). Museum visitors, and employees, are mostly white. The MFA is trying to change that. WBUR: The Artery. 
https://www.wbur.org/artery/2017/06/o6/mfa-strategic-plandiversity

Stroh, D. P. (2015). Systems thinking for social change: A practical guide to solving complex problems, avoiding unintended consequences, and achieving lasting results. Chelsea Green Publishing.

Westermann, M. (2019, January 28). Art museum staff demographic survey 2018. The Andrew W. Mellon Foundation.

https://mellon.org/news-blog/articles/art-museum-staffdemographic-survey-2018/

Williams, S. (2016, April 11). Implications of archival labor. On Archivy. https://medium.com/on-archivy/implications-of-archival-laborb6o6d8do2014 